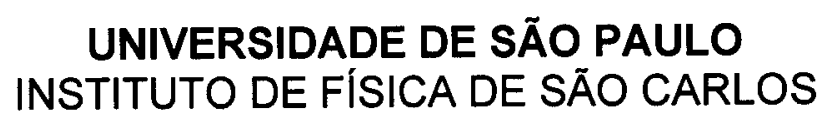

\title{
SOBRE O FENÔMENO DA NUCLEAÇÃO
}

Norberto Helil Pasqua

$$
\text { ac }
$$

USPAFSCISBI

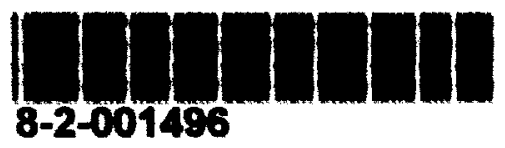

Orientador: Prof. Dr. Bernhard Joachim Mokross

São Carlos, março de 2003. 


\section{Pasqua, Norberto Helil}

Sobre o Fenômeno da Nucleação/Norberto Helil Paqua.

São Carlos, 2003.

$115 \mathrm{p}$.

Carlos, USP. 2003.

Dissertação (Mestrado) - Instituto de Física de São

Orientador: Prof. Dr. Bernhard Joachim Mokross

1. Nucleação. 2. Transição de fase.

I. Título. 
MEMBROS DA COMISSÃO JULGADORA DA DISSERTAÇÃO DE MESTRADO DE NORBERTO HELIL PASQUA, APRESENTADA AO INSTITUTO DE FÍ́SICA DE SÃo CARLOS, DA UNIVERSIDAdE DE SÃo PAULO, EM 28/03/2003.

\section{COM IS S Ã O J U L G A D O RA:}

\section{Bermtond) Niowkm.}

Prof. Dr. Bernhard Joachim Mokross (Orientador) - IFSC/USP

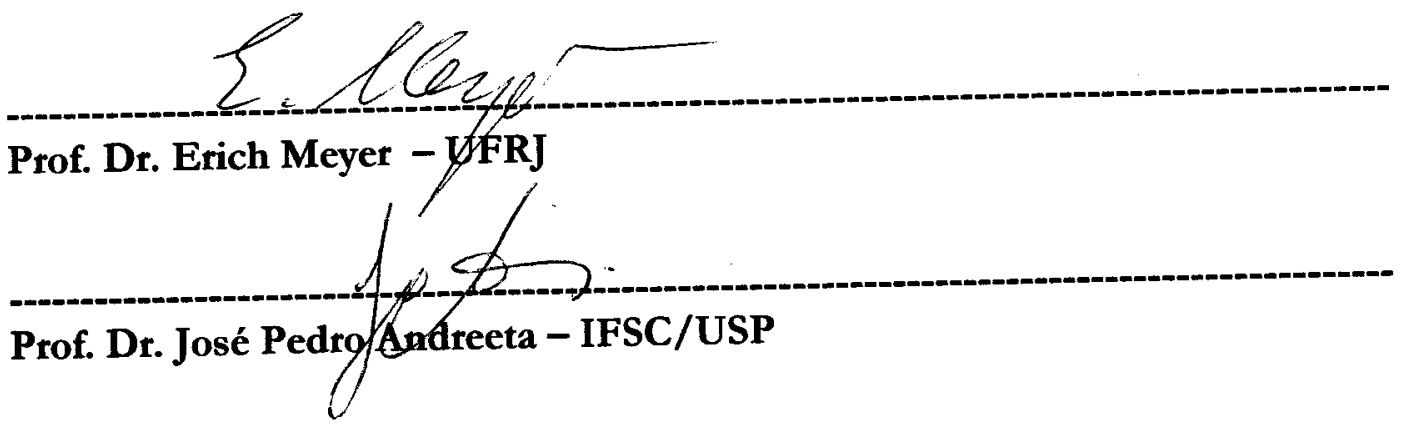




\section{Prefácio}

O presente trabalho versa sobre o fenômeno da transição de fase de primeira ordem. Desde a primeira abordagem teórica, no início do século $\mathrm{XX}$, os avanços no conhecimento sobre a cinética da nucleação são notórios. Porém, muitos resultados são de acurácia questionável ou limitada a pequenos intervalos de temperatura. Buscando o aperfeiçoamento, muitos autores têm proposto correções às teorias com abordagens fenomenológicas. Se por um lado tem-se a possibilidade de melhorar a acurácia dos resultados, por outro particulariza a aplicação. Entretanto, continua a busca por uma teoria geral que dê conta, de forma elegante, do fenômeno da nucleação.

No Capítulo 1 são apresentados estados do sistema que, uma vez fora do equilíbrio, encontra-se propenso a apresentar a transição de fase de primeira ordem. Mostrase também formas de se analisar o fenômeno a partir da energia livre de Gibbs e da equação de estado de van der Waals, bem como identificar a força motriz da nucleação, com auxílio de propriedades termodinâmicas do sistema (e/ou subsistema).

Uma das primeiras teorias autoconsistentes e uma das mais conhecidas, tida como Teoria Clássica da Nucleação (TCN), é a de Becker-Döring (BD), apresentada em 1925. É mostrada de forma mais detalhada nas primeiras sessões do Capítulo 2. A importância em detalhá-la é devido ao fato de ter servido de referência para outros modelos desenvolvidos posteriormente. Dois deles, o de Dilmann-Meier (DM) e o de Reiss-Kegel-Katz (RKK), são apresentados de forma mais sucinta na Sessão 2.6. O primeiro, um modelo semifenomenológico, além de trazer a TCN como caso especial, evidenciou maior acurácia. E o segundo, uma das mais recentes teorias autoconsis- 
tentes, apresenta a taxa de nucleação com melhor dependência com a temperatura, quando comparado com os resultados da TCN.

Uma abordagem quase independente do modelo da TCN é mostrada no Capítulo 3. Trata-se da Teoria Adiabática da Nucleação (TAN), a qual propõe que durante a transição de fase de primeira ordem a pressão e a temperatura do sistema não são necessariamente iguais àquelas observadas no início e no final do processo. Tendo como ferramental principal a Termodinâmica, a importância deste modelo, não só do ponto de vista acadêmico, é a proposta de um novo olhar para o processo de nucleação. Os resultados encontrados para a nucleação de vapores (de água, de benzeno, de etanol e de amônia) encontram-se em razoável acordo com estimativas gerais.

Os dois capítulos seguintes destinam-se à apresentação e aplicação da Teoria Entrópica da Nucleação (TEN). Mostrado no Capítulo 4, o modelo, ainda em fase de construção, parte dos fundamentos da TAN em que evidencia a entropia como sendo a força motriz do fenômeno da transição de fase, mas rompe com aqueles da TCN ao abrir mão de conceitos como o de tensão superficial. Mediante teorias auxiliares como a da flutuação em seu aspecto mais simplificado, no Capítulo 5, calcula-se o tamanho do núcleo crítico para o vapor da água. Em comparação com dados experimentais, os resultados são promissores.

Na sequiência, têm-se os apêndices destinados principalmente a complementar a TEN e o cálculo do núcleo crítico. Neles, encontram-se relações termodinâmicas úteis, bem como deduções de algumas funções; uma descrição da teoria da flutuação; uma análise da equação de estado de van der Waals, bem como uma introdução à teoria de funções residuais, usada na obtenção de propriedades termodinâmicas; também são apresentados dados experimentais, manipulados através do método dos mínimos 
quadrados, destinados à comparação com os teóricos; e, finalmente, algorítmos utilizados no software Maple V para o cálculo do núcleo crítico.

Ainda em relação à organização do presente trabalho, cabe mais um comentário. As referências colocadas em nota de rodapé devem-se a uma bibliografia complementar, no sentido de que estas citações não foram necessariamente estudadas. Servirão muitas vezes para posicionar o leitor frente ao tema ora apresentado. 


\section{Conteúdo}

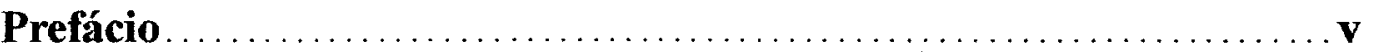

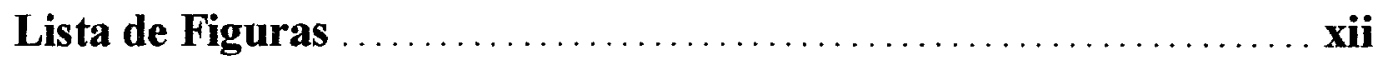

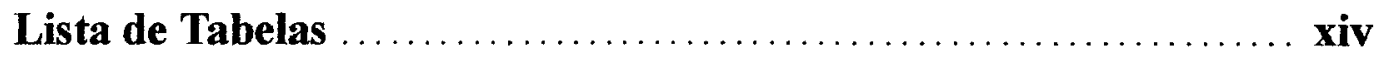

Lista dos Principais Símbolos $\ldots \ldots \ldots \ldots \ldots \ldots \ldots \ldots \ldots \ldots \ldots \ldots \ldots$

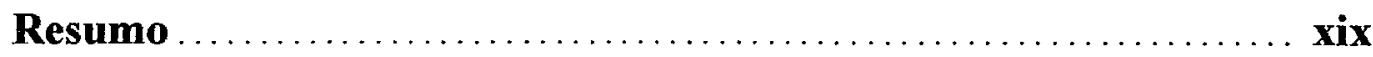

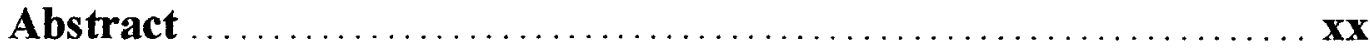

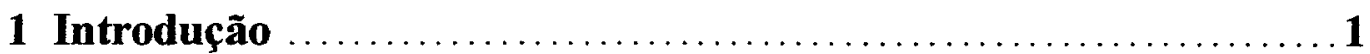

1.1 Fase e Equilíbrio Termodinâmico $\ldots \ldots \ldots \ldots \ldots \ldots \ldots \ldots \ldots \ldots \ldots \ldots \ldots \ldots \ldots$

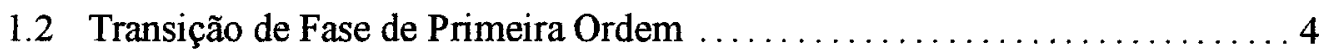

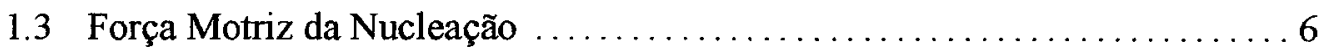

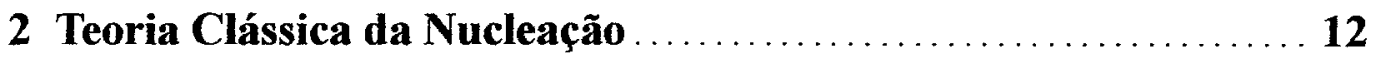

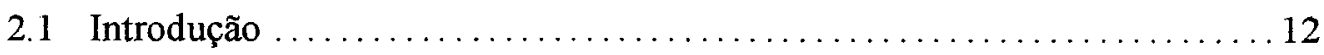

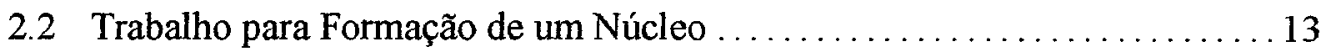

2.2.1 Postulados de Gibbs (sistemas unários) ................... 13

2.2.2 Nucleação Homogênea .................................. 16

2.3 Tamanho do Núcleo e Trabalho de Nucleação ...................... 19

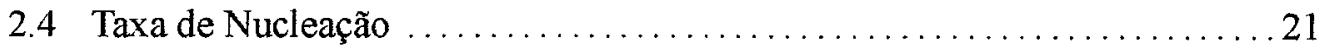

2.4 .1 Condensação de Vapor ................................ 29

2.5 Deficiências na Teoria Clássica .................................. 30

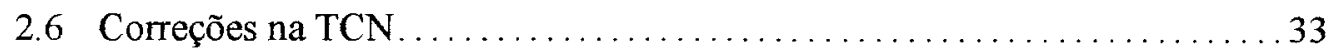

2.6.1 Teoria de Dilmann-Meier . . . . . . . . . . . . . . . . . . . . . . . . 33 


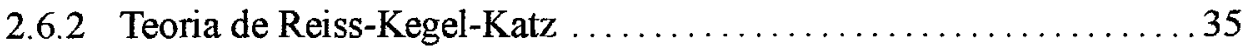

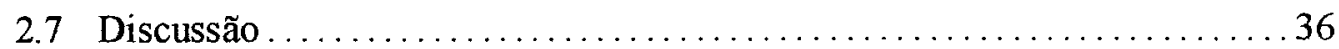

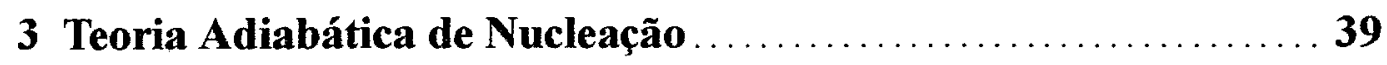

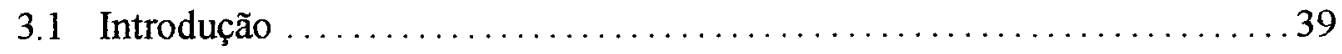

3.2 Considerações Termodinâmicas ................................. 39

3.3 Flutuações no Subsistema.................................... 44

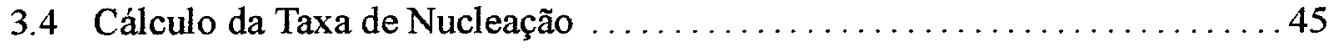

3.5 Tamanho do Núcleo Crítico .............................. 47

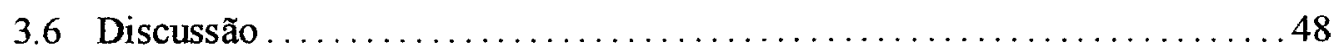

4 Teoria Entrópica da Nucleação $\ldots \ldots \ldots \ldots \ldots \ldots \ldots \ldots \ldots \ldots \ldots \ldots$

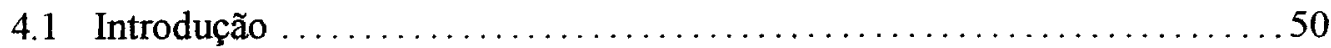

4.2 Fundamentação Teórica ................................. 50

4.3 Tamanho do Núcleo Crítico .............................. 57

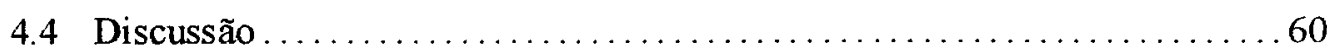

5 Cálculo do Núcleo Crítico ............................. 62

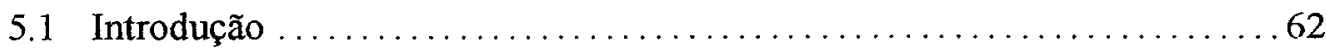

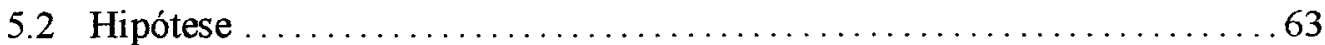

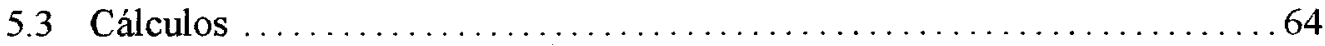

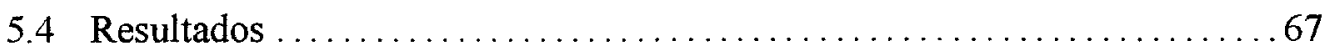

6 Conclusões e Perspectivas ............................. 71

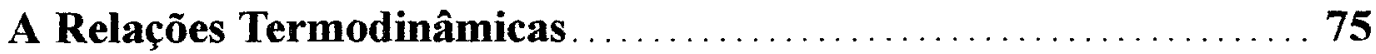


A.1 Relações de Maxwell . . . . . . . . . . . . . . . . . . . . . . . . . . . 75

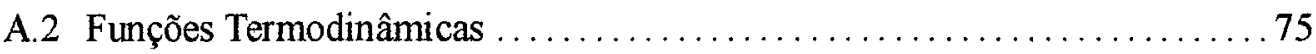

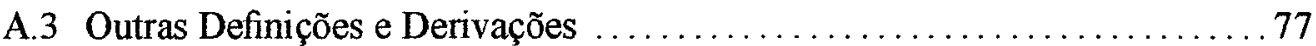

B Entropia de um Fluido Incompressível e de um Gás Perfeito . . . 78

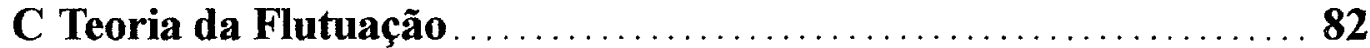

D Equação de Estado van der Waals . . . . . . . . . . . . . . . 84

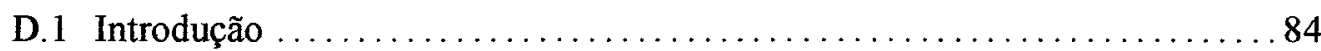

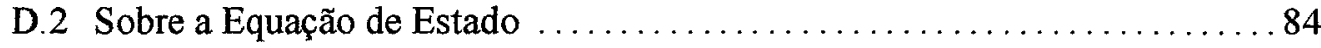

D.3 A Lei das Áreas de Maxwell ............................. 86

D.3.1 Cálculo Analítico de $(p, v, T)$ no Equilíbrio Termodinâmico $\ldots . . .87$

D.4 Comparação com experimento ............................. 89

D.5 Lei dos Estados Correspondentes.......................... 91

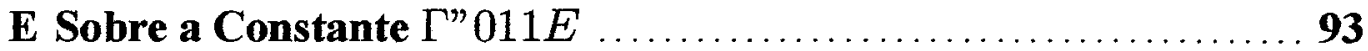

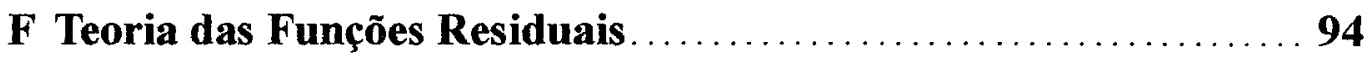

F.1 Cálculo da Entalpia................................... 96

G Experimento com a Nucleação da Água .................. 98

G.1 Dados Coletados para $T_{\mathrm{H}_{2}, \mathrm{~A} A r}=240 \mathrm{~K} \ldots \ldots \ldots \ldots \ldots \ldots \ldots \ldots \ldots \ldots \ldots \ldots$

G.2 Análise dos Dados. .................................. 104

G.2.1 Método Mínimos Quadrados ........................... 104

G.2.2 Resultados Gerais: Viisanen et al. ................... 106

G.2.3 Resultados Gerais: Wölk-Strey ................... 108

H Programação Maple V para Cálculo Núcleo Crítico .......... 110 
Referências

114 


\section{Lista de Figuras}

1.1 Diagrama de fase simplificado para a água. Em destaque são mostradas as principais fases que são objeto de estudo deste trabalho: líquida e

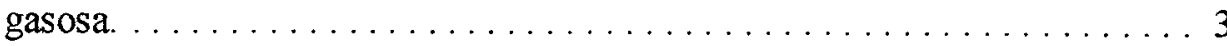

1.2 Em (a) isotermas da equação de van der Waal; em (b) a energia livre de Gibbs especifica como função do volume específico apresenta dois mínimos, $G\left(V^{l}\right)$ e $G\left(V^{g}\right)$. Fazendo $p \neq p^{e}$, o sistema é levado à região de metaestabilidade.

2.3 Situações 1 e 2 antes e após a formação de um aglomerado, onde se destaca a tensão superficial.

2.4 Situações 1 e 2, antes e após a formação de um aglomerado. . . . . . . 17

2.5 Gráfico indica a existência de núcleo crítico, $n^{*}$, com raio crítico, $r^{*} \ldots \ldots 19$

2.6 Representação esquemática do modelo de Szilard, em que é mostrado o processo de condensação de vapor. A câmara $B$ é isotérmica e está conectada com um reservatório de partículas na fase ambiente $A$. Iniciada a nucleação, uma população de aglomerados subcríticos e supercríticos é formada. Os núcleos com número de partículas $n \geq g \gg n^{*}$ são removidos da câmara instantaneamente via a membrana semipermeável (2). Simultaneamente, uma quantidade equivalente de monômeros entra no sistema através da membrana (1). O sistema é mantido numa supersaturação constante e uma taxa de nucleação independente do tempo pode ser estabelecida.

2.7 Densidade, $\rho$, pressão de equilíbrio de vapor, $p^{e}$, e tensão de superfície de $\mathrm{H}_{2} \mathrm{O}$ e $\mathrm{D}_{2} \mathrm{O}$ como função da temperatura. $\mathrm{Os}$ círculos pertencem à agua leve e os quadrados à água pesada.

2.8 Comparação das teorias RKK e BD com os dados experimentais.

Note-se que próximo a $T=240 \mathrm{~K}$ há boa concordância entre as duas abordagens.

3.9 No início e no final da transição da fase as propriedades termodinâmicas, pressão e temperatura, do elemento de volume são iguais às do sistema, ou seja, $p=p_{0}$ e $T=T_{0}$, respectivamente, mas não necessariamente durante o processo.

4.10 Diagrama de Mollier modificado. O esquema representa as fases líquida e gasosa de uma substância pura. . . . . . . . . . . . . . . . . 53

4.11 Esquema proposto para a transição de fase de primeira ordem. 56 
4.12 Diagrama de Mollier qualitativo mostrando um sistema com duas fases, $A$ e $B$ em equilíbrio. $\Delta s_{L}$ e $\Delta h_{L}$ representam a entropia e a entalpia latentes, respectivamente. No ponto $h$ há decomposição de fases, onde $n=n_{A}+n_{B}$. O inverso da declividade das tangentes em $s(h)$ é a temperatura $T$.

5.13 Esquema ilustrando a variação de temperatura de um elemento de volume. Os pontos espinodais são projetados sobre a reta $p=p^{e} \ldots \ldots \ldots \ldots 64$

5.14 Os pontos binodals, spinodals e metaestável estão sobre a reta $p=p^{e} \ldots \ldots 65$

$5.15 \mathrm{O}$ núcleo crítico calculado pela TEN apresenta dependência com a temperatura $T$, semelhante à encontrada por Viisanen et al . . . . . . 69

5.16 O núcleo crítico calculado pela TEN apresenta dependência com a temperatura $T$, semelhante à encontrada por Wölk-Strey.

D.17 As propriedades termodinâmicas de um fluido VDW em equilíbrio podem ser encontradas calculando as áreas $A_{1}$ e $A_{2}$ de modo que $A_{1}=A_{2} \ldots .86$

D.18 Para encontrar $T^{e}$ cumpre fixar $p^{e}$ e variar $v^{g, e}$ até encontrar $A_{1}=A_{2}$ ou

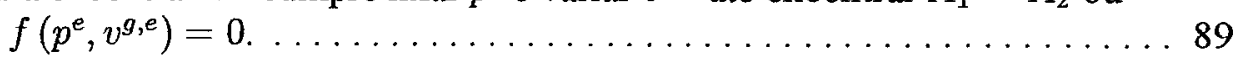

D.19 Os segmentos $\overline{a b}$ e $\overline{d e}$ têm significado físico.

F.20 Os três passos propostos estão representados de forma equivalente nestes dois gráficos.

G.21 Esquema do equipamento usado no estudo da nucleação. 98

G.22 $\Delta t_{\text {exp }}$ e $\Delta p_{\text {exp }}$ são encontrados via cálculo do trapézio.

G.23 Os trabalhos de Strey et all. [6][23] mostram que o gás carregador não interfere na nucleação do vapor de água. 


\section{Lista de Tabelas}

Segue abaixo uma lista das principais tabelas deste trabalho e as respectivas páginas onde se encontram.

Tabela 4.1 - Pontos Procurados

Tabela 5.1 - Pontos Procurados (via VDW)

Tabela 5.2 - Pontos Procurados (via VDW e Teoria da Funções Residuais) 65

Tabela 5.3 - Comparação Núcleo Crítico Teórico e Experimental: Viisanen et all. 66 Tabela 5.4 - Comparação Núcleo Crítico Teórico e Experimental: Wölk-Strey . . . 66

Tabela G.1 - Ensaio experimental 1 102

Tabela G. 2 - Ensaio experimental 2 102

Tabela G. 3 - Ensaio experimental 3 102

Tabela G. 4 - Ensaio experimental 4 103

Tabela G.5 - Ensaio experimental 5 103

Tabela G. 6 - Ensaio experimental 6

Tabela G.7 - Série 1: $T_{\mathrm{H}_{2} \mathrm{O}, \mathrm{Xe}_{e}}=259 \mathrm{~K}$ 106

Tabela G.8 - Série 2: $T_{\mathrm{H}_{2} \mathrm{O}, \mathrm{Ar}}=253.7 \mathrm{~K}$ 106

Tabela G.9-Série 3: $T_{\mathrm{H}_{2} \mathrm{O}, \mathrm{Ar}}=248.5 \mathrm{~K}$

Tabela G.10 - Série 4: $T_{\mathrm{H}_{2} \mathrm{O}, \mathrm{Ar}}=244.1 \mathrm{~K}$ 
Tabela G.11-Série 5: $T_{H_{2} O, A r}=238.8 \mathrm{~K}$

Tabela G. 12 - Série 6: $T_{\mathrm{H}_{2} \mathrm{O}, \mathrm{Ar}}=233.5 \mathrm{~K}$

Tabela G.13 - Série 7: $T_{\mathrm{H}_{2} \mathrm{O}, \mathrm{Ar}}=228 \mathrm{~K}$ 107

Tabela G.14- Série 8: $T_{\mathrm{H}_{2} \mathrm{O}, \mathrm{Ar}}=222.6 \mathrm{~K}$ 107

Tabela G.15 - Série 9: $T_{\mathrm{H}_{2} \mathrm{O}, \mathrm{Ar}}=217.1 \mathrm{~K}$ 107

Tabela G.16-Série A: $T_{\mathrm{H}_{2} \mathrm{O}, \mathrm{Ar}}=260 \mathrm{~K}$ 108

Tabela G. 17 - Série B: $T_{\mathrm{H}_{2} \mathrm{O}, \mathrm{Ar}}=250 \mathrm{~K}$ 108

Tabela G. 18 - Série C: $T_{\mathrm{H}_{2} \mathrm{O}, \mathrm{Ar}}=240 \mathrm{~K}$ 108

Tabela G.19-Série D: $T_{\mathrm{H}_{2} \mathrm{O}, \mathrm{Ar}}=230 \mathrm{~K}$ 109

Tabela G.20 - Série E: $T_{\mathrm{H}_{2} \mathrm{O}, \mathrm{Ar}}=220 \mathrm{~K}$ 109 


\section{Lista dos Principais Símbolos}

Segue abaixo uma lista com os principais símbolos utilizados ao longo deste trabalho, acompanhados das respectivas sessões onde aparecem pela primeira vez.

Stmbolos Romanos

\begin{tabular}{|c|c|}
\hline$A$ & $\begin{array}{l}\text { superficie, área da interface } \ldots \ldots \ldots \ldots \\
\text { disponibilidade } \ldots \ldots \\
\text { estado no binodal } \ldots \ldots \ldots \\
\ldots\end{array}$ \\
\hline & constante do fluido de van der Waals ............ \\
\hline$a$ & $\begin{array}{l}\text { constante aglomerado esférico } \ldots \ldots \ldots \ldots \ldots \ldots \ldots \ldots \ldots \\
\text { estado no spinodal } \ldots \ldots \ldots \ldots \ldots \ldots \ldots \ldots\end{array}$ \\
\hline$B$ & aglomerado em reação química binária...$\ldots \ldots \ldots \ldots$ \\
\hline & dal $\ldots \ldots \ldots \ldots \ldots \ldots \ldots \ldots \ldots \ldots \ldots \ldots \ldots$ \\
\hline$b$ & $\begin{array}{l}\text { constante do fluido de van der Waals } \ldots \ldots \ldots \ldots \ldots \ldots \ldots \ldots \\
\text { estado no spinodal } \ldots \ldots \ldots \ldots \ldots \ldots \ldots \ldots \ldots \ldots \ldots \ldots\end{array}$ \\
\hline$c$ & $\begin{array}{l}\text { calor específico, a pressão constante, } c_{p} \text {, a volume constante, } \\
c_{v} \ldots \ldots \ldots \ldots \ldots \ldots \ldots \ldots \ldots \ldots \ldots \ldots \ldots \ldots \ldots \ldots \ldots\end{array}$ \\
\hline$f$ & Imholtz por partíc \\
\hline$G$ & Gibbs $\ldots \ldots \ldots \ldots \ldots$ \\
\hline$g$ & $\begin{array}{l}\text { vre de Gibbs por partícula } \ldots \ldots \ldots \ldots \ldots \ldots \ldots \ldots \\
\text { do aglomerado }\end{array}$ \\
\hline$H$ & italpia. \\
\hline h. & $\cdots$ \\
\hline$J$ & $\ldots \ldots \ldots \ldots \ldots \ldots$ \\
\hline$k_{B}$ & Boltzmann \\
\hline & $\cdots$ \\
\hline$L$ & 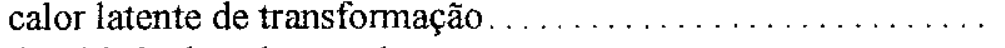 \\
\hline$M$ & tomerados . . . . . . . . . \\
\hline$m$ & omero $\ldots \ldots \ldots$ \\
\hline$N$ & número de monômeros no sistema $\ldots \ldots \ldots \ldots \ldots \ldots \ldots \ldots$ \\
\hline$n$ & $\begin{array}{l}\text { número de monômeros no aglomerado } \ldots \ldots \ldots \ldots \ldots \ldots \ldots \ldots \ldots \ldots \\
\text { número de moles } \ldots \ldots \ldots \ldots \ldots \ldots \ldots \ldots \ldots \ldots \ldots\end{array}$ \\
\hline & $\ldots \ldots \ldots \ldots \ldots$ \\
\hline$Q$ & ... \\
\hline & onstante universal dos gases \\
\hline
\end{tabular}




\begin{tabular}{|c|c|}
\hline$r$ & glomerado (esférico). \\
\hline 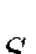 & entropia . \\
\hline$S$ & supersaturação . \\
\hline$s$ & $\left\{\begin{array}{l}\text { fase sólida } \ldots \ldots \ldots \ldots \\
\text { entropia por partícula } \ldots \\
\text { spinodal }{ }^{3} \ldots \ldots \ldots \ldots \ldots\end{array}\right.$ \\
\hline$T$ & temperatura. \\
\hline$U$ & energia interna. . \\
\hline$u$ & energia interna por partícula. \\
\hline$V$ & volume do sistema, do elemento de volume $\ldots \ldots \ldots \ldots \ldots \ldots$ \\
\hline$v$ & 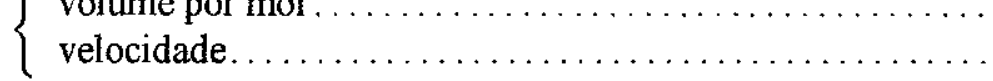 \\
\hline$w$ & $\begin{array}{l}\text { número médio de monômeros que é incorporado (ou retirado) } \\
\text { ao núcleo de tamanho } n \text { por unidade de tempo } \ldots \ldots \ldots \ldots \ldots\end{array}$ \\
\hline$Z$ & $\begin{array}{l}\text { número de monômeros que se chocam com um elemento de } \\
\text { superficie por unidade de tempo } \ldots \ldots \ldots \ldots \ldots \ldots \ldots \ldots \ldots\end{array}$ \\
\hline & pressibilidade . . . . \\
\hline
\end{tabular}

\section{Simbolos Gregos}

$\alpha \quad$ coeficiente de dilatação isotérmica ................. 4.2

$\beta \quad$ compressibilidade isobárica ..................... 4.2

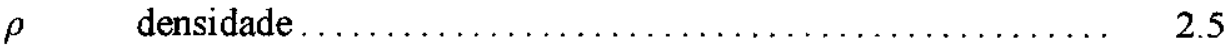

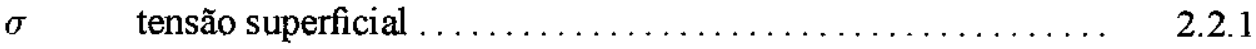

$\mu \quad$ potencial químico $\ldots \ldots \ldots \ldots \ldots \ldots \ldots \ldots \ldots \ldots, 1.1$

\section{Superscript}

* quantidades críticas na transição de fase.............. 2.2

- decaimento do aglomerado ...................... 2.4

$+\quad$ crescimento do aglomerado ..................... 2.4

$e \quad$ quantidades termodinâmicas no equilíbrio ............. 1,1

ex quantidade excessiva ........................... 2.2

ref quantidades termodinâmicas de referência ............. 1.3

vap vaporização ................................ 3.2

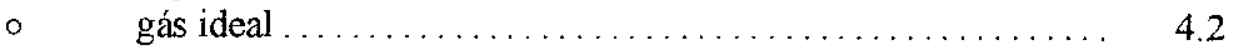

1 Por questões de linguagem, o termo spinodal será grafado como "espinodal" no singular e "espinodais" no plural. 


\section{Subscript}

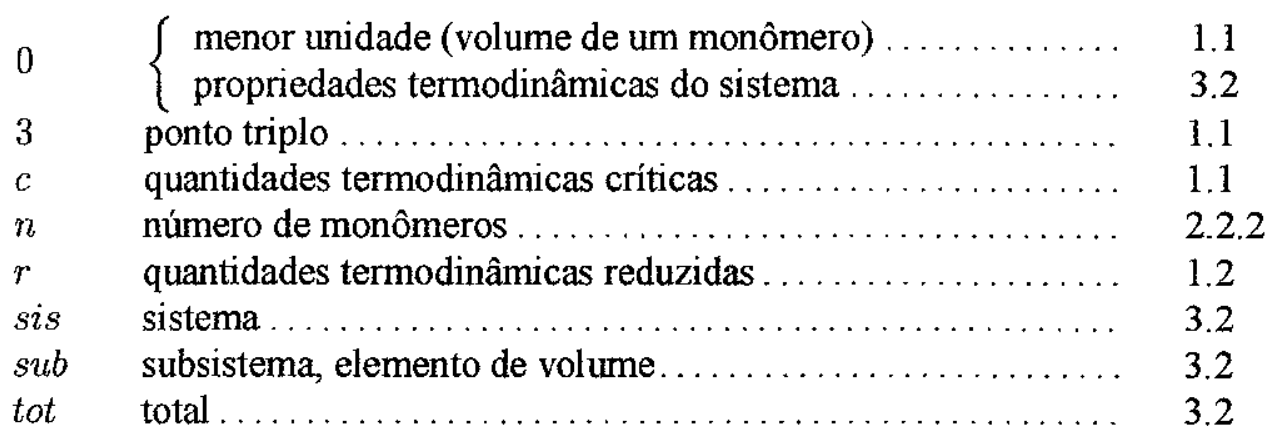




\section{Resumo}

Desde a apresentação do primeiro modelo da transição de fase de primeira ordem, no início do século $\mathrm{XX}$, acumulou-se muito conhecimento a respeito da cinética deste fenômeno. A Teoria Clássica da Nucleação (TCN) calcula o tamanho do núcleo crítico maximizando a diferença na energia livre de Gibbs entre as fases atual e nova, separadas por uma superfície de tensão bem definida. Técnicas experimentais modernas indicam que a TCN calcula a taxa de nucleação com acurácia razoável somente em estreita faixa de temperatura, indicando deficiências no modelo. Correções na teoria melhorou sua dependência com a temperatura, mas os resultados encontrados são superiores aos medidos experimentalmente em cerca de quatro ordens de grandeza.

Diferentes abordagens têm surgido, como a Teoria Adiabática da Nucleação e a Teoria Entrópica da Nucleação (TEN). Ainda que aquela traga em seu escopo teórico parte do modelo clássico, como a tensão superficial, elege a maximização da entropia como a força motriz da transição de fase. O mesmo fez a TEN, porém sem especificar uma superfície de tensão.

A primeira aplicação desta teoria foi na condensação do vapor de água. Mediante uma teoria da flutuação, no seu aspecto mais simplificado, foi determinado o tamanho do núcleo crítico. Os resultados obtidos são menores do que os experimentais em cerca de três ordens de grandeza, devido à excessiva simplicidade do modelo empregado. Entretanto, verifica-se que a dependência do tamanho do núcleo com a supersaturação assemelha-se aos dados experimentais. Os resultados indicam que a abordagem entrópica é promissora. 


\begin{abstract}
In Classical Nucleation Theory (CNT) the size of the critical nucleous is obtained by maximizing the difference in bulk Gibbs free energy between the new and the evolving phase separated by a surface having a well defined tension, in relation to the nucleous size. CNT, albeit the introduction of numerous correction terms, did not compare well with experimental data by many orders of magnitude. Other theories have been proposed as the Adiabatic and Entropy Theories, ANT and ENT, respectively. While ANT rests on some CNT assumptions as the existence of a well defined surface separating the new and the old phase, considers the entropy as the driving force of phase transition instead of Gibbs Free Energy. On the other hand, ENT only rests on the assunption of the entropy as the driving force without considering a surface tension. This theory is applied to the study of water vapor condensation, by calculating the size of the critical nucleous with the aid small amplitude fluctuation theory. The results compare well with experimental values, being off by about 3 orders of magnitude but its dependence with supersaturation agrees well with experiment. The results are satisfactory and may be improved by refining the theory.
\end{abstract}




\section{Capítulo 1 \\ Introdução}

\subsection{Fase e Equilíbrio Termodinâmico}

Em Física são três os estados de agregação da matéria, a dizer, sólido $\left({ }^{s}\right)$, líquido $\left({ }^{l}\right)$ e gasoso $\left({ }^{g}\right)$. Todas as substâncias podem existir em um desses estados, sendo que os sólidos podem ser observados em diferentes modificações alotrópicas ${ }^{2}$.

Gibbs $^{3}$, visando um termo que representasse as diferentes formas de existência de uma substância pura, criou o conceito fase. Este é mais abrangente que o de estado de agregação da matéria, pois qualquer região homogênea dentro de um sistema é chamada de fase.

Sob certas condições duas ou mais fases podem coexistir, quando se observa que as fronteiras de cada uma são bem definidas. Além disso, parâmetros intensivos [2] como pressão, $p$, temperatura, $T$, e potencial químico, $\mu$, são iguais nas duas configurações. Neste caso, diz-se que o sistema encontra-se num estado de equilíbrio termodinâmico $e$. Assim, dada a coexistência de duas fases de uma substância pura, por exemplo, líquido e gás, verifica-se que

$$
\begin{gathered}
p^{l}=p^{g}=p^{e}, \\
T^{l}=T^{g}=T^{e}
\end{gathered}
$$

\footnotetext{
2 Diferentes configurações dos átomos na rede ou estrutura cristalina do material. É o caso do enxofre, $\mathrm{S}$, que à temperatura de $100^{\circ} \mathrm{C}$ e submetido à pressão atmosférica apresenta-se sob duas diferentes formas, o amarelo-limão rômbico e o alaranjado monoclínico [1].

3 Josiah Willard Gibbs, físico americano do inicio do século XIX.
} 
e

$$
\mu^{l}=\mu^{g}=\mu^{e}
$$

O conceito de fase também considera substâncias não puras, ou seja, misturas ou soluções. Nessas, as propriedades termodinâmicas intensivas também se apresentam uniformes e homogêneas dentro das fases.

Das equações (1.1) a (1.3) pode-se encontrar que o potencial químico é a energia livre de Gibbs por partícula, $g$, para cada fase, ou seja,

$$
\mu^{l} \equiv g^{l}(p, T)
$$

e

$$
\mu^{g} \equiv g^{g}(p, T)
$$

de modo que no equilíbrio termodinâmico (ETD)

$$
g^{l}(p, T)=g^{g}(p, T)
$$

Diferenciando, tem-se

$$
d g^{l}=d g^{g}
$$

ou

$$
-s^{l} d T+v^{l} d p=-s^{g} d T+v^{g} d p .
$$

Reorganizando os termos chega-se a

$$
\frac{d p}{d T}=\frac{s^{g}-s^{l}}{v^{g}-v^{l}}
$$

a qual é conhecida como equação de Clausius-Clapeyron. Outra forma de representar esta equação é fazer $s^{g}-s^{t}=L / T$, em que $L$ é o calor latente específico de evaporação $\mathrm{e} v^{l}-v^{g}=\Delta v$, ou seja,

$$
\frac{d p}{d T}=\frac{L}{T \Delta v}
$$


O gráfico $p$ versus $T$ da equação (1.9) ou da (1.10), para os diversos calores latentes, $L$, forma as partes do diagrama de fases referente aos estados de coexistência para uma dada substância. Na Figura 1.1 está esquematizado o diagrama de fases para a água. Em destaque tem-se a curva de coexistência líquido-gás, que tem como limite os pontos triplo, $\left(p_{3}, v_{3}, T_{3}\right)$, e crítico, $\left(p_{c}, v_{c}, T_{c}\right)$.

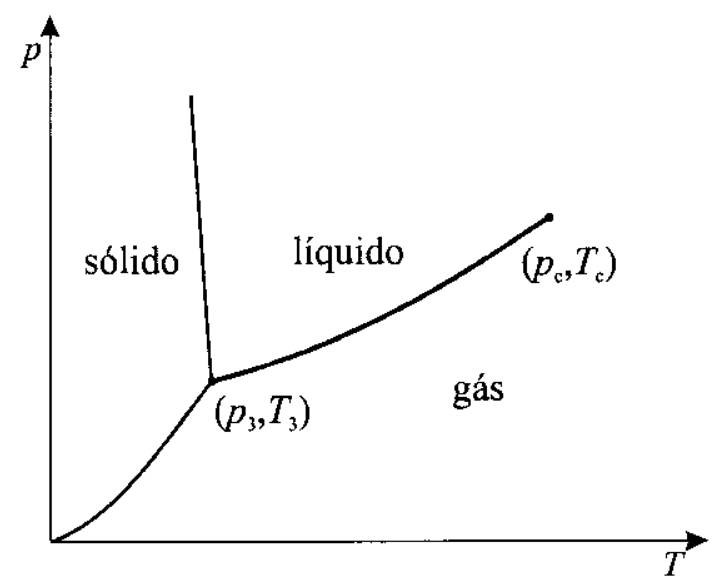

Fig. 1.1- Diagrama de fase simplificado para a água. Em destaque são mostradas as principais fases que são objeto de estudo deste trabalho: líquida e gasosa.

No ponto triplo verifica-se a coexistência de três fases. Para a água, a coexistência das fases sólida, líquida e gasosa é observada quando se encontra no estado em que $T_{3}=273.16 \mathrm{~K}, p_{3}=6.107 \times 10^{2} \mathrm{~Pa}-\mathrm{e}$ os volumes específicos do líquido e do gás são, respectivamente, $v_{3}^{l}=1.81 \times 10^{-5} \mathrm{~m}^{3} / \mathrm{mol} \mathrm{e} v_{3}^{g}=3.72 \mathrm{~m}^{3} / \mathrm{mol}$. O ponto crítico é caracterizado por um estado em que a temperatura e pressão são tais que a densidade do vapor é igual à do líquido, $\rho^{l}=\rho^{g}$, de modo que não se pode distinguir uma fase da outra . Para a água, a temperatura crítica é $T_{c}=647.31 \mathrm{~K}$, a pressão crítica é $p_{c}=2.21 \times 10^{7} \mathrm{~Pa}$ - e o volume específico crítico para ambas as fases é $v_{c}^{l}=v_{c}^{g}=5.71 \times 10^{-5} \mathrm{~m}^{3} / \mathrm{mol}$. 
É possível, porém, conduzir um sistema composto somente de vapor a um estado em que a temperatura é menor que a de condensação, para uma dada pressão, sem ocorrer a transição de fase, ou seja, é mantido o estado gasoso da substância quando esta deveria apresentar-se em estado líquido. Tal estado é conhecido como metaestável. Uma substância na fase vapor que se encontra num estado metaestável é conhecida como supersaturada ou superesfriada. E a fase líquida no estado metaestável é tida como supersaturada ou superaquecida. Alterações na pressão e/ou na temperatura, ou mesmo devido a flutuações destas grandezas, levará o sistema a apresentar o fenômeno da transição de fase de primeira ordem.

\subsection{Transição de Fase de Primeira Ordem}

O fenômeno transição de fase de primeira ordem ${ }^{4}$ considera mudanças no estado da matéria que, por si só, é bastante amplo. Por motivos de clareza na exposição deste trabalho, uma vez que o mesmo versa sobre mudanças de estado em fluidos, a transição de fase considerada será entre as fases líquida e gasosa.

A natureza fisica da transição de fase gás-líquido pode ser suficientemente bem ilustrada com a análise do comportamento de fluidos que obedecem à equação de estado de van der Waals (VDW) [1][5], dada por

$$
\left(p+\frac{N^{2} a}{V^{2}}\right)(V-N b)=N k_{B} T
$$

\footnotetext{
4 Na transição de fase de primeira ordem o surgimento da nova fase é caracterizada pela descontinuidade das variáveis extensivas como o volume. É observada em processos de mudança de estado físico sólido-líquido, líquido-gás.

Existe a transição de fase de segunda ordem, caracterizada pela descontinuidade, p. ex., do calor específico à pressão constante ou, de maneira geral, na segunda derivada das grandezas termodinâmicas. É observada na reordenação dos átomos em redes cristalinas.
} 
onde $a$ e $b$ são constantes do fluido que refletem a interação e o volume moleculares, respectivamente, $N$ é o número de partículas do sistema e $k_{B}$ é a constante de Boltzmann.

A Figura 1.2-a mostra três isotermas típicas: duas a $T<T_{c}$ e outra a $T=$ $T_{c .}$. Na de número 1 , o segmento $\overline{a e}$ é isobárico, o qual indica a transição de fase observada em laboratório; os segmentos $\overline{a b} \mathrm{e} \overline{d e}$, indicam regiões de metaestabilidade, ou seja, líquido e vapor supersaturados, respectivamente; e em $\overline{b d}$, tem-se a região de instabilidade. Os pontos $a$ e $e$ são conhecidos como binodal e os pontos $b$ e $d$ como spinodal ${ }^{5}$. Diferentes isotermas formam as curvas (binodal e espinodal) que delimitam as regiões de estabilidade, de metaestabilidade e instabilidade (linhas pontilhadas). Na isoterma critica os pontos binodal e espinodal equivalem-se, ou seja, as fases líquida e gasosa são indistinguíveis.

A equação de estado de van der Waals pode ser simplificada substituindo as constantes $k_{B}, a$ e $b$ pelos parâmetros críticos, $p_{c}, V_{c}$ e $T_{c}$ [1][5], conforme mostrado no Apêndice D. Isto resulta em

$$
\left(p_{r}+\frac{3}{V_{r}^{2}}\right)\left(3 V_{r}-1\right)=8 T_{r}
$$

a qual é denominada equação reduzida de VDW ou principio dos estados correspondentes. É uma equação universal no sentido de que não depende explicitamente das constantes $a$ e $b$ do fluido e da constante de Boltzmann, $k_{B}$; e também não depende explicitamente do número de partículas do sistema.

5 Por questões de linguagem, o termo spinodal será grafado como "espinodal" no singular e como "espinodais" no plural. 


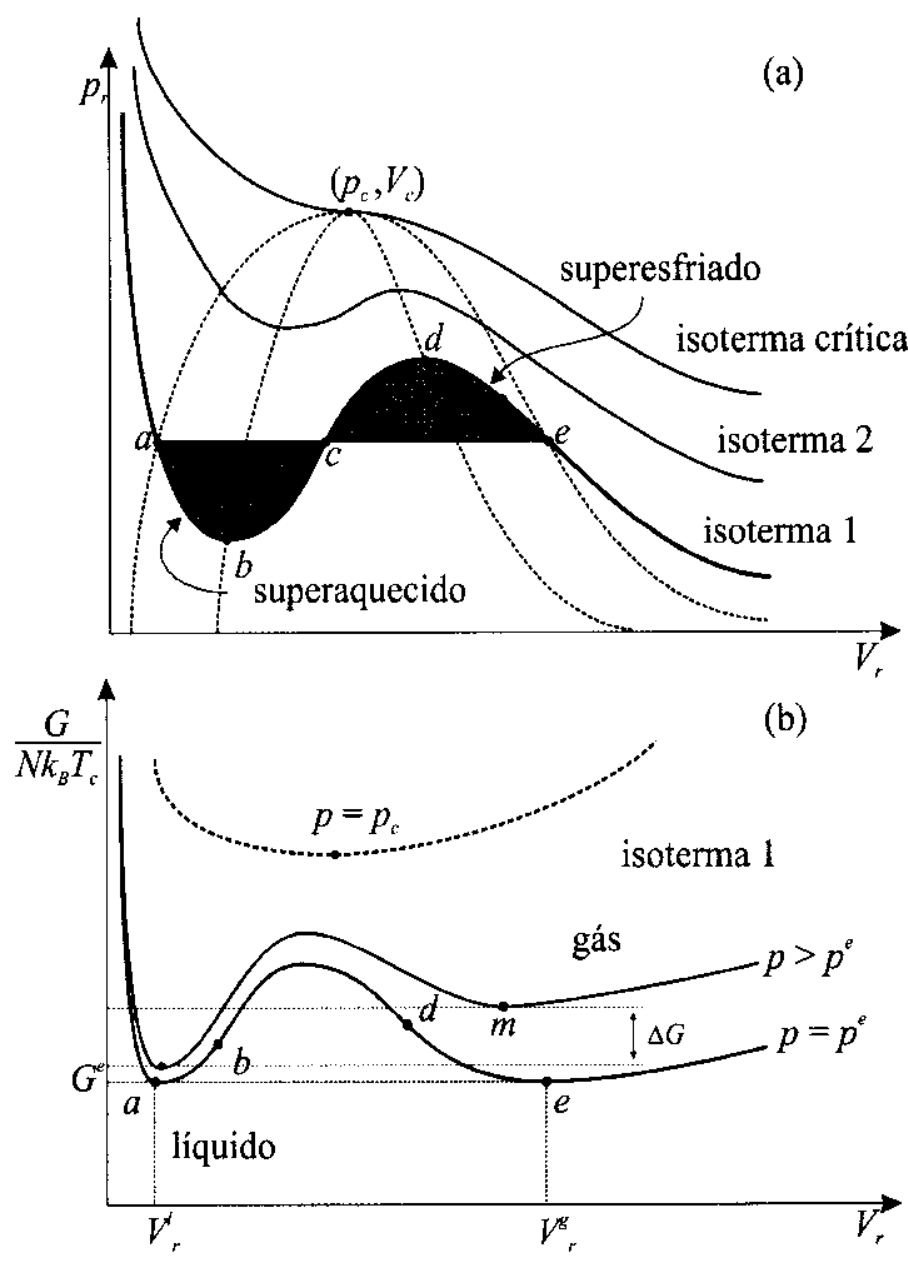

Fig. 1.2- Em (a) isotermas da equação de van der Waal; em (b) a energia livre de Gibbs específica como função do volume específico apresenta dois mínimos, $G\left(V^{l}\right)$ e $G\left(V^{g}\right)$. Fazendo $p \neq p^{e}$, o sistema é levado à região de metaestabilidade.

\subsection{Força Motriz da Nucleação}

A transição de um estado inicial metaestável (p. ex. vapor supersaturado) para um estado final estável (p. ex. líquido) ocorre em função da necessidade do fluido em ocupar um estado de menor energia [5]. Uma quantidade que representa a força motriz para a nucleação ${ }^{6}$, segundo a TCN é

$$
\Delta \mu=\frac{G^{\text {final }}-G^{\text {inicial }}}{N}=\mu^{\text {final }}-\mu^{\text {inicial }}
$$

6 Surgimento de aglomerados da nova fase, o que caracteriza a transição de fase de primeira ordem. 
Fisicamente, $\Delta \mu$ é o ganho em energia livre por partícula, quando associada com a passagem de um nível superior, $g^{\text {inicial }}$, para um nível de menor energia livre, $g^{\text {final }}$ (vide Figura 1.2-b) Esta propriedade termodinâmica pode ser expressa em termos dos parâmetros $p$ e $T$, o que é vantajoso do ponto de vista experimental, dada a controlabilidade dos mesmos.

A energia livre de Gibbs para um fluido VDW, pode ser escrita como (vide Tabela A.6),

$$
G=F+p V
$$

onde $F$ é a energia livre de Helmholtz (Tabela A.5), a qual tem a forma

$$
F=-\int S(T) d T-\int p(V) d V
$$

Admitindo que a nucleação dá-se a temperatura constante, a equação (1.14) pode ser resolvida em termos de variáveis reduzidas com o auxílio da equação (1.15), na qual substituiu-se a equação (1.12), ou seja,

$$
G=-p_{c} V_{c} \int\left(\frac{8 T_{r}}{3 V_{r}-1}-\frac{3}{V_{r}^{2}}\right) d V_{r}+p_{c} V_{c} p_{r} V_{r}
$$

resultando em

$$
G=G^{r e f}\left(T_{r}\right)+\frac{8}{3} p_{c} V_{c}\left[\frac{3}{8} p_{r} V_{r}-\frac{9}{8 v_{r}}-T_{r} \ln \left(3 V_{r}-1\right)\right],
$$

onde $G^{r e f}$ é uma energia de referência [5].

Define-se o fator de compressibilidade, $z$, tomado a partir da equação de estado do gás ideal [16], como

$$
z=\frac{p V}{N k_{B} T}
$$

o qual reflete o quanto um fluido real desvia-se do ideal (quando $z=1$ ). Para um fluido VDW, calculado no ponto crítico,

$$
z_{c}=\frac{p_{c} V_{c}}{N k_{B} T_{c}}=\frac{3}{8} .
$$


Com a ajuda da equação (1.19) na (1.17), chega-se a

$$
\left[G\left(V_{r}\right)\right]_{p_{r}, T_{r}}=G^{r e f}\left(T_{r}\right)+N k_{B} T_{c}\left[\frac{3}{8} p_{r} V_{r}-\frac{9}{8 V_{r}}-T_{r} \ln \left(3 V_{r}-1\right)\right],
$$

ou, considerando a energia livre por partícula,

$$
\left[g\left(V_{r}\right)\right]_{p_{r}, T_{r}}=g^{r e f}\left(T_{r}\right)+k_{B} T_{c}\left[\frac{3}{8} p_{r} V_{r}-\frac{9}{8 V_{r}}-T_{r} \ln \left(3 V_{r}-1\right)\right] .
$$

Considere a transição de um fluido da fase gasosa (inicial) para a líquida (final). Esta ocorre quando a pressão reduzida $p_{r}$ satisfizer a condição $p_{r}>p_{r}^{e}$. Usando-se a equação (1.21) tem-se

$$
\begin{aligned}
& g^{\text {final }}=g^{l}=g^{r e f}\left(T_{r}\right)+k_{B} T_{c}\left[\frac{3}{8} p_{r} V_{r}^{l}-\frac{9}{8 V_{r}^{l}}-T_{r} \ln \left(3 V_{r}^{l}-1\right)\right] \\
& g^{\text {inicial }}=g^{g}=g^{r e f}\left(T_{r}\right)+k_{B} T_{c}\left[\frac{3}{8} p_{r} V_{r}^{g}-\frac{9}{8 V_{r}^{g}}-T_{r} \ln \left(3 V_{r}^{g}-1\right)\right]
\end{aligned}
$$

onde $V_{r}^{l}\left(p_{r}, T_{r}\right)$ e $V_{r}^{g}\left(p_{r}, T_{r}\right)$ são os volumes reduzidos do líquido e do gás, respectivamente, no ponto em que $g$ tem um mínimo [5], conforme Figura 1.2-b,

$$
\left(\frac{\partial g}{\partial V_{r}}\right)_{T_{r}}=\left(\frac{\partial f}{\partial V_{r}}\right)_{T_{r}}+p_{r}=-p_{r}\left(V_{r}\right)+p_{r}=0
$$

e

$$
\left(\frac{\partial^{2} g}{\partial V_{r}^{2}}\right)_{T_{r}}=\left(\frac{\partial^{2} f}{\partial V_{r}^{2}}\right)_{T_{r}}=-\left(\frac{\partial p}{\partial V_{r}}\right)_{T_{r}}>0
$$

Levando as equações (1.22) e (1.23) em (1.13), tem-se a fórmula exata

$$
\Delta \mu=-k_{B} T_{c}\left[T_{r} \ln \left(\frac{3 V_{r}^{l}-1}{3 V_{r}^{g}-1}\right)+\frac{9}{8}\left(\frac{1}{V_{r}^{l}}-\frac{1}{V_{r}^{g}}\right)-\frac{3}{8} p_{r}\left(V_{r}^{l}-V_{r}^{g}\right)\right]
$$

É interessante escrever a equação (1.26) em termos de $p_{r}$ e de $p_{r}^{e}$, (ou, equivalentemente, de $V_{r}$ e de $V_{r}^{e}$ ). A razão $p_{r} / p_{r}^{e}$ (ou, $\left.V_{r} / V_{r}^{e}\right)$, conhecida como supersaturação, $S$, auxilia na determinação da direção da transição de fase [5]:

- quando $S=1$ (ou $p_{r}=p_{r}^{e}$ ), o sistema encontra-se em equilibrio termodinâmico, de modo que $\mu^{l}=\mu^{g}$; 
- quando $S>1$ (ou $p_{r}>p_{r}^{e}$ ), a transição gás-líquido (nucleação) pode tomar lugar: o gás encontra-se no estado metaestável, de modo que $\mu^{l}<\mu^{g} ; \mathrm{e}$

- quando $S<1$ (ou $p_{r}<p_{r}^{e}$ ), verifica-se a transição líquido-gás (denucleação): o líquido encontra-se no estado metaestável, de modo que $\mu^{l}>\mu^{g}$.

No equilíbrio termodinâmico (ETD) verifica-se $\Delta \mu^{e}=\mu^{l, e}-\mu^{g, e}=0$. Entretanto, pode-se formalmente representar tal equilíbrio de outra maneira. Com ajuda da equação (1.22) calculada em $p_{r}^{e}, \operatorname{com} V_{r}^{l}\left(p_{r}^{e}, T_{r}\right)=V_{r}^{l, e}$, para a fase líquida (final), e da equação (1.23) calculada em $p_{r}^{e}, \operatorname{com} V_{r}^{g}\left(p_{r}^{e}, T_{r}\right)=V_{r}^{g, e}$, para a fase gasosa (inicial), tem-se

$$
\Delta \mu^{e}=0=-k_{B} T_{c}\left[T_{r} \ln \left(\frac{3 V_{r}^{l, e}-1}{3 V_{r}^{g, e}-1}\right)+\frac{9}{8}\left(\frac{1}{V_{r}^{l, e}}-\frac{1}{V_{r}^{g, e}}\right)-\frac{3}{8} p_{r}^{e}\left(V_{r}^{l, e}-V_{r}^{g, e}\right)\right],
$$

Ainda no âmbito da representação formal, pode-se escrever $\Delta \mu=\Delta \mu-\Delta \mu^{e} \mathrm{e}$, com auxílio da equação (1.27), obtém-se a fórmula equivalente à equação (1.26)

$$
\begin{aligned}
\Delta \mu= & -k_{B} T_{c}\left\{T_{r} \ln \left[\left(\frac{3 V_{r}^{l}-1}{3 V_{r}^{g}-1}\right)\left(\frac{3 V_{r}^{g, e}-1}{3 V_{r}^{l, e}-1}\right)\right]\right. \\
& +\frac{9}{8}\left[\left(\frac{1}{V_{r}^{l}}-\frac{1}{V_{r}^{g}}\right)-\left(\frac{1}{V_{r}^{l, e}}-\frac{1}{V_{r}^{g, e}}\right)\right] \\
& \left.-\frac{3}{8}\left[p_{r}\left(V_{r}^{l}-V_{r}^{g}\right)-p_{r}^{e}\left(V_{r}^{l, e}-V_{r}^{g, e}\right)\right]\right\}
\end{aligned}
$$

Note que se $p_{r}=p_{r}^{e}$, então $V_{r}^{l}=V_{r}^{l, e}$ e $V_{r}^{g}=V_{r}^{g, e}$, de modo que $\Delta \mu=0$, ou seja, o sistema encontra-se em ETD.

A equação (1.26) ou (1.28) considera efeitos de gases reais ou de fluidos compressíveis. No domínio de temperaturas suficientemente menores que a crítica, $T<T_{c}$, e para pressões menores que a no espinodal, $p_{r}<p_{r}^{s}$, pode-se considerar [5]

$$
3 V_{r}^{g} \gg 1 \text { e } 3 V_{r}^{g, e} \gg 1
$$




$$
V_{r}^{l} \cong V_{r}^{l, e} \cong \frac{N v_{0}}{V_{c}} \quad \text { (a maioria dos líquidos é incompressivel) }
$$

e

$$
p_{r} V_{r}^{g} \cong p_{r}^{e} V_{r}^{g, e} \cong \frac{8}{3} T_{r} \quad \text { (o gás é aproximadamente ideal) }
$$

onde $v_{0}$ é o volume de um monômero ${ }^{7}$. Assim, a equação (1.28) pode ser escrita na forma

$$
\Delta \mu=k_{B} T_{c}\left[T_{r} \ln \left(\frac{V_{r}^{g, e}}{V_{r}^{g}}\right)+\frac{9}{8}\left(\frac{1}{V_{r}^{g, e}}-\frac{1}{V_{r}^{g}}\right)+\frac{3}{8}\left(p_{r}^{e} V_{r}^{l, e}-p_{r} V_{r}^{l}\right)\right]
$$

ou, desprezando-se o segundo termo do lado direito desta equação, visto que $9 / 8$. $\left(1 / V_{r}^{g, e}-1 / V_{r}^{g}\right) \cong 0$

$$
\Delta \mu=k_{B} T \ln \left(\frac{V_{r}^{g, e}}{V_{r}^{g}}\right)-\frac{3}{8} k_{B} T_{c}\left(p_{r} V_{r}^{l}-p_{r}^{e} V_{r}^{l, e}\right) .
$$

É mais interessante ter a expressão acima em termos somente de $V, T$ ou de $p, T$. Usando a equação do gás ideal para a fase gasosa $\left(p V^{g}=N k_{B} T\right)$, e reconsiderando as grandezas reduzidas definidas anteriormente,

$$
\Delta \mu=k_{B} T \ln \left(\frac{V^{g, e}}{V^{g}}\right)-\frac{3}{8}\left(\frac{k_{B} T_{c}}{p_{c} V_{c}}\right) N k_{B} T\left(\frac{V^{l}}{V^{g}}-\frac{V^{l, e}}{V^{g, e}}\right)
$$

ou, com a equação (1.19), tem-se a força motriz em termos de $V$ e $T$,

$$
\Delta \mu=k_{B} T \ln \left(\frac{V^{g, e}}{V^{g}}\right)-k_{B} T\left(\frac{V^{l}}{V^{g}}-\frac{V^{l, e}}{V^{g, e}}\right) .
$$

Já em termos de $p, T$, com auxílio das equações (1.19) e (1.29) a (1.31),

$$
\Delta \mu=k_{B} T \ln \left(\frac{p}{p^{e}}\right)-v_{0}\left(p-p^{e}\right)
$$

A equação (1.36) expressa a condensação de vapores quando $p>p^{e}$, onde a dependência do potencial químico da fase inicial (vapor) e o da fase final (líquido)

\footnotetext{
7 Monômero ou partícula é entendida como a unidade da substância em estudo, ou seja, átomos ou moléculas.
} 
sobre a pressão efetiva $p$ é dada por (Guggenheim 1957, em [4])

$$
\mu^{g}(p)=\mu^{e}+k_{B} T \ln \left(\frac{p}{p^{e}}\right)
$$

e

$$
\mu^{l}(p)=\mu^{e}+v_{0}\left(p-p^{e}\right)
$$

onde $\mu^{e}=\mu^{g}\left(p^{e}\right)=\mu^{l}\left(p^{e}\right)$. De acordo com Zettlemayer (1969) [5], usualmente $v_{0} p^{e}<<k_{B} T$ (a energia de um monômero é muito menor que a energia térmica) e $v_{0} p$ é negligenciável na maior parte dos casos, com aproximação suficientemente acurada, a equação (1.36) toma a forma

$$
\Delta \mu=k_{B} T \ln \left(\frac{p}{p^{e}}\right)
$$

ou

$$
\Delta \mu=k_{B} T \ln S \text {, }
$$

relembrando que o argumento do logaritmo, $p / p^{e}$ é denominado supersaturação, $S$.

Portanto, a força motriz da nucleação, equação (1.40), é dependente somente da temperatura e da supersaturação, de modo que características dos monômeros não são relevantes nesse ponto. 


\section{Capítulo 2 \\ Teoria Clássica da Nucleação}

\subsection{Introdução}

A teoria para descrever o fenômeno da transição de fase de primeira ordem, hoje conhecida como Teoria Clássica da Nucleação (TCN), foi apresentada por M. Volmer e A. Z. Weber ${ }^{8}$, no ano de 1925. Na seqüência, L. Z. Farkas ${ }^{9}$ e, depois, R. Becker e W. Döring ${ }^{10}$, aperfeiçoaram o modelo para predições quantitativas do fenômeno da nucleação. Ainda que de acurácia questionável [6] [23], a TCN lançou luz sobre um fenômeno de grande importância tecnológica.

Com o avanço das técnicas de nucleação e medidas mais acuradas, o modelo mostrou-se inconsistente [6] [23]. Várias correções têm sido propostas à TCN. Dentre as mais recentes destaca-se a teoria de A. Dillmann e a G. E. A. Meier [7][8] de acurácia muito boa, que é uma teoria semifenomenológica em que foram usadas técnicas empíricas e numéricas; e a teoria auto-consistente proposta por H. Reiss, W. K. Kegel e J. L. Katz ${ }^{11}$.

Paralelamente, têm surgido trabalhos propondo abordagens alternativas, como os de Erich Meyer [9][10][11] e de Bernhard Joachim Mokross [17][18], teorias estas que serão analisadas mais adiante (respectivamente, Capitulos 3 e 4).

\footnotetext{
8 Volmer, M. and Weber, A.Z. Phys. Chem. (Leipzig), 119 (1926) 227.

9 Farkas, L.Z. Phys. Chem. (Leipzig), 125 (1927) 236.

10 Becker, R.; Dōring W. Am. Phys. 1935, 24, 719.

11 Reiss, H.; Kegel,W. K.; Katz, J. L. Resolution or the Problems of Replacement Free Energy, 1/S, and Internal Consistency in Nucleation Theory by Consideration of the Length Scale for Mixing Entropy. Phys. Rev. Lett. 1997, 78, 4506.
} 


\subsection{Trabalho para Formação de um Núcleo}

Para que haja transição de fase é necessário que a fase inicial, da qual evolve a fase final, esteja num estado metaestável (ou supersaturado). Isto não significa que um vapor colocado neste estado irá condensar-se prontamente. A capacidade da fase inicial em permanecer um certo tempo num estado metaestável é uma das mais notáveis características da transição de fase de primeira ordem, pois revela o fato deste estado estar separado do estado estável por uma barreira de energia. Entende-se que o processo de transição de fase inicia-se com a formação de um aglomerado da nova fase (ou embrião), contendo $n$ monômeros. Quando este embrião, contém uma quantidade mínima de monômeros, $n^{*}$, capaz de vencer a barreira energética, ele é denominado núcleo crítico, ou simplesmente núcleo, se $n \geq n^{*}$.

Conhecer a altura desta barreira de energia é fundamental para a compreensão do processo de nucleação. Supõe-se que a variação de densidade local na fase atual é responsável pela formação de um núcleo crítico com $n^{*}$ monômeros. Assim, é de se esperar que a barreira para a transição de fase, $\Delta G^{*}$, seja da ordem de $n^{*} \Delta \mu$, ou seja,

$$
\Delta G^{*} \sim n^{*} \Delta \mu
$$

Para se encontrar equação (2.1) devem-se considerar os postulados de Gibbs.

\subsubsection{Postulados de Gibbs (sistemas unários)}

A idéia básica de Gibbs foi tratar o fenômeno da nucleação em um sistema, como a mistura de duas partes homogêneas (fases inicial e final) separadas por uma superfície matemática e, portanto, nítida. A partir disto, elaborou alguns postulados [4]. 


\section{Postulado 1}

O sistema consiste de fases volumétricas homogêneas separadas por uma superfície matemática que representa a região interfacial. A esta superfície matemática é atribuída propriedades físicas que introduzem termos não-lineares no cálculo do trabalho.

Considere-se um sistema formado por uma substância pura colocado num estado de supersaturação e dois momentos distintos, imediatamente antes do surgimento do primeiro embrião (situação 1) e logo após (situação 2), conforme Figura 2.3.

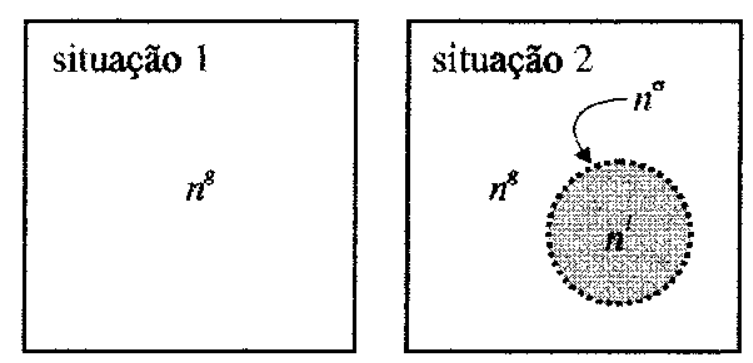

Fig. 2.3- Situações 1 e 2 antes e após a formação de um aglomerado, onde se destaca a tensão superficial.

Pode-se escrever a energia interna, $U$, a entropia, $S$, e o número de partículas, $N$, para a situação 1 como

$$
\begin{gathered}
U^{(1)}=U^{g}, \\
S^{(1)}=S^{g}
\end{gathered}
$$

e

$$
N^{(1)}=n^{g} .
$$

E, para a situação 2,

$$
\begin{gathered}
U^{(2)}=U^{g}+U^{l}+U^{\sigma}, \\
S^{(2)}=S^{g}+S^{l}+S^{\sigma}
\end{gathered}
$$




$$
N^{(2)}=n^{g}+n^{l}+n^{\sigma}
$$

onde o índice $\sigma$ diz respeito à região interfacial. Estas quantidades dependem, portanto, das propriedades da região interfacial e da escolha da superfície divisória.

\section{Postulado 2}

Nas duas situações as contribuições de quantidades termodinâmicas de fases homogêneas não se alteram. São iguais àquelas de sistemas macroscópicos e são separadas por uma interface plana.

Restringindo as considerações à uma interface esférica (suposição 1) e associando a tensão ou energia superficial específica, $\sigma$, a esta superfície divisória, de modo que esta obedeça a uma relação similar à fundamental ${ }^{12}$ (suposição 2), pode-se escrever,

$$
U^{\sigma}=T^{\sigma} S^{\sigma}+\mu^{\sigma} n^{\sigma}+\sigma A
$$

de modo que a variação seja dada por

$$
d U^{\sigma}=T^{\sigma} d S^{\sigma}+\mu^{\sigma} d n^{\sigma}+\sigma d A
$$

onde

$$
S^{\sigma} d T^{\sigma}+n^{\sigma} d \mu^{\sigma}+A d \sigma=0
$$

com $A$ sendo a área da interface.

Em análises subseqüentes, é assumido (suposição 3) que a coexistência de fases, ou seja, o núcleo da fase recentemente formado e a fase atual, estão ambos em equilíbrio termodinâmico intemo (local), enquanto o sistema como um todo não está.

12 A relação fundamental da termodinâmica é dada por

$$
d U=T d S-p d V+\sum_{i} \mu_{i} d n_{i}
$$


Isto significa que, além de entender o processo como sendo irreversível, o núcleo pode crescer (e completar a transição) ou decair (para a fase atual).

\section{Postulado 3}

Ainda que não seja possivel medir ou definir de forma não ambígua e independente as propriedades termodinâmicas da fase superficial, assume-se que as quantidades superficiais intensivas, $\mu^{\sigma}$ e $T^{\sigma}$ são iguais aos correspondentes valores da nova fase (de maior densidade) ${ }^{13}$.

\subsubsection{Nucleação Homogênea}

A nucleação é considerada homogênea quando aglomerados da nova fase encontramse imersos na fase atual, de modo que esta não esteja em contato com nenhuma outra fase e/ou outras espécies de monômeros ou mesmo superfície.

Seja um sistema de densidade uniforme com $N$ monômeros de uma dada substância, colocado em um estado de vapor supersaturado. Na situação l não há aglomerados da nova fase, de modo que a energia livre de Gibbs é escrita como

$$
G^{(1)}=N \mu^{\text {inicial }}
$$

A situação 2 , por sua vez, contém um aglomerado com densidade homogênea maior que a da situação 1, conforme esquematizado na Figura 2.4. Nesta situação a nova fase, constituída de $n$ monômeros, é separada da fase "mãe" por uma superficie divisória,

13 Considerando a transição da fase gasosa para a líquida, assume-se com este Postulado 3 a equivalência de propriedades termodinâmicas entre a nova fase e a interface, ou seja,

$$
T^{\sigma}=T^{l} \text { e } \mu^{\sigma}=\mu^{l}
$$


de modo que a energia livre é dada por

$$
G^{(2)}=(N-n) \mu^{\text {inicial }}+n \mu^{\text {final }}+G^{\text {ex }}(n),
$$

onde $G^{e x}(n)$ é a energia em excesso do aglomerado que, como será mostrado mais adiante, está relacionada à energia de superfície. Cabe notar que na Teoria Clássica da Nucleação (TCN) admite-se que o vapor seja mantido à temperatura e pressão constantes e $\mu^{\text {inicial }}$ não varia nos estados 1 e 2 .

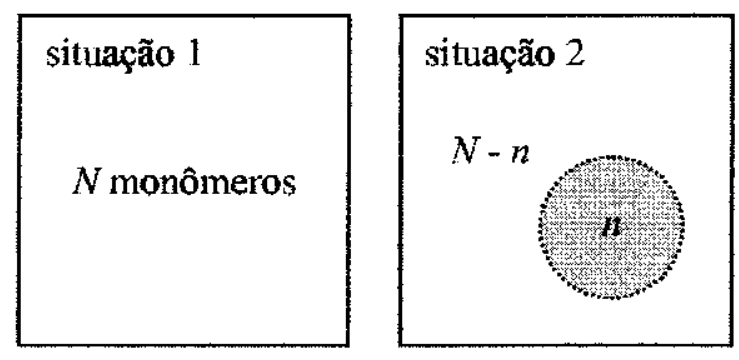

Fig. 2.4- Situações 1 e 2, antes e após a formação de um aglomerado.

O trabalho para a formação de um embrião $\operatorname{com} n$ partículas é dado por

$$
\Delta G(n)=G^{(2)}(n)-G^{(1)}
$$

ou

$$
\Delta G(n)=-n \Delta \mu+G^{e x}(n),
$$

onde $\Delta \mu=\mu^{\text {final }}-\mu^{\text {inicial }}$. Portanto, conhecer $G^{e x}(n)$ é fundamental na determinação de $\Delta G(n)$. Abraham entre outros [4], mostrou que, para a fase condensada, a energia de excesso é proporcional à superficie do aglomerado, $G^{e x} \propto A_{n}$, onde é assumido que o fator de proporcionalidade é $\sigma /\left(\mathrm{J} \cdot \mathrm{m}^{-2}\right)$, isto é, a energia de superficie específica da interface (fase nova)/(fase atual), independente do número de monômeros. Cabe notar 
que o emprego de $\sigma$ é herança dos estudos da capilaridade, razão pela qual a TCN é também chamada de Teoria Capilar da Nucleação.

De acordo com o Postulado 2, o aglomerado da nova fase tem forma regular, de modo que $A_{n}=c V_{n}^{2 / 3}$, onde $c$ é um fator numérico que depende da geometria do aglomerado e $V_{n}$ é o volume do mesmo. Considerando a fase condensada como pequeninas gotas esféricas, tem-se que $c=(36 \pi)^{1 / 3}$ e $V_{n}=\frac{4}{3} \pi r_{n}^{3}=n v_{0}$, onde $v_{0}$ é o volume de um monômero (Ono e Kono 1960, em [4]). Assim,

$$
G^{e x}(n)=\sigma A_{n}=\sigma c V_{n}^{2 / 3}
$$

ou,

$$
G^{e x}(n)=a \sigma n^{2 / 3},
$$

onde $a=\left(36 \pi v_{0}^{2}\right)^{1 / 3}$. Em termos de $r\left(\equiv r_{n}\right)$,

$$
G^{e x}(r)=4 \pi \sigma r^{2}
$$

Assim, de acordo com a TCN, o trabalho para a formação de aglomerados da fase condensada, como função do número de monômeros, é

$$
\Delta G(n)=-n \Delta \mu+a \sigma n^{2 / 3}
$$

ou, em termos do raio do aglomerado,

$$
\Delta G(r)=-\frac{4 \pi}{3 v_{0}} r^{3} \Delta \mu+4 \pi \sigma r^{2} \text {. }
$$

O primeiro membro da direita da equação (2.19) é interpretado como energia volumétrica e o segundo como energia superficial do aglomerado. 


\subsection{Tamanho do Núcleo e Trabalho de Nucleação}

A equação (2.19) sugere uma concorrência entre as energias volumétrica e superficial na formação de um núcleo. O gráfico desta função, mostrado na Figura 2.5, indica a existência de um raio crítico, $r^{*}$, a partir do qual a energia volumétrica deve dominar, resultando um núcleo estável.

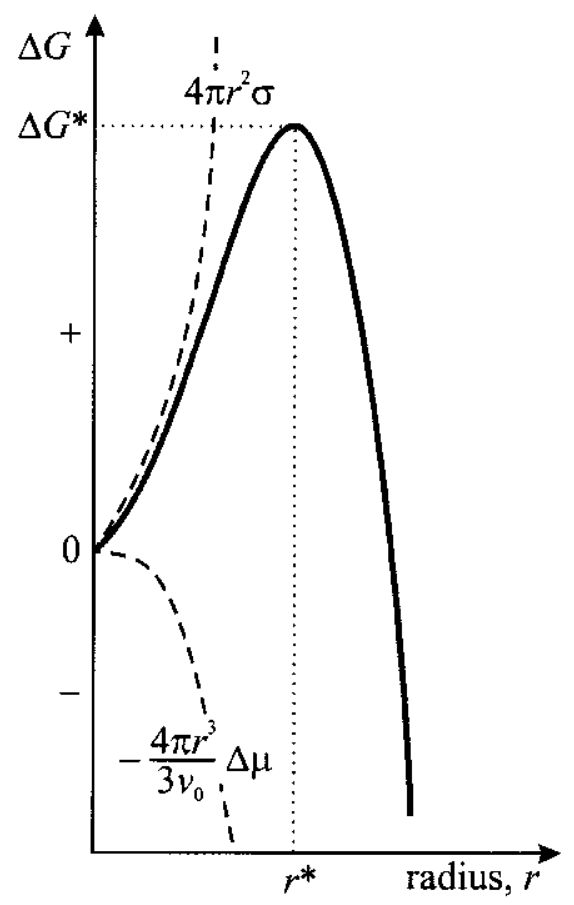

Fig. 2.5- Gráfico indica a existência de núcleo crítico, $n^{*}$, com raio crítico, $r^{*}$.

O raio crítico pode ser estimado tomando-se a derivada da equação (2.19) em relação ao raio e igualada a zero, ou seja,

$$
\left.\frac{d(\Delta G)}{d r}\right|_{r=r^{*}}=-\frac{4 \pi}{v_{0}}\left(r^{*}\right)^{2} \Delta \mu+8 \pi \sigma r^{*}=0 .
$$

Resolvendo para $r^{*}$ encontra-se

$$
r^{*}=\frac{2 v_{0} \sigma}{\Delta \mu}
$$


sendo esta expressão usualmente chamada equação de Gibbs-Thomson ou Kelvin.

A confirmação de que $\Delta G^{*}$ é máximo em $r^{*}$ é obtida calculando a derivada segunda da equação (2.19) no ponto $r=r^{*}$,

$$
\left.\frac{d^{2}(\Delta G)}{d r^{2}}\right|_{r=r^{*}}=-\frac{8 \pi}{v_{0}} r^{*} \Delta \mu+8 \pi \sigma
$$

e, usando a equação (2.21) obtém-se,

$$
\left.\frac{d^{2}(\Delta G)}{d r^{2}}\right|_{r=r^{*}}=-8 \pi \sigma<0
$$

confirmando ser um ponto de máximo.

Os aglomerados da nova fase com raios menores que o crítico, $r<r^{*}$, chamados embriões, são instáveis, de modo que tenderão a ser reabsorvidos com o conseqüente decréscimo da energia livre. Para aglomerados com $r>r^{*}$, chamados de núcleos, a energia livre também decresce, porém tornando-os estáveis. Esses núcleos venceram a barreira energética dando início à transição de fase.

Pode-se estimar a quantidade de monômeros no núcleo crítico. Considerando $v_{0}$ o volume de cada monômero e $n v_{0}$ o volume de um embrião composto de $n$ partículas, o núcleo crítico é dado por

$$
n^{*}=\frac{4}{3} \frac{\pi\left(r^{*}\right)^{3}}{v_{0}}
$$

ou usando a equação (2.21),

$$
n^{*}=\frac{32 \pi v_{0}^{2} \sigma^{3}}{3(\Delta \mu)^{3}} \text {. }
$$

Levando a equação (2.21) na (2.19) tem-se a barreira de energia crítica, $\Delta G^{*}$, associada à formação do núcleo crítico,

$$
\Delta G^{*}=\frac{16 \pi v_{0}^{2} \sigma^{3}}{3(\Delta \mu)^{2}}
$$

ou com auxílio da equação (2.25),

$$
\Delta G^{*}=\frac{1}{2} n^{*} \Delta \mu
$$


onde é confirmada a equação (2.1).

Com a equação (2.21) resolvida para $\Delta \mu$ e levada em (2.19) obtém-se

$$
\Delta G=\frac{1}{3}\left(4 \pi \sigma r^{2}\right)\left(3-2 \frac{r}{r^{*}}\right)
$$

Com auxílio da equação (2.21) levada acima em (2.28) e, após alguma manipulação algébrica, chega-se à sua forma equivalente [4],

$$
\Delta G=\Delta G^{*}\left[3\left(\frac{r}{r^{*}}\right)^{2}-2\left(\frac{r}{r^{*}}\right)^{3}\right]
$$

onde $\Delta G^{*}$ é dado pela equação (2.26). Pode-se expressar esta equação em termos da quantidade de monômeros no aglomerado, tendo em conta que $n=\frac{V}{v_{0}}=\frac{4 \pi}{3 v_{0}} r^{3}$, ou seja,

$$
\Delta G=\Delta G^{*}\left[3\left(\frac{n}{n^{*}}\right)^{2 / 3}-2\left(\frac{n}{n^{*}}\right)\right]
$$

Tomando-se agora a segunda derivada da equação acima em relação a $n$, calculada para $n=n^{*}$ obtém-se

$$
\left.\frac{\partial^{2}(\Delta G)}{\partial n^{2}}\right|_{n=n^{*}}=-\frac{2}{3} \frac{\Delta G^{*}}{\left(n^{*}\right)^{2}}
$$

relação esta que será útil mais adiante, quando for calculada a taxa de nucleação.

\subsection{Taxa de Nucleação}

A cinética da nucleação homogênea, dentro da $\mathrm{TCN}$, é obtida com base em uma série de suposições [4], inicialmente propostas por Volmer-Weber e aperfeiçoadas por Becker-Döring e por Zel'dovich.

\section{Suposição 1}


O sistema é considerado espacialmente homogêneo, onde, no caso mais simplificado, monômeros de um dos componentes agrupam-se para formar um embrião de uma nova fase.

\section{Suposição 2}

É suposto que um núcleo $B_{n}$, consistindo de $n$ monômeros, cresce ou decai por adição ou evaporação de um monômero $B_{1}$, em um processo parecido com uma reação química binária dada por

$$
B_{n}+B_{1} \rightleftarrows B_{n+1}
$$

\section{Suposição 3}

A partir da Suposição 2, tem-se que o número de embriões ou de núcleos por unidade de volume, $M /\left(\mathrm{cm}^{-3}\right)$, em relação ao número de monômeros $n$ num dado instante $t$, pode variar por meio de dois processos de acordo com a reação dada em (2.32). A equação básica para a descrição dessa variação é

$$
\frac{d}{d t} M(n, t)=J(n-1, t)-J(n, t)
$$

para $n \geqslant 2$, onde a taxa de nucleação $J /\left(\mathrm{cm}^{-3} \mathrm{~s}^{-1}\right)$ é definida como

$$
J(n, t)=w^{(+)}(n, t) \cdot M(n, t)-w^{(-)}(n+1, t) \cdot M(n+1, t),
$$

de modo que, $w^{(+)}(n, t)$ é o número médio de monômeros que é incorporado ao núcleo de tamanho $n$ por unidade de tempo, e $w^{(-)}(n, t)$ descreve similarmente a taxa de decaimento.

Suposição 4: forma de equilíbrio dos núcleos

A equação (2.33) está implicitamente sujeita ao pressuposto que o estado do embrião é determinado unicamente pelo número de monômeros que o compõe. Este 
pressuposto é motivado pelo argumento de que o embrião adota rapidamente a geometria e estrutura de equilíbrio correspondente ao número de monômeros que o formam, representando, portanto, a única configuração que deve ser considerada.

\section{Suposição 5}

Os resultados analíticos são obtidos para o caso em que o estado do sistema não se altere no curso da nucleação, ou seja, a supersaturação permanece constante durante o processo.

\section{Suposição 6}

Assim que o núcleo alcança um limite superior de tamanho

$$
n=g \gg n^{*}
$$

o mesmo é removido e $g$ monômeros são adicionados ao sistema. Dessa forma a condição

$$
M(n, t)=0, \quad \text { para } n \geqslant g \gg n^{*},
$$

é sempre satisfeita no modelo do sistema. Esta representação, conhecida como modelo de Szilard, é ilustrada na figura abaixo.

Com este modelo, o número de monômeros por volume é conservado e a relação

$$
M(1, t)+\sum_{n=2}^{g-1} n M(n, t) \equiv M=c t e
$$

é mantida durante o processo.

Suposição 7: aproximação do estado estacionário

Iniciando o sistema com uma distribuição homogênea de monômeros, após um certo intervalo de tempo, $\tau$, estabelece-se uma distribuição estacionária de aglomerados de diversos tamanhos, independente do tempo. 


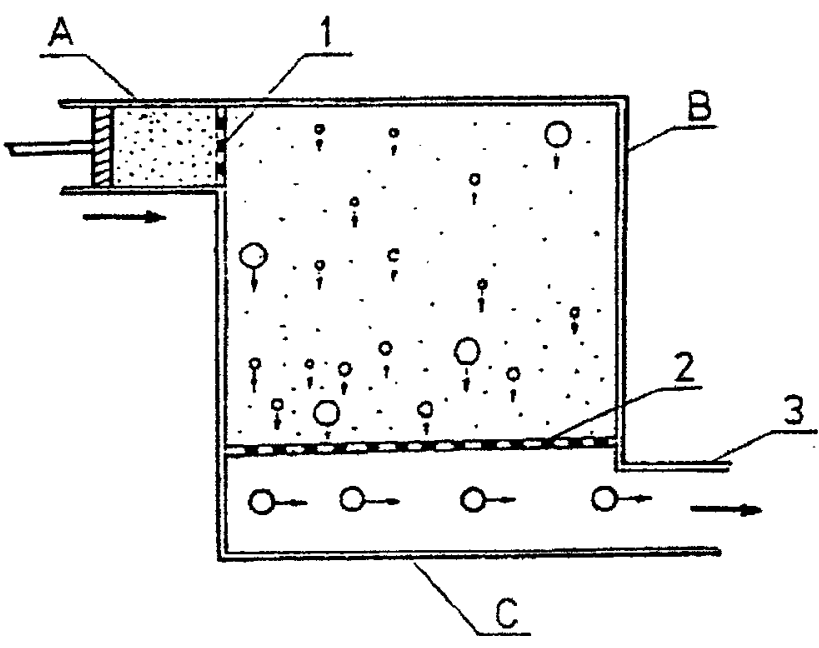

Fig. 2.6- Representação esquemática do modelo de Szilard, em que é mostrado o processo de condensação de vapor. A câmara $B$ é isotérmica e está conectada com um reservatório de partículas na fase ambiente $A$. Iniciada a nucleação, uma população de aglomerados subcríticos e supercríticos é formada. Os núcleos com número de partículas $n \geq g \gg n^{*}$ são removidos da câmara instantaneamente via a membrana semipermeável (2). Simultaneamente, uma quantidade equivalente de monômeros entra no sistema através da membrana (1). O sistema é mantido numa supersaturação constante e uma taxa de nucleação independente do tempo pode ser estabelecida.

Suposições relativas à distribuição de equilíbrio, $M^{(e)}(n)$, de aglomerados.

\section{Suposição 8}

O ensemble de aglomerados com tamanhos diversos pode ser considerado como uma mistura ideal (similar a uma mistura de gases ideais).

\section{Suposição 9}

A distribuição de equilíbrio de aglomerados, $M^{(e)}(n)$, corresponde a um mínimo restrito de energia livre de Gibbs, $G$, de modo que os vínculos (2.32) (2.36) e (2.37) são satisfeitos.

\section{Suposição 10}

O número de monômeros agregados em embriões e/ou núcleos, com tamanho $n \geqslant 2$, é pequeno comparado com o número total de monômeros do sistema. 
Baseado nas Suposições de 8 a 10, a distribuição de equilíbrio do tipo Boltzmann pode ser obtida na forma [4]

$$
M^{(e)}(n)=M \cdot \exp \left[-\frac{\Delta G(n)}{k_{B} T}\right]
$$

a qual é usada como um estado de referência, para a determinação do coeficiente cinético $w^{(-)}$. Na abordagem de Becker-Döring esta equação é introduzida como teorema.

Assumindo que o estado é estacionário, a distribuição de aglomerados no sistema não varia com o tempo. Desta forma, tem-se que $J(n-1)=J(n)$ é válido para todo $n$ pertencente ao intervalo $2 \leqslant n \leqslant(g-1)$.

A partir da equação (2.33) com ajuda da (2.34), ou seja,

$$
\frac{d}{d t} M(n, t)=\left[w^{(+)}(n-1, t) \cdot M(n-1, t)-w^{(-)}(n, t) \cdot M(n, t)\right]-J(n, t)=0
$$

obtém-se um sistema com $(g-2)$ equações em que a $n$-ésima equação é da forma

$$
w^{(+)}(n-1, t) \cdot M(n-1, t)-w^{(-)}(n, t) \cdot M(n, t)=J(n, t)
$$

Vale lembrar que se $n \geq g$ tem-se a condição de Szilard, de modo que

$$
w^{(+)}(n-1, t) \cdot M(n-1, t)=0 .
$$

Numa forma mais compacta, o sistema de equações pode ser escrito como

$$
w_{n-1}^{(+)} M_{n-1}-w_{n}^{(-)} M_{n}=J, \quad \text { para } 2 \leqslant n \leqslant(g-1)
$$

ou, considerando $n$ uma variável muda,

$$
w_{n}^{(+)} M_{n}-w_{n+1}^{(-)} M_{n+1}=J, \quad \text { para } 1 \leqslant n \leqslant(g-2)
$$


Este sistema pode ser resolvido para $J$, multiplicando cada equação, a partir da segunda, $n=2$, pelo produtório $\prod_{i=2}^{n} \frac{w_{i}^{(-)}}{w_{i}^{(+)}}$e substituindo na anterior, de modo a obter $w_{1}^{(+)} M_{1}-J\left[\frac{w_{2}^{(-)}}{w_{2}^{(+)}}+\frac{w_{2}^{(-)}}{w_{2}^{(+)}} \frac{w_{3}^{(-)}}{w_{3}^{(+)}}+\frac{w_{2}^{(-)}}{w_{2}^{(+)}} \frac{w_{3}^{(-)}}{w_{3}^{(+)}} \frac{w_{4}^{(-)}}{w_{4}^{(+)}}+\cdots+\prod_{i=2}^{g-2} \frac{w_{i}^{(-)}}{w_{i}^{(+)}}\right]=J$

ou

$$
J=\frac{w_{1}^{(+)} M_{1}}{1+\sum_{n=2}^{g-2}\left[\prod_{i=2}^{n} \frac{w_{i}^{(-)}}{w_{i}^{(+)}}\right]}
$$

Suposição 11: princípio do balanço detalhado

Em um estado de equilíbrio os fluxos ou direções das possíveis reações estão em balanço, conforme equação (2.32). Tal estado é alcançado com o estado estacionário, em que os $M$ aglomerados de tamanho $n \geq g$, encontram-se no limite, quando são retirados do sistema, em acordo com a condição de Szilard. Aplicando esta condição às $(g-2)$ equações dadas por (2.43), e considerando a distribuição de equilíbrio como referência, $M_{n}^{(e)}$, tem-se um sistema de equações em que a $n$-ésima equação, na forma compacta, é dada por

$$
w_{n}^{(+)} M_{n}^{(e)}-w_{n+1}^{(-)} M_{n+1}^{(e)}=0 .
$$

Destas equações acima se obtém, considerando a equação (2.38),

$$
\frac{w_{n}^{(+)}}{w_{n+1}^{(-)}}=\frac{M_{n+1}^{(e)}}{M_{n}^{(e)}}=\exp \left[-\frac{\Delta G(n+1)-\Delta G(n)}{k_{B} T}\right] .
$$

E, a combinação destas equações (2.47), com $M_{1}^{(e)} \cong M$, leva a

$$
\prod_{i=2}^{n} \frac{w_{i}^{(-)}}{w_{i}^{(+)}}=\frac{w_{1}^{(+)} M_{1}^{(e)}}{w_{n}^{(+)} M_{n}^{(e)}}
$$

que ao ser substituída na equação (2.45), resulta em

$$
J=\frac{1}{\sum_{n=1}^{g-1}\left[\frac{1}{w_{n}^{(+)} M_{n}^{(e)}}\right]}
$$




\section{Suposição 12}

Com o intuito de resolver a equação (2.49), o número de monômeros, $n$, é considerado aproximadamente como uma variável contínua.

$$
J=\frac{1}{\int_{n=1}^{g-1} \frac{1}{w_{n}^{(+)} M_{n}^{(e)}} d n}
$$

É uma boa aproximação somente para sistemas onde o tamanho do núcleo crítico for suficientemente grande $\left(n^{*}>>1\right)$. A distribuição $M_{n}^{(e)}$ tem um mínimo quando o aglomerado é de tamanho crítico $\left(n=n^{*}\right)$. Esta afirmação torna-se clara levando em conta o estado de equilíbrio e novamente a condição de Szilard. Nesta configuração, os aglomerados do sistema tendem ao tamanho de $g$ monômeros, de modo que aqueles de tamanho crítico sejam a minoria. Isto permite reescrever a equação (2.50), com ajuda da equação (2.38), da seguinte forma

$$
J=\frac{w^{(+)}\left(n^{*}\right) \cdot M}{\int_{n=1}^{g-1} \exp \left[\frac{\Delta G(n)}{k_{B} T}\right] d n}
$$

Expandindo $\Delta G(n)$ em série de Taylor, na vizinhança de $n=n^{*}$, até o termo de segunda ordem tem-se

$$
\Delta G(n)=\Delta G\left(n^{*}\right)+\frac{1}{2}\left(\frac{\partial^{2} \Delta G(n)}{\partial n^{2}}\right)_{n=n^{*}}\left(n-n^{*}\right)^{2}+O\left[(\Delta G(n))^{3}\right]
$$

onde $\left(\frac{\partial \Delta G(n)}{\partial n}\right)_{n=n^{*}}\left(n-n^{*}\right)=0$, por ser ponto de mínimo. Levando na equação (2.51), resulta

$$
J \cong \frac{w^{(+)}\left(n^{*}\right) \cdot M}{\int_{n=1}^{g-1} \exp \left[\frac{\Delta G\left(n^{*}\right)}{k_{B} T}+\frac{1}{2 k_{B} T}\left(\frac{\partial^{2} \Delta G(n)}{\partial n^{2}}\right)_{n=n^{*}}\left(n-n^{*}\right)^{2}\right] d n}
$$


ou

$$
J \cong \frac{w^{(+)}\left(n^{*}\right) \cdot M \cdot \exp \left[-\frac{\Delta G\left(n^{*}\right)}{k_{B} T}\right]}{\int_{n=1}^{g-1} \exp \left[\frac{1}{2 k_{B} T}\left(\frac{\partial^{2} \Delta G(n)}{\partial n^{2}}\right)_{n=n^{*}}\left(n-n^{*}\right)^{2}\right] d n} .
$$

Cabe notar que a equação (2.52) é uma das principais aproximações usadas em toda a teoria da nucleação, apresentada primeiramente por Becker e Döring (1935) [4].

A integral na equação (2.54) acima é facilmente encontrada tomando-se $g \gg 1$ ou $g \rightarrow \infty$, ou seja,

$$
\int_{n=1}^{g-1} \exp \left[\frac{1}{2 k_{B} T}\left(\frac{\partial^{2} \Delta G(n)}{\partial n^{2}}\right)_{n=n^{*}}\left(n-n^{*}\right)^{2}\right] d n \cong \int_{x=0}^{\infty} e^{-(-a) x^{2}} d x=\frac{1}{2} \sqrt{\frac{\pi}{-a}}
$$

onde $a=\frac{1}{2 k_{B} T}\left(\frac{\partial^{2} \Delta G(n)}{\partial n^{2}}\right)_{n=n^{*}}, n-n^{*}=x$ e $d n=d x$. Assim, a equação (2.54) é expressa como

$$
J=w^{(+)}\left(n^{*}\right) \cdot M \cdot\left[-\frac{2}{\pi k_{B} T}\left(\frac{\partial^{2} \Delta G(n)}{\partial n^{2}}\right)_{n=n^{*}}\right]^{\frac{1}{2}} \exp \left(-\frac{\Delta G\left(n^{*}\right)}{k_{B} T}\right),
$$

que é uma boa aproximação para a equação (2.51) quando $n^{*} \gg 1$ (Suposição 12).

Com estas considerações a equação básica da TCN pode ser escrita na forma

$$
J=w^{(+)}\left(n^{*}\right) \cdot \Gamma_{z} \cdot M \cdot \exp \left(-\frac{\Delta G\left(n^{*}\right)}{k_{B} T}\right)
$$

onde $w^{(+)}\left(n^{*}\right)$ é o coeficiente cinético de crescimento e $\Gamma_{z}$ é usualmente denotado como fator de Zel'dovich [4] definido por

$$
\Gamma_{z}=\left[-\frac{2}{\pi k_{B} T}\left(\frac{\partial^{2} \Delta G(n)}{\partial n^{2}}\right)_{n=n^{*}}\right]^{\frac{1}{2}}
$$

Com o auxílio da equação (2.31) tem-se o fator $\Gamma_{z}$ expresso como

$$
\Gamma_{z}=\left[\frac{4}{3 \pi k_{B} T} \frac{\Delta G^{*}}{\left(n^{*}\right)^{2}}\right]^{\frac{1}{2}}
$$

ou, usando as equações $(2.27),(2.21)$ e (2.24),

$$
\Gamma_{z}=\frac{v_{0}}{\pi\left(r^{*}\right)^{2}}\left(\frac{\sigma}{k_{B} T}\right)^{\frac{1}{2}}
$$


Deste modo, a equação (2.57) pode ser escrita como

$$
J=w^{(+)}\left(n^{*}\right) \cdot M \cdot \frac{v_{0}}{\pi\left(r^{*}\right)^{2}}\left(\frac{\sigma}{k_{B} T}\right)^{\frac{1}{2}} \cdot \exp \left(-\frac{\Delta G\left(n^{*}\right)}{k_{B} T}\right)
$$

ou, com ajuda da (2.21) e da (2.26) terá a forma

$$
J=J_{0} \cdot \exp \left(-\frac{\Delta G^{*}}{k_{B} T}\right)
$$

onde $J_{0}=w^{(+)}\left(n^{*}\right) \cdot M \cdot \frac{4 v_{0} \sigma}{3 \Delta G^{*}}\left(\frac{\sigma}{k_{B} T}\right)^{\frac{1}{2}}$. Esta expressão é a variação temporal da equação (2.38), onde o pré-fator $J_{0}$ é a síntese da TCN.

\subsubsection{Condensação de Vapor}

A distribuição de velocidades de monômeros idênticos de massa $m_{0}$ em um gás de um componente, pode ser escrita como [2][20]

$$
d w\left(v_{x}, v_{y}, v_{z}\right)=\left(\frac{m_{0}}{2 \pi k_{B} T}\right)^{\frac{3}{2}} \exp \left(-\frac{m_{0}|\vec{v}|^{2}}{2 k_{B} T}\right) d v_{x} d v_{y} d v_{z}
$$

cuja média do valor absoluto é

$$
\langle v\rangle=\left(\frac{8 k_{B} T}{\pi m_{0}}\right)^{\frac{1}{2}}
$$

O número de monômeros que se chocam com um elemento de superficie por unidade de tempo, $Z /\left(\mathrm{m}^{-2} \mathrm{~s}^{-1}\right)$, pode ser expresso através da densidade desses monômeros, $M$, e da velocidade média na direção do eixo- $z,\left\langle v_{z}\right\rangle$, tomada como referência [4], ou seja,

$$
Z=\frac{1}{4} M\langle v\rangle=\frac{1}{4} M\left(\frac{8 k_{B} T}{\pi m_{0}}\right)^{\frac{1}{2}}
$$

onde foi usado $\left\langle v_{z}\right\rangle=\frac{1}{4}\langle v\rangle$.

O coeficiente cinético de crescimento, $w_{n}^{(+)}$, é definido como

$$
w_{n}^{(+)}=Z A_{n}
$$


onde $A_{n}=4 \pi r_{n}^{2}$, em acordo com a Sessão 2.2.2. Quando $n=n^{*}$, tem-se

$$
w^{(+)}\left(n^{*}\right)=M \pi\left(r^{*}\right)^{2}\left(\frac{8 k_{B} T}{\pi m_{0}}\right)^{\frac{1}{2}}
$$

Levando a equação (2.67) na equação da taxa de nucleação, (2.61), encontra-se que

$$
J=v_{0} M^{2}\left(\frac{2 \sigma}{\pi m_{0}}\right)^{\frac{1}{2}} \exp \left(-\frac{\Delta G^{*}}{k_{B} T}\right)
$$

ou

$$
J=v_{0}\left(\frac{p}{k_{B} T}\right)^{2}\left(\frac{2 \sigma}{\pi m_{0}}\right)^{\frac{1}{2}} \exp \left(-\frac{\Delta G^{*}}{k_{B} T}\right)
$$

onde se usou $M \equiv \frac{N}{V}=\frac{p}{k_{B} T}$, já que, inicialmente, o vapor é tido aproximadamente como um gás ideal, de modo que $M(1) \equiv N$, onde $N$ é o número de partículas do sistema. Escrevendo de forma compacta como em (2.62), encontra-se a taxa de nucleação proposta por Becker-Döring,

$$
J_{B D}=J_{0} \exp \left(-\frac{\Delta G^{*}}{k_{B} T}\right)
$$

onde $J_{0}=v_{0}\left(\frac{p}{k_{B} T}\right)^{2}\left(\frac{8 \sigma}{\pi m_{0}}\right)^{\frac{1}{2}}$ é o pré-fator da taxa de nucleação.

\subsection{Deficiências na Teoria Clássica}

Apesar de já se ter compreendido muito da cinética da transição de fase de primeira ordem, diversos problemas na formulação da teoria, bem como na aplicação da teoria em casos particulares, permanecem em aberto. Citando alguns:

- Nucleação e crescimento procedem sem decréscimo da força motriz em violação ao princípio de Châtellier-Braun ${ }^{14}$ [18]. Com este princípio, além de afetar o

14 Este princípio diz que a ação exterior que tira o corpo do estado de equilíbrio térmico, estimula processos neste que tendem a contrapor esta ação debilitando o resultado da mesma. Assim, por exemplo, o aquecimento do corpo estimula processos relacionados com a absorção 
calor latente do sistema, tem-se o indicativo de que a temperatura não deve ser constante durante a nucleação;

- Simples flutuações de variáveis termodinâmicas como por exemplo pressão ou temperatura, não são consideradas. Isto torna o processo proposto pela $\mathrm{TCN}$ muito mais complicado e conseqüentemente menos provável [10];

- Simulações computacionais e experimentos sofisticados indicam que a interface não é bem definida e sim difusa ou podendo apresentar estrutura fractal (principalmente para pequenos embriões e núcleos) [18];

- TCN contém um erro fundamental em que prediz uma barreira finita de energia para que haja nucleação mesmo no espinodal, sendo que a propriedade central neste estado é o desaparecimento desta barreira com o fluido passando de um estado termodinamicamente metaestável para um instável [18].

- Deve ser garantido que a quantidade condensada de substância seja imediatamente substituída por processo de difusão (modelo de Szilard) [4] [18]. Evidentemente que num caso real há depleção do material, pelo menos localmente;

- É predito a dependência da taxa de nucleação $J$ com a supersaturação $S$ e com a temperatura $T$, ou seja, $J=J(S, T)$. No entanto, em relação à temperatura, a dependência é notadamente forte. As taxas de nucleação encontradas são altas a temperaturas mais elevadas e baixas a temperaturas menores, representando séria deficiência na TCN [6] [23]. (A Figura 2.8 ilustra de calor e, vice-versa, o esfriamento contribui para o surgimento processos em que se desprende calor [3]. 
o problema da temperatura na determinação da taxa de nucleação) Porém, o resultado qualitativo da taxa de nucleação não se altera se assume que com o decréscimo da temperatura as quantidades extrapoladas, tensão superficial, $\sigma$, pressão de equilíbrio de vapor, $p^{e}$, e densidade do líquido, $\rho$, tornam-se menos confiáveis. A figura seguinte evidencia as alterações nas quantidades acima citadas.

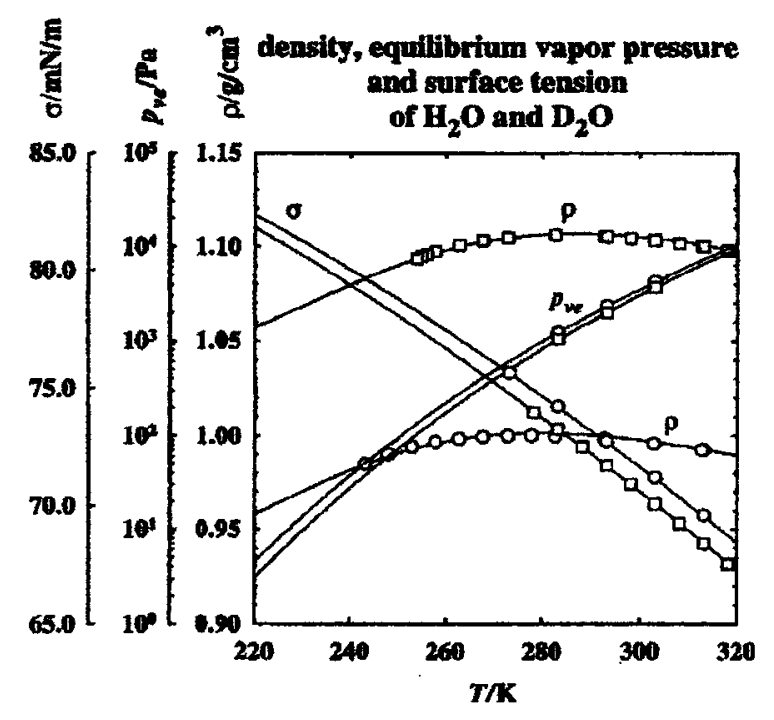

Fig. 2.7- Densidade, $\rho$, pressão de equilíbrio de vapor, $p^{e}$, e tensão de superfície de $\mathrm{H}_{2} \mathrm{O}$ e $\mathrm{D}_{2} \mathrm{O}$ como função da temperatura. Os círculos pertencem à agua leve e os quadrados à água pesada.

Segundo Viisanen et al. [6], além da água, estas observações estão em acordo com vários outros sistemas como nonane, propanol e a série homóloga de alcoóis. 


\subsection{Correções na TCN}

Com avanços nas técnicas experimentais para determinar as taxas de nucleação, os desvios da TCN tornaram-se sistemáticos. Ainda que para temperaturas em tomo de $238 \mathrm{~K}$ a acurácia é boa, atualmente não se observam resultados semelhantes para outros valores de $T$ [6][23]. Desde seu surgimento, por volta de 1925, correções têm sido propostas. Duas delas são aqui comentadas, a de Dilmann-Meier e a de Reiss-KegelKatz, pela sua acurária e pela sua atualidade.

\subsubsection{Teoria de Dilmann-Meier}

A teoria de A. Dillmann e G.E.A Meier (D-M) [7] [8] é tida como semifenomenológica, uma vez que parte de sua estrutura tem origem empírica. Os autores partem da taxa de nucleação na forma generalizada dada por McDonald ${ }^{15}$,

$$
J=\sqrt{-\left.\frac{1}{2 \pi k_{B} T} \frac{\partial^{2} \Delta G(n)}{\partial n^{2}}\right|_{n=n^{*}}} Z_{n^{*}} \frac{1}{V} \exp \left(-\frac{\Delta G\left(n^{*}\right)}{k_{B} T}\right),
$$

onde o fator $Z_{n^{*}}$ dado por

$$
Z_{n^{*}}=\frac{p A_{n^{*}}}{\sqrt{2 \pi m_{0} k_{B} T}}
$$

representa o número colisões por segundo de monômeros sobre a superfície de um núcleo crítico, e $A_{n^{*}}$ a superficie do núcleo crítico $\left[=a\left(n^{*}\right)^{2 / 3}\right.$, se o núcleo crítico for esférico, conforme Sessão 2.2.2]. Nesta expressão, $p$ é a pressão do sistema e $m_{0}$ é a massa de um monômero.

Em seguida utilizam o modelo semifenomenológico para a energia livre de Gibbs na formação do núcleo crítico, na forma similar à originalmente proposta por Fisher ${ }^{16}$

$$
\Delta G_{n}=\beta_{n} \sigma a n^{2 / 3}+\tau k_{B} T \ln n-k_{B} T \ln \left(q_{0} V\right)-n k_{B} T \ln S,
$$

15 J.E. McDonald, Am. J. Phys. 30 (1962) 870; 31 (1963) 31.
16 ME. Fisher, Physics 3 (1967) 255. 
onde $\sigma$ é a tensão superficial, $a n^{2 / 3}$ é superfície de um núcleo esférico contendo $n$ moléculas, $\tau$ e $q_{0}$ são constantes determinadas experimentalmente. A quantidade $\beta_{n}$ descreve desvios da energia livre de superfície do núcleo comparado com uma gota macroscópica. Tal quantidade é encontrada forçando uma comparação entre uma equação estado de gases reais e uma equação de estado fenomenológica [7] [8], de modo que com algumas simplificações chega-se a

$$
\beta_{n} \cong 1+\alpha_{1} n^{-1 / 3}+\alpha_{2} n^{-2 / 3}
$$

onde os parâmentos $\alpha_{1}$ e $\alpha_{2}$ são dados por

$$
\alpha_{1}=\frac{\left(\beta_{2}-1\right)-\left(\beta_{1}-1\right) 2^{-2 / 3}}{2^{-1 / 3}-2^{-2 / 3}}
$$

e

$$
\alpha_{2}=-\frac{\left(\beta_{2}-1\right)-\left(\beta_{1}-1\right) 2^{-1 / 3}}{2^{-1 / 3}-2^{-2 / 3}}
$$

sendo que $\beta_{1}$ e $\beta_{2}$ são escritos como

$$
\beta_{1}=-\frac{1}{\theta} \ln \left(\frac{p_{s a t}}{q_{0} k_{B} T}\right)
$$

e

$$
\beta_{2}=-\frac{1}{\theta 2^{2 / 3}} \ln \left[-\left(\frac{p_{\text {sat }}}{q_{0} k_{B} T}\right)^{2} 2^{\tau-1} q_{0} B\right]
$$

onde $p_{\text {sat }}$ é a pressão de saturação e $\theta=\frac{\sigma A_{1}}{k_{B} T}$.

Com as equações (2.74) a (2.78) todos os parâmetros do modelo são dados em termos de quantidade macroscópicas conhecidas. Deste modo, a taxa de nucleação calculada a partir de (2.71), juntamente com o modelo da gota dado pela equação (2.73) é dada por

$$
J=\frac{1}{3} \sqrt{\frac{\theta}{\pi}\left[1+\alpha_{1}\left(n^{*}\right)^{-1 / 3}+\frac{9 \tau}{2 \theta}\left(n^{*}\right)^{-2 / 3}\right]} \frac{p A_{1}}{\sqrt{2 \pi m_{0} k_{B} T}} \rho_{n^{*}}
$$


com

$$
\rho_{n^{*}}=q_{0} \exp \left[-\beta_{n^{*}} \theta\left(n^{*}\right)^{2 / 3}-\tau \ln n^{*}+n^{*} \ln S\right] .
$$

O tamanho do núcleo crítico, $n^{*}$, é encontrado através da raiz real da seguinte equação cúbica,

$$
a \tau x^{3}+\frac{1}{3} \alpha_{1} \theta x^{2}+\frac{2}{3} \theta x-\ln S=0 .
$$

Este modelo contém a TCN como caso especial, em que $\tau=0$ (sem graus de liberdade adicionais), $\beta_{n}=1$ (o núcleo é uma gota macroscópica) e $q_{0}=\frac{p}{k_{B} T}$.

\subsubsection{Teoria de Reiss-Kegel-Katz}

Os autores H. Reiss, W. K. Kegel e J. L. Katz ${ }^{17}$ (RKK) desenvolveram uma teoria autoconsistente que faz algumas alterações na $\mathrm{TCN}$, como melhorar a dependência com a temperatura.

Reescrevem a energia livre do sistema, quando este contém aglomerados com densidade homogênea (equação (2.12)), acrescentando um termo referente à entropia da mistura de fases,

$$
G=(N-n) \mu^{\text {inicial }}+n \mu^{f i n a l}+G^{e x}(n)-T S_{m i x},
$$

onde $\mu^{\text {inicial }}$ é o potencial químico da fase atual, $\mu^{\text {final }}$ o da fase emergente e $G^{e x}(n)$ é a energia livre de excesso (conforme equação (2.16)).

Na seqüência, a equação (2.38), de importância central na TCN (derivada do princípio do balanço detalhado) é reescrita como

$$
M^{(e)}(n)=\frac{R}{S} \cdot N^{g} \cdot \exp \left[-\frac{\Delta G(n)}{k_{B} T}\right],
$$

17 Reiss, H., Kegel, W. K. and Katz, J. L. Resolution of the Problems of Replacement Free Energy, $1 / S$, and Internal Consistency in Nucleation Theory by Consideration of the Length Scale for Mixing Entropy. Phys. Rev. Lett. 78 (1997) 4506. 
onde $R$ é um fator obtido com o então chamado reposicionamento da energia livre ${ }^{18}$, que se origina das considerações dos graus de liberdade translacionais do aglomerado; e o fator $1 / S$, inverso da supersaturação, destina-se a satisfazer a lei da ação das massas com respeito à concentração de monômeros não-aglomerados ${ }^{19}$. Apesar das críticas recebidas, os autores corrigiram uma "inconsistência interna" da TCN. Assumindo $n=1 \mathrm{em}(2.83)$, conseguiram obter $M^{(e)}(1)=N^{g} / V$, resultado este exigido na TCN mas não obtido.

Com estas considerações, Reiss-Kegel-Katz derivaram a taxa de nucleação dada por

$$
J_{R K K}=\left(\frac{n^{*} N_{A} k_{B} T \rho \beta}{m}\right)^{-1 / 2} \frac{\exp \Theta}{S} J_{B D}
$$

onde $J_{B D}$ é a taxa de nucleação de Becker-Döring dada por (2.70), e o fator $\frac{\exp \Theta}{S}$, obtido por Steven L. Girshick e Chia-Pin $\mathrm{Chiu}^{20}$ em que $\Theta$ é proporcinal à energia de superfície de um monômero, assim definida

$$
\Theta=\frac{(36 \pi)^{1 / 3} v_{m}^{2 / 3} \sigma}{k_{B} T}
$$

\subsection{Discussão}

Recentemente, Strey et al. [6] [23] têm sugerido que a equação (2.62),

$$
J=J_{0} \exp \left(-\frac{\Delta G^{*}}{k_{B} T}\right)
$$

18 ob. cit., referências [2] a [6].

19 ob. cit., referências [7] a [9].

20 Girshick, S. L.; Chiu, C.-P. Kinetic Nucleation Theory: A new expression for the rate of homogeneous nucletion from an ideal supersaturated vapor. J. Chem. Phys. 1990, 93, 1273. 
é geral no sentido de não depender de nenhuma abordagem teórica. Assim, a partir de dados experimentais como pressão (supersaturação) e taxa de nucleação é possível calcular o tamanho do núcleo crítico.

Tomando o logaritmo da equação (2.86) e derivando-a em relação ao logaritmo da supersaturação leva a

$$
\frac{\partial \ln J}{\partial \ln S}=-\frac{\partial\left(-\Delta G^{*} / k_{B} T\right)}{\partial \ln S}+\frac{\partial \ln J_{0}}{\partial \ln S}
$$

Considerando que o trabalho crítico dado pela equação,

$$
\Delta G^{*}=\frac{1}{2} n^{*} \Delta \mu
$$

pode ser expresso em termos da supersaturação, com auxílio da equação

$$
\Delta \mu=k_{B} T \ln S
$$

então a equação (2.87) resulta em

$$
\frac{\partial \ln J}{\partial \ln S} \cong n^{*} \text {. }
$$

Com a abordagem semifenomenológica, os autores Dillmann-Meier conseguiram calcular a supersaturação, em função da temperatura, com margem de erro de 3 a $5 \%$ para a água [7] [8] (vide Figura 2.8). Resultados similares foram obtidos para uma variedade de outras substâncias ${ }^{21}$.

Ainda que este modelo extrapole as pretensões deste trabalho, no que se refere à TEN, é importante tê-lo como referência, dada sua acurácia. Extrapola porque os autores fundiram várias frentes: análise teórica, numérica e fenomenológica; enquanto que a TEN tem como escopo conceitos fundamentais da termodinâmica, da física estatística e da teoria das flutuações.

21 A. Dillmann and G.E.A. Meier, Bericht 1/1989, Max-Planck-Institut für Strömungsforschung, Göttingen, FRG (1989). 
Os cálculos feitos com a Reiss-Kegel-Katz indicam melhor dependência da taxa de nucleação com a temperatura. Porém é desviada para cima quando comparada com dados experimentais por um fator cerca de quatro ordens de grandeza (vide Figura 2.8).

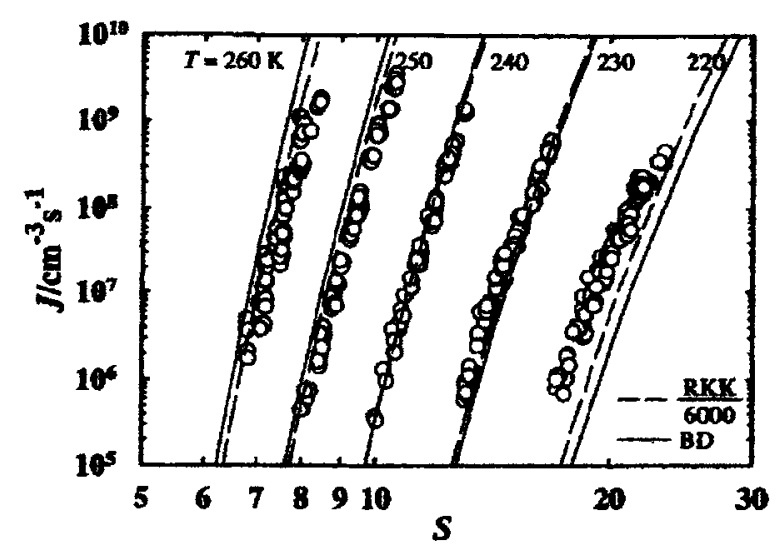

Fig. 2.8- Comparação das teorias RKK e BD com os dados experimentais. Note-se que próximo a $T=240 \mathrm{~K}$ há boa concordância entre as duas abordagens. 


\section{Capítulo 3 \\ Teoria Adiabática de Nucleação}

\subsection{Introdução}

A Teoria Adiabática da Nucleação (TAN) propõe que a transição de fase de primeira ordem não seja, necessariamente, um fenômeno isotérmico e destaca, ao invés da energia livre de Gibbs, o aumento de entropia como força motriz deste processo. Admite que pressão e temperatura do sistema são iguais no início e no final do processo, como mostra a experiência, mas não obrigatoriamente durante a transição.

\subsection{Considerações Termodinâmicas}

Diferentemente da TCN, a TAN considera que o processo de transição de fase tem início em um subsistema (elemento de volume) imerso em um sistema (meio ou vizinhança) que se encontra à pressão $p_{0}$ e temperatura $T_{0}$, como mostra a Figura 3.9. A variação espontânea no estado do subsistema é devido à minimização da disponibilidade $^{22} A$ do elemento de volume, ao invés da energia livre de Gibbs, $G$ [10], como será visto mais adiante nesta sessão.

Quando um sistema migra de um estado para outro, havendo transição de fase, observa-se um aumento da entropia total (sistema e subsistema), em acordo com a desigualdade de Clausius, definida como [13]

$$
\Delta S_{t o t}=\Delta S_{0}+\Delta S \geq 0
$$

22 Do inglês: availability. 


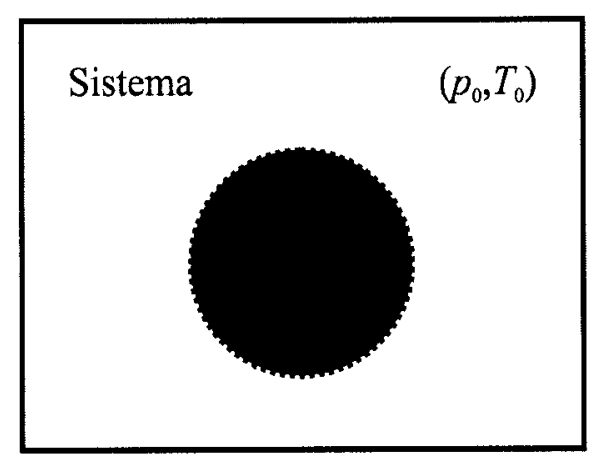

Fig. 3.9- No início e no final da transição da fase as propriedades termodinâmicas, pressão e temperatura, do elemento de volume são iguais às do sistema, ou seja, $p=p_{0} \mathrm{e} T=T_{0}$, respectivamente, mas não necessariamente durante o processo.

onde $\Delta S_{0}$ é a variação da entropia do sistema (ou vizinhança) e $\Delta S$ é a variação da entropia do elemento de volume (ou subsistema).

Considerando apenas o subsistema, a desigualdade de Clausius, expressa através da Segunda Lei da Termodinâmica, pode ser enunciada como

$$
\Delta S=\Delta S_{e}+\Delta S_{i} \geqslant 0
$$

na qual a variação da entropia do elemento de volume, $\Delta S$, é devida às variações da interação deste com a vizinhança (transferência), $\Delta S_{e}$, e devido às variações produzidas internamente, $\Delta S_{i}$.

O aumento da entropia do subsistema, devido à sua interação com a vizinhança, está relacionado com o fluxo de calor para dentro deste,

$$
\Delta S_{e}=\frac{\Delta Q}{T_{0}}
$$

onde se supõe que a temperatura fora deste elemento de volume é constante de valor $T_{0}$ (ou entendido como sendo um reservatório térmico). Se o fluxo de calor for do subsistema para a vizinhança, $\Delta S_{e}$ assumirá valores negativos.

Quanto à entropia produzida dentro do elemento de volume, esta será positiva para todos os processos irreversíveis e zero para aqueles reversíveis. Nunca será nega- 
tiva, de modo que pode-se escrever

$$
\Delta S_{i} \geqslant 0
$$

Assim, a desigualdade de Clausius para o subsistema que recebe calor pode ser escrita na forma

$$
\Delta S \geqslant \frac{\Delta Q}{T_{0}}
$$

Nesta expressão, a razão entre o calor fornecido ao subsistema, $\Delta Q$, e a temperatura do sistema, $T_{0}$, torna $\Delta S$ uma função de estado. Isto permite que a nucleação, processo intrinsecamente irreversível, seja analisada a partir de outros processos reversíveis equivalentes desde que as entropias inicial e final sejam as mesmas.

A disponibilidade $A$ pode ser expressa a partir da Primeira Lei da Termodinâmica [10] resolvida para a variação de calor

$$
\Delta Q=\Delta U+p_{0} \Delta V
$$

onde $U$ e $V$ são, respectivamente, energia interna e volume do subsistema e $p_{0}$ é a pressão externa (sistema). Levando esta expressão, equação (3.6) em (3.5) resulta em

$$
\Delta S \geqslant \frac{\Delta U+p_{0} \Delta V}{T_{0}}
$$

ou

$$
-\frac{1}{T_{0}}\left(\Delta U+p_{0} \Delta V-T_{0} \Delta S\right) \geqslant 0 .
$$

A partir da equação (3.8) define-se a variação da disponibilidade do subsistema, ou seja,

$$
\Delta A \equiv \Delta U+p_{0} \Delta V-T_{0} \Delta S \leqslant 0
$$

A definição da variação da energia livre de Gibbs do elemento de volume, $\Delta G$, é semelhante à da disponibilidade,

$$
\Delta G \equiv \Delta U+p \Delta V-T \Delta S
$$


porém, as variáveis $p$ e $T$ referem-se ao subsistema, enquanto que em (3.9) as variáveis $p_{0}$ e $T_{0}$ são valores da sistema.

Observando agora o sistema, pode-se reinterpretar a desigualdade de Clausius, equação (3.1), em que $\Delta S_{0}$ é a variação da entropia do sistema devido ao fluxo de calor para o subsistema (entropia transferida para o elemento de volume). Assim, com auxílio da equação (3.3) pode-se escrever

$$
\Delta S_{0}=-\Delta S_{e}=-\frac{\Delta Q}{T_{0}}
$$

Levando a equação (3.6) na equação acima e substituindo-a na equação (3.1) resulta em

$$
\Delta S_{t o t}=-\frac{1}{T_{0}}\left(\Delta U+p_{0} \Delta V-T_{0} \Delta S\right) \geqslant 0,
$$

ou ainda, com ajuda da equação (3.9),

$$
\Delta S_{t o t}=-\frac{\Delta A}{T_{0}} \geqslant 0
$$

As inequações (3.9) e (3.13) mostram que, num processo espontâneo de mudança de estado do sistema, há diminuição da disponibilidade e/ou aumento da entropia total.

Portanto, à medida que o sistema evolui, a disponibilidade tende a um mínimo, quer o processo seja reversível ou não. Neste caso, a disponibilidade poderia ser chamada de força motriz da transição de fase, pois as variáveis pressão e temperatura da vizinhança, mantidas constantes ao longo do processo são externas ao subsistema. Porém, a partir da equação (3.13), pode-se concluir que na realidade a verdadeira força motriz do processo de transição de fase de primeira ordem é a entropia total do sistema [10].

Deve-se atentar para uma diferença fundamental entre a TCN e a TAN. Naquela, a transição de fase ocorre a pressão $p_{0}$ e temperatura $T_{0}$ constantes. É uma observação 
macroscópica que indica um processo isotérmico. Porém, com a TAN entende-se que o elemento de volume apresenta temperatura e pressão iguais ao do sistema no início e no final do processo de nucleação, mas não necessariamente durante o mesmo. Esta concepção faz sentido quando se leva em conta que a definição de temperatura está relacionada com o estado de agitação dos monômeros. E o surgimento de um aglomerado da nova fase afeta consideravelmente a energia cinética dos monômeros do elemento de volume.

Considerando o sistema isolado adiabaticamente, observa-se

$$
\Delta Q=0
$$

além de

$$
\Delta p_{0}=0
$$

visto a pressão inicial e a final serem iguais antes e depois do processo. Neste caso, a equação (3.6) para um processo reversível pode ser expressa como

$$
\Delta U+p_{0} \Delta V=\Delta\left(U+p_{0} V\right)=\Delta H=0
$$

onde $H$ é a entalpia do sistema. Desta forma, quando o sistema sofre uma transição de fase, a entropia aumenta (veja equação (3.1)) enquanto que as entalpias inicial e final são iguais.

Do ponto de vista experimental as equações (3.15) e (3.16) são importantes, pois em geral é mais fácil manter constante a pressão de um sistema que seu volume. Além disso, tais equações são aplicáveis a sistemas unários, bem como a binários [11]. 


\subsection{Flutuações no Subsistema}

A TAN admite que o mecanismo básico responsável pela formação de núcleos num fluido supersaturado é a flutuação tanto da temperatura como da pressão (ou volume ou densidade). Com a flutuação, num curto intervalo de tempo e numa pequena porção do sistema, tem-se uma variação da energia interna, $\Delta U$, que é muito pequena em relação à energia interna do susbsistema, $U$, de modo que é possível expandi-la numa série de Taylor em torno das variáveis do sistema, $S_{0}$ e $V_{0}$ [14]. Sendo $U=U(S, V)$, encontra-se

$$
U(S, V)=\left.\sum_{i=0}^{\infty} \frac{1}{i !}\left[\left(S-S_{0}\right) \frac{\partial}{\partial S}+\left(V-V_{0}\right) \frac{\partial}{\partial V}\right]^{i} U(S, V)\right|_{S=S_{0}, V=V_{0}}
$$

ou, truncando-a no termo de segunda ordem e, fazendo alguma manipulação algébrica, encontra-se

$$
\Delta U \cong\left(\frac{\partial U}{\partial S} \Delta S+\frac{\partial U}{\partial V} \Delta V\right)+\frac{1}{2}\left[\frac{\partial^{2} U}{\partial S^{2}}(\Delta S)^{2}+2 \frac{\partial^{2} U}{\partial S \partial V}(\Delta S \Delta V)+\frac{\partial^{2} U}{\partial V^{2}}(\Delta V)^{2}\right]
$$

onde $\Delta U=U-U_{0}, \Delta S=S-S_{0}, \Delta V=V-V_{0}$. No primeiro termo da expansão verifica-se que $\frac{\partial U}{\partial S}=T_{0}$ e $\frac{\partial U}{\partial V}=-p_{0}$, ou seja, a temperatura e a pressão do sistema, respectivamente, modo que

$$
\left(\frac{\partial U}{\partial S} \Delta S+\frac{\partial U}{\partial V} \Delta V\right)=T_{0} \Delta S-p_{0} \Delta V
$$

Considerando o segundo termo da expansão tem-se,

$$
\begin{aligned}
& \frac{\partial^{2} U}{\partial S^{2}}(\Delta S)^{2}+2 \frac{\partial^{2} U}{\partial S \partial V}(\Delta S \Delta V)+\frac{\partial^{2} U}{\partial V^{2}}(\Delta V)^{2} \\
= & \Delta S \frac{\partial}{\partial S}\left(\frac{\partial U}{\partial S} \Delta S+\frac{\partial U}{\partial V} \Delta V\right)+\Delta V \frac{\partial}{\partial V}\left(\frac{\partial U}{\partial S} \Delta S+\frac{\partial U}{\partial V} \Delta V\right) \\
= & \Delta S \frac{\partial}{\partial S}(\Delta U)+\Delta V \frac{\partial}{\partial V}(\Delta U) \\
= & \Delta S \Delta\left(\frac{\partial U}{\partial S}\right)_{V}+\Delta V \Delta\left(\frac{\partial U}{\partial V}\right)_{S}
\end{aligned}
$$




$$
=\Delta S \Delta T-\Delta V \Delta p
$$

Dessa forma, pode-se expressar a flutuação da energia interna como sendo

$$
\Delta U=T_{0} \Delta S-p_{0} \Delta V+\frac{1}{2}[\Delta S \Delta T-\Delta V \Delta p]
$$

onde pressão e temperatura são da vizinhança. Deve-se ressaltar que a expressão acima é válida para flutuações de energia com amplitudes suficientemente pequenas, quando comparadas com a energia total do subsistema [14].

Evidentemente que com a flutuação levando $n$ monômeros a ultrapassar o espinodal, tem-se garantido a formação de embriões da nova fase, mas não obrigatoriamente de tamanho igual ou maior que o crítico, o que garantiria o início da nucleação. Devese considerar que também há flutuações na nova fase, fazendo com que o embrião decaia, e os monômeros retornem à fase precursora. Entretanto, momentaneamente, supõe-se que com a flutuação, $n$ moléculas formaram um núcleo crítico da nova fase, $n=n^{*}$, iniciando o processo de transição de fase. Busca-se, então, a taxa de nucleação e o tamanho do núcleo crítico.

\subsection{Cálculo da Taxa de Nucleação}

Na TAN a taxa de nucleação, $J$, é definida como (veja referência ${ }^{23}[68]$ em [12])

$$
J=\sum_{n=n^{*}}^{\infty} f_{n} \cdot g_{n}
$$

onde $f_{n}$ é a freqüência com que as flutuações consideradas deverão ocorrer e $g_{n}$ o número de grupos por unidade de volume candidatos à flutuação, e $n^{*}$ é o número mínimo de monômeros que participam do processo de decomposição spinodal (ou

23 Becker, R. Theorie der Waeme. Berlin. Springer. 1961. 
núcleo crítico). Considerando que a freqüência é dada por,

$$
f_{n}=\sqrt{\frac{3 k_{B} T_{r} T_{c}}{m_{0}}}\left\langle n v_{r} v_{c}\right\rangle^{-1 / 3} W_{n}
$$

onde $k_{B}$ é a constante de Boltzmann, $m_{0}$ é a massa de um monômero, $n$ o número de monômeros do grupo que flutua, $v_{0}$ é o volume médio do grupo de monômeros; e que o número de grupos é dado por

$$
g_{n}=\frac{1}{n v_{r 0}}
$$

e $W_{n}$ é a probabilidade de que uma flutuação de volume envolvendo $n$ monômeros ultrapasse o espinodal vapor-líquido. Dessa forma, a série em (3.22) pode ser escrita como

$$
J=\left(v_{c}^{-4 / 3} \sqrt{\frac{3 k_{B} T_{c}}{m_{0}}}\right) v_{r 0}^{-1} T_{r}^{1 / 2}\left\langle v_{r}\right\rangle^{-1 / 3} \sum_{n=n^{*}}^{\infty} n^{-4 / 3} W_{n}
$$

Segundo Elón M. de Sá [12], esta série converge rapidamente, de modo que se pode truncá-la no segundo termo e, numa primeira aproximação obter

$$
J \cong\left(v_{c}^{-4 / 3} \sqrt{\frac{3 k_{B} T_{c}}{m_{0}}}\right) v_{r 0}^{-1} T_{r}^{1 / 2}\left\langle v_{r}\right\rangle^{-1 / 3}\left(n^{*}\right)^{-4 / 3} W_{n^{*}}
$$

ou

$$
J=J_{0} \cdot \frac{1}{\left(n^{*}\right)^{4 / 3}} \cdot \frac{T_{r}^{1 / 2}}{v_{r 0} \cdot\left\langle v_{r}\right\rangle^{1 / 3}} \cdot W_{n^{*}}
$$

onde $J_{0}=\sqrt{\frac{3 k_{B} T_{c}}{m_{0}}}\left\langle v_{c}\right\rangle^{-4 / 3}$. No trabalho de de Sá considera -se $J_{0} \cong 6 \times 10^{(33 \pm 1)}$ $\mathrm{cm}^{-3} \mathrm{~s}^{-1}$, obtido a partir dos trabalhos de H. L. Jaeger et al. ${ }^{24}$ e de D. B. Dawson ${ }^{25}$.

\footnotetext{
24 Jaeger, H. L.; Wilson, E. J.; Hill, P. G.; Russel, K. C. J. Chem Phys. 51, 5380 (1969).

25 Dawson, D. B.; Wilson, E. J.; Hill, P. G.; Russell, K. C. J. Chem Phys. 51, 5389 (1969).
} 


\subsection{Tamanho do Núcleo Crítico}

$O$ raio, $r^{e}$, de um núcleo em equilíbrio é dado pela equação de Kelvin, conforme (1.40) e (2.21)

$$
r^{e}=\frac{2 v_{0} \sigma}{k_{B} T_{0} \ln S}
$$

onde $v^{l}$ é o volume por molécula do líquido, $\sigma$ é a tensão superficial do líquido e $p^{e}$ é a pressão de equilíbrio das fases líquida e gasosa à temperatura externa $T_{0}$. Segundo Tolman ${ }^{26}[12]$ a tensão superficial de um núcleo com raio $r$ é dada por

$$
\sigma=\frac{\sigma_{\infty}}{1+\frac{2 \delta}{r^{e}}}
$$

onde $\delta$ é o parâmetro de Tolman, cujo valor é estimado como sendo a metade da espessura da interface entre as fases líquida e gasosa de um sistema fluido e $\sigma_{\infty}$ é a tensão superficial de uma superficie plana.

Em acordo com os postulados de Gibbs (vide Capítulo 2), admite-se que a separação entre as fases líquida e gasosa na interface do núcleo é nítida.

Definindo

$$
r_{0}=r^{e}+\delta
$$

e utilizando a equação (3.29a) em (3.28) e depois substituindo-a em (3.30) chega-se a

$$
r_{0}=\frac{2 v_{0} \sigma_{\infty}}{k_{B} T_{0} \ln S}-\delta
$$

Com esta expressão é possível obter a quantidade de moléculas, $n_{c}$, que condensam num núcleo em equilíbrio num gás superesfriado, ou seja,

$$
n_{c}=\frac{4 \pi}{3} \frac{r_{0}^{3}}{v_{0}}=\frac{32 \pi}{3}\left[\frac{\left(v_{0}\right)^{2 / 3} \sigma_{\infty}}{k_{B} T_{0} \ln S}-\frac{\delta_{0}}{2}\right]^{3},
$$

onde usou-se $\delta=\delta_{0}\left(T_{r}\right) \sqrt[3]{v^{l}}$ (conforme [12]).

26 Tolman, R.C. The Effect of Droplet Size on Surface Tension. J. Chem. Phys. 17 (1949) 333-337. 
A TAN admite que após uma flutuação de $n^{*}$ moléculas para uma região de instabilidade, um processo local de decomposição espinodal deve ocorrer. Dessa forma, parte dessas moléculas, $n_{e}$, deve voltar a evaporar enquanto que outra parte, $n_{c}$, deve condensar, formando o núcleo. Admite também que $n_{e}$ e $n_{c}$ são aproximadamente iguais. Assim, finalmente,

$$
n^{*}=n_{e}+n_{c} \cong 2 n_{c}
$$

ou seja,

$$
n^{*}=\frac{64 \pi}{3}\left[\frac{\left(v^{l}\right)^{2 / 3} \sigma_{\infty}}{k_{B} T_{0} \ln S}-\frac{\delta_{0}}{2}\right]^{3} \text {. }
$$

\subsection{Discussão}

Com a TAN, Meyer [11] foi capaz de predizer para substâncias puras, com notável acuidade, sob que condições líquidos superaquecidos evaporam-se e líquidos superesfriados solidificam-se. Com as equações (3.27) (3.34), juntamente com a equação de estado de Peng-Robinson [16], calculou a taxa de nucleação para alguns gases, além da água. Os pontos experimentais foram obtidos a partir de jatos de gás supersônicos por H. L. Jaeger et al. e de D. B. Dawson (vide nota de rodapé na sessão anterior). Nesses experimentos os jatos supersônicos provocaram a condensação de gotículas no gás que se expandia, com taxa experimental estimada em $10^{(15 \pm 3)} \mathrm{cm}^{-3} \mathrm{~s}^{-1}$. Para o caso da água, Meyer et al. [12][19] encontrou as taxas variando no intervalo $10^{(20 \pm 6)}$ $\mathrm{cm}^{-3} \mathrm{~s}^{-1}$, em razoável acordo com os valores experimentais.

As iniciais críticas feitas à TAN devem-se às considerações geométricas, feitas ad hoc, em relação à quantidade mínima de monômeros envolvidos na flutuação: em torno de 60 [10]. Mediante ao refinamento da teoria, Meyer encontrou uma expressão 
para o cálculo do núcleo crítico, equação (3.34), a qual apresenta apreciável concordância com os dados experimentais.

Este modelo não exclui a possibilidade de no processo de nucleação ocorrer flutuações isotérmicas. A resposta à questão de qual mecanismo é responsável pelo fenômeno da nucleação depende de qual modelo explica e prediz fatos experimentais com maior acurácia e de forma mais elegante e compacta. 


\section{Capítulo 4 \\ Teoria Entrópica da Nucleação}

\subsection{Introdução}

A Teoria Entrópica da Nucleação (TEN) aborda o fenômeno da nucleação a partir da maximização da entropia do material que sofre a transição de fase, sem especificar uma superficie de tensão. A variação da entropia contida na transformação de um elemento de volume corresponde ao calor latente, de modo que aquela se apresenta como uma diferencial exata. Isto permite que a nucleação, processo intrinsecamente irreversível, seja analisada a partir de outros processos reversiveis equivalentes desde que as entropias inicial e final sejam as mesmas. Para visualizar a dinâmica e facilitar a análise foi escolhido um processo adiabático e isobárico, o qual também apresenta importância experimental.

\subsection{Fundamentação Teórica}

A existência de fases metaestáveis, que persistem por longos períodos de tempo, refletem o fato de que existem barreiras cinéticas para transições de fase de primeira ordem. Pequenas flutuações de fase (estável) tendem a desaparecer, enquanto flutuações de maior amplitude tendem a crescer e afetar todo o sistema. A formação do núcleo crítico deve-se àquela flutuação cuja amplitude se localiza exatamente entre estas duas situações; e a taxa de nucleação (isto é, de formação de núcleos criticos por unidade de volume e tempo) determina a velocidade com que a transição de fase se 
realiza, pois o crescimento dos núcleos críticos geralmente é muito maior do que a velocidade de formação dos mesmos.

Uma vez o processo ativado, a velocidade de formação de núcleos críticos depende do tamanho da barreira energética que é o trabalho de formação de um núcleo crítico. O cálculo deste valor é de importância central nas teorias de nucleação.

Não há dúvidas de que o processo de nucleação está vinculado à existência de flutuações, e que estas são manifestações do aspecto de muitos corpos de que são formados os sistemas termodinâmicos [10][14][17] [22].

Em um sistema em estado estável as flutuações decrescem, resultando contribuições para a evolução de um tipo de ruído estatístico. Entretanto, num estado metaestável, quando as flutuações têm uma amplitude capaz de levar uma pequena porção do sistema para uma situação de instabilidade, aquelas se ampliam até atingirem dimensões macroscópicas. Assim que um novo estado estável é atingido a descrição macroscópica novamente se torna válida [22]. A possibilidade do material se reorganizar após atingir um ponto de instabilidade apenas ocorre quando o sistema está suficientemente longe do equilíbrio. Este é o caso do estado metaestável.

A condição de estabilidade em forma local para um sistema fora do equilíbrio [18][22], é dada por

$$
\left(\delta^{2} s\right)_{e}<0
$$

onde $s$ é a entropia específica e o sub-índice $e$ indica que o desvio é a partir da posição de equilíbrio. Assumido que esta condição se verifica para o material que ao flutuar atinge a região de instabilidade e sofre decomposição espinodal, pode-se dizer que a "força motriz" que "impulsiona" o processo de nucleação é a entropia. Desta forma 
esta propriedade termodinâmica apresenta-se como uma variável natural para estudar estes processos.

Nucleação é um processo irreversível e não existe transição de fase sem variação de entropia (produzida e/ou transferida). A entropia sendo uma diferencial exata permite certa flexibilidade na abordagem do processo de nucleação. Qualquer que seja o processo (isotérmico, adiabático etc.) responsável pela nucleação de um pequeno elemento de volume, deve acarretar uma variação de entropia suficiente para produzir um núcleo estável na nova fase. Assim sendo, independentemente do processo e das condições de contorno sob as quais a nucleação se processa pode-se, para efeito de cálculo, escolher qualquer processo reversivel, desde que as propriedades iniciais e finais do volume em evolução sejam as mesmas do processo real. A variação de entropia que o volume sofre ao evolver para a nova fase pode, portanto, ser calculada considerando o processo adiabático e isobárico sem qualquer perda de generalidade. [18]

Um fluido incompressível tem sua entropia especifica em função da entalpia específica e da pressão expressa por [1]

$$
s^{l}=c \ln \left[\frac{h^{l}-v^{l, r e f}\left(p-p^{r e f}\right)}{c T^{r e f}}+1\right]
$$

onde admite-se que os calores específicos equivalem-se, $c_{p}=c_{v}=c$ e o super-índice $\left({ }^{r e f}\right)$ indica valores do estado de referência (vizinhança do ponto triplo, conforme Apêndice B), de modo que para $p=p^{r e f}=$ cte tem-se $s^{l}=0$ quando $h^{l}=0$, por definição.

$\mathrm{E}$, analogamente, para um gás ideal [1],

$$
s^{g}=s^{v a p}+c_{p}^{\circ} \ln \left\{\left(\frac{p}{p^{r e f}}\right)^{-\frac{R}{c_{p}}}\left[\frac{\left(h^{g}-h^{v a p}\right)-v^{g, r e f}\left(p-p^{r e f}\right)}{c_{p}^{\circ} T^{r e f}}\right]+1\right\}
$$


em que para $p=p^{r e f}=c t e$, tem-se $s=s^{v a p}$ quando $h=h^{v a p}$, onde $c_{p}^{\circ}$ é o calor específico a pressão constante e $s^{v a p}$ e $h^{v a p}$ são a entropia e a entalpia específicos de vaporização, respectivamente.

O diagrama de Mollier (entalpia-entropia-pressão) modificado ${ }^{27}$ para evidenciar a transição de fase, mostra de forma esquemática as duas fases - líquida e gasosa, descritas pelas equações (4.2) e (4.3), respectivamente - submetidas a uma pressão $p$ constante.

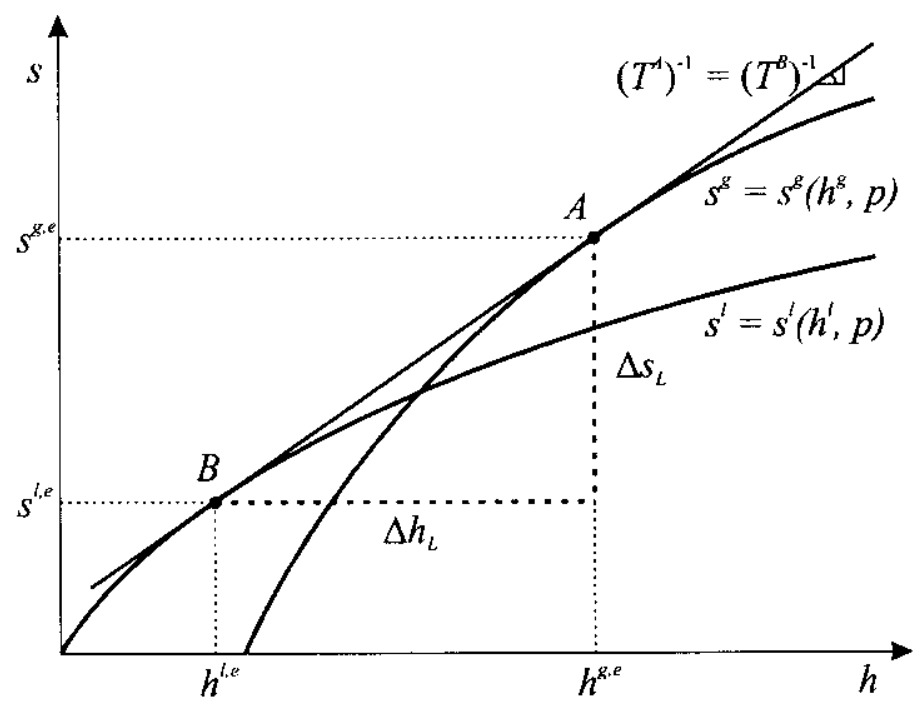

Fig. 4.10- Diagrama de Mollier modificado. O esquema representa as fases líquida e gasosa de uma substância pura.

A tangente $B A$ comum às duas curvas indica o equilíbrio entre as fases (conforme Sessão 1.1)

$$
\left(\frac{d s^{l}}{d h^{l}}\right)_{p}=\left(\frac{d s^{g}}{d h^{g}}\right)_{p}
$$

ou, destacando os pontos da Figura 4.10,

$$
\frac{1}{T_{B}}=\frac{1}{T_{A}}=\frac{1}{T^{e}}
$$

27 Por conveniência os eixos ordenados foram invertidos para facilitar análise posterior. 
A diferença de entropia entre as fases no equilíbrio, bem como a de entalpia, fornece respectivamente a entropia e a entalpia latentes, $\Delta s_{L}$ e $\Delta h_{L}$.

A análise da Figura 4.10 sugere que a transição de fase de primeira ordem, via nucleação, não pode ocorrer ao longo da tangente comum aos pontos de equilíbrio ( $A$ e $B$ na Figura 4.11). Isto é devido ao fato de a variação do volume não ser contínua, o que impossibilita uma variação linear da entalpia. Em consequêencia, a temperatura do elemento de volume deve variar.

Os pontos espinodais $a$ e $b$ esquematizados na Figura 4.11 são os limites de estabilidade dos estados metaestáveis (continuidade termodinâmica). Para determinar pelo menos qualitativamente a curva que une os pontos $a$ e $b$ procedeu-se da seguinte maneira. A estabilidade do sistema pode ser analisada a partir da variação da entropia por partículacomo sendo função da entalpia por partícula e da pressão, cuja variação é dada por (vide Tabela A.2)

$$
d s=\frac{1}{T} d h-\frac{v}{T} d p
$$

Tomando a segunda diferencial encontra-se

$$
d^{2} s=-\frac{1}{T^{2}}\left(\frac{\partial T}{\partial h}\right)_{p} d h^{2}-\left[\frac{1}{T}\left(\frac{\partial v}{\partial p}\right)_{T}-\frac{v}{T^{2}}\left(\frac{\partial T}{\partial p}\right)_{v}\right] d p^{2}
$$

ou,

$$
d^{2} s=-\frac{1}{T^{2} c_{p}} d h^{2}-\frac{v \alpha}{T}\left[1+\frac{1}{T \beta}\right] d p^{2},
$$

uma vez que $c_{p}=\left(\frac{\partial h}{\partial T}\right)_{p} \alpha$ e $\beta$ são respectivamente coeficiente de expansão isobárica e coeficiente de compressão isotérmica (vide Apêndice A.2).

Considerando o processo como sendo isobárico e adiabático, a equação (4.8) assume a forma

$$
d^{2} s=-\frac{1}{c_{p} T^{2}} d h^{2}
$$


Da relação que conecta os calores específicos a pressão e volume constante $[10][14]$,

e da definição dos pontos no espinodal como

$$
c_{p}-c_{v}=T \frac{\left(\frac{\partial p}{\partial T}\right)_{v}^{2}}{\left(\frac{\partial p}{\partial v}\right)_{T}}
$$

$$
\left(\frac{\partial p}{\partial v}\right)_{T}=0
$$

verifica-se que no espinodal $c_{p}=\infty$, devido ao fato de $c_{p}>c_{v}$ - onde este último, por depender numa primeira aproximação somente da temperatura, não diverge no espinodal - e de $\left(\frac{\partial p}{\partial T}\right)_{v}$ ser uma função que não diverge.

Como no espinodal $c_{p} \rightarrow \infty$, tem-se que

$$
d^{2} s=0
$$

Geometricamente, este ponto representa ponto de inflexão e, termodinamicamente, limite de estabilidade. Assim, para $d^{2} s<0$ o sistema encontra-se em estado estável ou metaestável; e para $d^{2} s>0$ implica em $c_{p}<0$, porém sem realidade física representando, portanto, instabilidade e inevitavelmente a decomposição espinodal.

Portanto, na Figura 4.11 nota-se ser natural a existência de um segmento $\overline{a b}$ que une os pontos $a$ e $b$. Os segmentos posteriores a $a$ e os anteriores a $b$ representam regiões de metaestabilidade e estabilidade do sistema (descrita pelas equações é (4.2) e (4.3)). Assim sendo, os pontos $A$ e $B$ representam as duas fases em equilíbrio à mesma temperatura; os pontos $a$ e $b$ são, respectivamente, os espinodais da fase líquida e da fase gasosa. Os segmentos $\overline{A a}$ e $\overline{b B}$ representam regiões de metaestabilidade e, $\overline{a b}$ de instabilidade, onde ocorre a decomposição espinodal. 


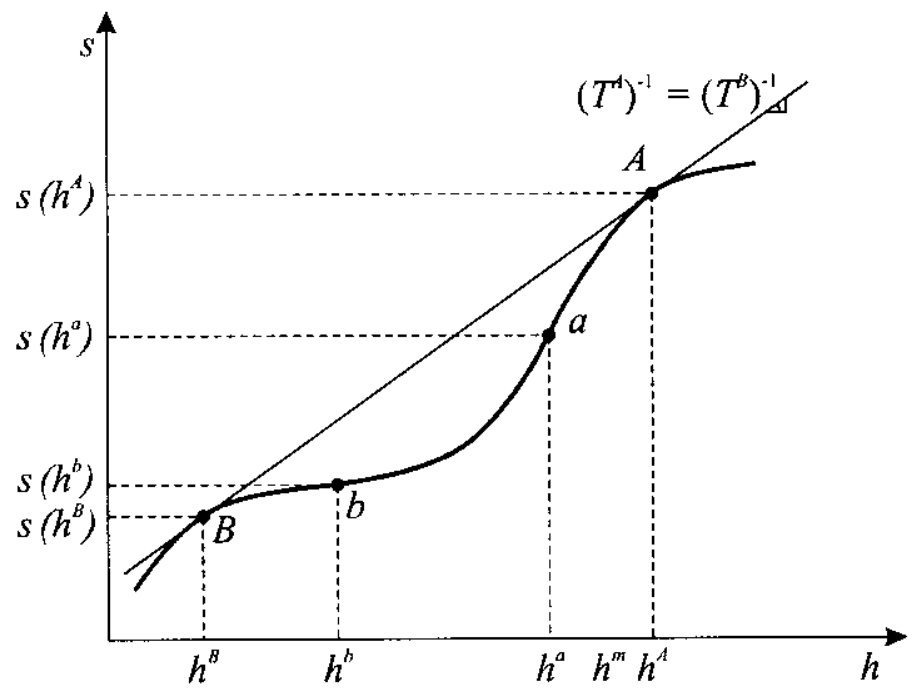

Fig. 4.11- Esquema proposto para a transição de fase de primeira ordem.

A forma quadrática dada por (4.8) mostra que flutuações de $h$ e de $p$ são independentes, de modo que a escolha destas variáveis é bastante conveniente. A análise pode, portanto, proceder tomando $p=$ cte sem perda de generalidade, como já foi justificado anteriormente.

Cabe notar que os pontos $A, B$ e $a, b$ são encontrados tomando-se respectivamente as derivadas primeira e segunda da entropia em relação à entalpia a pressão constante, de modo que

$$
\left(\frac{\partial s^{B}}{\partial h^{B}}\right)_{p}=\left(\frac{\partial s^{A}}{\partial h^{A}}\right)_{p}=\frac{1}{T^{e}}
$$

$\mathrm{e}$

$$
\left(\frac{\partial^{2} s^{b}}{\partial\left(h^{b}\right)^{2}}\right)_{p}=\left(\frac{\partial^{2} s^{a}}{\partial\left(h^{a}\right)^{2}}\right)_{p}=0
$$

Além disso, de forma geral a expressão $\left(\frac{\partial s}{\partial h}\right)_{p}=\frac{1}{T}$ indica a variação da temperatura fora do ponto de equilíbrio das fases, evidenciando a conveniência do uso do diagrama de Mollier. 


\subsection{Tamanho do Núcleo Crítico}

As condições de estabilidade são válidas na região metaestável até o limite do espinodal (continuidade termodinâmica, caracterizado pelos pontos $a$ e $b$ na Figura 4.11. O processo de nucleação inicia-se quando uma pequena parte do sistema (colocado em estado metaestável) sofre flutuação que atinge ou ultrapasse o espinodal, de modo que uma quantidade mínima de monômeros, $n \geq n^{*}$, estabiliza-se na nova fase.

Suponha que a quantidade de $n$ monômeros de um elemento de volume, mantido à pressão $p_{\exp }$, encontra-se no estado metaestável $m$. Então sua temperatura é $T^{m}$, a entalpia é $h^{m}$ e a entropia é $s^{m}=s\left(h^{m}\right)$. Esta porção do sistema ( $N$ monômeros) sofrendo uma flutuação pode ser levada até a região de instabilidade, por exemplo até o ponto com coordenadas $h$ e $s(h)$ na Figura 4.12. Esta flutuação pode ser caracterizada quer pela entalpia, quer pela temperatura.

A amplitude de flutuação da temperatura de um elemento de volume no estado metaestável, $\Delta T^{m}$ (vide Apêndice C), é dada por

$$
\left\langle\left(\Delta T^{m}\right)^{2}\right\rangle=\frac{k_{B}\left(T^{m}\right)^{2}}{C_{v}}
$$

onde $k_{B}$ é a constante de Boltzmann e $C_{v}$ é a capacidade calorífica a volume constante.

Tratando o vapor de água como gás ideal a capacidade calorifica a volume constante é dada por

$$
C_{v}=\left(\frac{\partial U}{\partial T}\right)_{v}=\frac{3}{2} N k_{B}
$$

onde $N$ é o número de partículas do sistema.

Considerando um subsistema constituído de $n$ monômeros que sofre flutuação de temperatura, a substituição de (4.16) em (4.15) resulta em

$$
\left\langle\left(\Delta T^{m}\right)^{2}\right\rangle^{1 / 2}=\sqrt{\frac{2}{3} \frac{\left(T^{m}\right)^{2}}{n}} .
$$


Para haver o fenômeno da nucleação, a flutuação deve ser de tal ordem que leve os $n$ monômeros a ultrapassar o espinodal [18]. Esta condição é expressa pela seguinte expressão

$$
\left\langle\left(\Delta T^{m}\right)^{2}\right\rangle^{1 / 2}=\sqrt{\frac{2}{3} \frac{\left(T^{m}\right)^{2}}{n}} \geq\left|T^{a}-T^{m}\right|,
$$

onde $T^{a}$ é a temperatura do elemento de volume da fase atual $A$, calculada no espinodal.

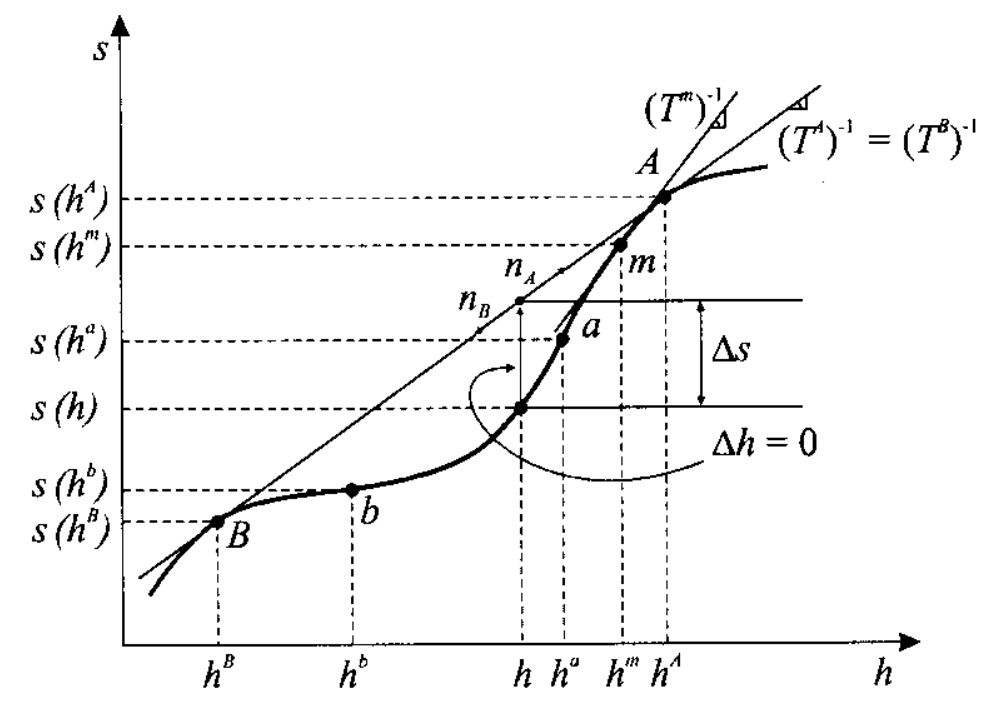

Fig. 4.12- Diagrama de Mollier qualitativo mostrando um sistema com duas fases, $A$ e $B$ em equilíbrio. $\Delta s_{L}$ e $\Delta h_{L}$ representam a entropia e a entalpia latentes, respectivamente. No ponto $h$ há decomposição de fases, onde $n=n_{A}+n_{B} . \mathrm{O}$ inverso da declividade das tangentes em $s(h)$ é a temperatura $T$.

A correspondente flutuação da entalpia por partícula, em torno de $h^{m}$ (vide Apêndice C), é

$$
\frac{\left\langle\left(\Delta H^{m}\right)^{2}\right\rangle^{1 / 2}}{n\left\langle h^{m}\right\rangle} \propto \frac{1}{\sqrt{n}},
$$

onde $h=\frac{H}{n}$. Se a flutuação é larga o bastante para carregar $n$ partículas para uma região totalmente instável com entalpia $h$, ou seja, que ultrapasse o spinodal, então 
pode-se escrever

$$
\left\langle\left(\Delta H^{m}\right)^{2}\right\rangle^{1 / 2}=\lambda_{m} \sqrt{n}\left\langle h^{m}\right\rangle \geq n\left|h^{a}-h^{m}\right|
$$

onde $\lambda_{m}$ é uma constante de proporcionalidade e $h^{a}$ é a entalpia por partícula da fase atual $A$ no espinodal. Os $n$ monômeros encontrando-se na região de instabilidade (entre os espinodais $a$ e $b$ ) sofrerão separação de fases (conforme esquematizado na Figura 4.12). Uma parte, composta de $n_{A}$ monômeros migrará para a fase $A$ e o restante $n_{B}=n-n_{A}$, vencendo a barreira energética, evolverá para a fase $B$, com temperatura $T_{A}=T_{B}$. Desta forma, duas situações podem ocorrer: $n_{B}<n^{*}$ ou $n_{B} \geq n^{*}$.

No caso em que $n_{B}<n^{*}$, o embrião da nova fase decairá e os $n$ monômeros termalizarão para $T^{m}$. Ou seja, o elemento de volume retorna ao estado metaestável $m$. No caso em que $n_{B} \geq n^{*}$ o núcleo crescerá, iniciando o processo de transição de fase. Exige-se, então, que $n_{B}$ seja suficientemente grande de modo que, ao flutuar, não volte à região de instabilidade. Portanto, deve-se verificar a seguinte desigualdade

$$
\left\langle\left(\Delta H^{B}\right)^{2}\right\rangle^{1 / 2}=\lambda_{B} \sqrt{n_{B}}\left\langle h^{B}\right\rangle \leq n_{B}\left|h^{B}-h^{b}\right|
$$

onde $\lambda_{B}$ é uma constante de proporcionalidade e $h^{B}$ é a entalpia por partícula no estado $B$. O objetivo então é encontrar o tamanho do núcleo crítico, $n_{B}=n^{*}$.

Resolvendo a equação (4.20) para $\lambda_{m}$ encontra-se

$$
\lambda_{m} \geq \sqrt{n} \frac{\left|h^{a}-h^{m}\right|}{h^{m}},
$$

onde admite-se que para o elemento de volume $\left\langle h^{m}\right\rangle \sim h^{m}$. Da equação (4.18) verifica-se que

$$
\sqrt{\frac{2}{3}} \frac{T^{m}}{\left|T^{a}-T^{m}\right|} \geq \sqrt{n}
$$

de modo que a equação (4.22) pode ser escrita como

$$
\lambda_{m}^{\prime} \geq \sqrt{\frac{2}{3}} \frac{T^{m}}{\left|T^{a}-T^{m}\right|} \frac{\left|h^{a}-h^{m}\right|}{h^{m}},
$$


onde $\lambda_{m}^{\prime} \geq \lambda_{m}$

Ainda com intuito de manter o rigor matemático admite-se que

$$
\lambda_{B} \propto \lambda_{m}^{\prime}
$$

tem-se que

$$
\lambda_{B}=\phi \lambda_{m}^{\prime}
$$

onde $\phi$ é uma constante a ser encontrada tal que $\phi \geq 1$. Isto permite resolver a equação (4.22) para $\sqrt{n_{B}}$ e encontrar

$$
\sqrt{n_{B}} \geq \phi \sqrt{\frac{2}{3}} \frac{T^{m}}{\left|T^{a}-T^{m}\right|} \frac{\left|h^{\alpha}-h^{m}\right|}{h^{m}} \frac{h^{B}}{\left|h^{B}-h^{b}\right|} .
$$

Porém, na ausência de uma fundamentação teórica que forneça $\phi$, adotou-se para o estágio atual deste trabalho, o valor unitário, $\phi=1$, visando a continuidade no cálculo do núcleo crítico (vide Apêndice E). Assim, tomando $n_{B}=n^{*}$,

$$
n^{*}=\frac{2}{3}\left[\frac{\left(\frac{h^{a}}{h^{m}}-1\right)}{\left(\frac{T^{a}}{T^{m}}-1\right)\left(1-\frac{h^{b}}{h^{B}}\right)}\right]^{2} \text {. }
$$

\subsection{Discussão}

Dado que o presente trabalho é sobre a condensação do vapor de água, calcular do tamanho do núcleo crítico dado pela equação (4.28) implica em determinar as entalpias e temperaturas na fase condensada e na vapor, bem como nos espinodais. Resumidamente tem-se que encontrar os seguintes pontos:

\begin{tabular}{l} 
Tabela 4.I - Pontos para cálculo de $n^{*}$ \\
\cline { 2 - 3 } \multicolumn{1}{c|}{} \\
\begin{tabular}{|c|c|c|}
\hline ponto\fase & líquida & gasosa \\
\hline$m$ & - & $\left(h^{m}, T^{m}\right)$ \\
\hline$a$ & - & $\left(h^{a}, T^{a}\right)$ \\
\hline$b$ & $\left(h^{b}\right)$ & - \\
\hline$B$ & $\left(h^{B}\right)$ & - \\
\hline
\end{tabular}
\end{tabular}


A existência de uma função $s=s(h, p)$ auxiliaria nesta tarefa, uma vez que nos pontos binodais tem-se que

$$
\left(\frac{\partial s}{\partial h}\right)_{p}=\frac{1}{T^{e}}
$$

e, nos espinodais,

$$
\left(\frac{\partial^{2} s}{\partial h^{2}}\right)_{p}=0
$$

Devido à dificuldade para obter uma expressão analítica para $s=s(h, p)$, as propriedades termodinâmicas listadas acima foram obtidas a partir da equação de estado, no caso a VDW, como será visto no Capítulo 5. Uma opção seria usar equação de estado de Peng-Robinson, dada por [16]

$$
p=\frac{R T}{v-b}-\frac{a\left(\omega, T_{r}\right)}{v(v+b)+b(v-b)} .
$$

Os estudos de Meyer et al. [12][19] mostram que esta equação apresenta boa acurácia para estados metaestáveis. Entretanto, encontrar a temperatura no spinodal, como mostrado na Apêndice D.3, mostrou-se tarefa complexa. O problema reside no fator que traduz as forças de van der Waals e sua dependência com a temperatura, $a\left(\omega, T_{r}\right)$, o que dificulta a manipulação algébrica. Sendo assim, foi natural a opção pela equação de estado de van der Waals, equação,

$$
p=\frac{R T}{v-b}-\frac{a}{v^{2}}
$$

devido à simplicidade que proporcionou à obtenção das propriedades termodinâmicas necessárias para o cálculo do núcleo critico. 


\section{Capítulo 5 \\ Cálculo do Núcleo Crítico}

\subsection{Introdução}

No Capítulo 4 obteve-se através da equação (4.28) o tamanho do núcleo crítico formado por $n^{*}$ monômeros, a qual é reescrita evidenciando a transição de fase vapor-líquido,

$$
n^{*}=\left\{\frac{1}{\sqrt{3}}\left(\frac{h^{g, s}}{h^{g, m}}-1\right)\left[\left(1-\frac{h^{l, s}}{h^{l, c}}\right)\left(\frac{T^{g, s}\left(h^{g, s}\right)}{T^{g, m}\left(h^{g, m}\right)}-1\right)\right]^{-1}\right\}^{2} .
$$

Segundo o modelo proposto neste trabalho (veja Sessão 4.2), o processo de nucleação é considerado isobárico e adiabático. Deve-se, portanto, calcular a temperatura e a entalpia nos pontos metaestável $\left(T^{g, m}\right.$ e $\left.h^{g, m}\right)$, espinodal $\left(T^{g, s}, h^{g, s}\right.$ e $\left.h^{l, s}\right)$ e binodal $\left(h^{l, e}\right)$ para obter o tamanho do núcleo crítico.

Os dados experimentais foram obtidos a partir dos trabalhos de Strey et al. [6][23] (vide Apêndice G). A pressão e temperatura experimentais, $p_{\exp }$ e $T_{\exp }$, foram medidas a partir do vapor de água colocado em um estado metaestável $m$ (encontrando em seguida a taxa de nucleação em função da supersaturação). Devido à dificuldade em encontrar a função $s=s(h, p)$, onde $\left(\frac{\partial s}{\partial h}\right)_{p}=\frac{1}{T}$, e tendo como referência aquelas duas grandezas $\left(p_{\exp }, T_{\exp }\right)$, optou-se por calcular o tamanho do núcleo crítico $n^{*}$ com auxílio da TEN $^{28}$ aliada à Teoria das Funções Residuais ${ }^{29}$ e à equação de estado de van de Waals ${ }^{30}$,

$$
p=\frac{R T}{v-b}-\frac{a}{v^{2}}
$$

\footnotetext{
Vide Capítulo 4.

Vide Apêndice F.

30 Vide Apêndice D.
} 
Para tanto, é assumido que a temperatura, na região onde se dá a formação do núcleo elemento de volume tomado como subsistema —, não é constante durante a transição de fase, ainda que macroscopicamente, a temperatura seja a mesma antes e depois da transição.

\subsection{Hipótese}

Na Figura 4.12 representou-se o estado metaestável $m$ num diagrama de Mollier modificado. Com ajuda da equação de van der Waals, (5.2), este estado é representado na Figura 5.13. Este ponto corresponde à temperatura, $T_{\exp }$, e pressão, $p_{\exp }$, utilizados no experimento efetuado para medir a taxa de nucleação, conforme exposto no Apêndice G. Na Figura 5.14, o ponto $m$ está localizado sobre a reta que une o estado gasoso, $A$, e o líquido, $B$, que corresponde à isoterma de equilíbrio cuja temperatura e pressão designou-se por $T^{e} e p^{e}$, respectivamente.

No processo de nucleação proposto, o ponto $m$ que representa o estado metaestável tem um temperatura $T_{\exp }$ que é diferente da temperatura $T^{e}$ de equilíbrio, conforme representado na Figura 5.14, pois $T_{\text {exp }}$ está no loop de van der Waals que representa o subsistema em evolução. A pressão $p_{\exp }$ é igual à pressão $p^{e}$, visto que o processo assumido se realiza a pressão constante. Pode-se escrever que

$$
p_{\exp } \equiv p^{e}
$$

e

$$
T^{e}=T\left(p^{e}\right)
$$

Segundo este mecanismo de nucleação, o subsistema poderá sofrer uma flutuação que o leve para além do espinodal $a$ da Figura 4.12 ou das Figuras 5.13 e 5.14. O 


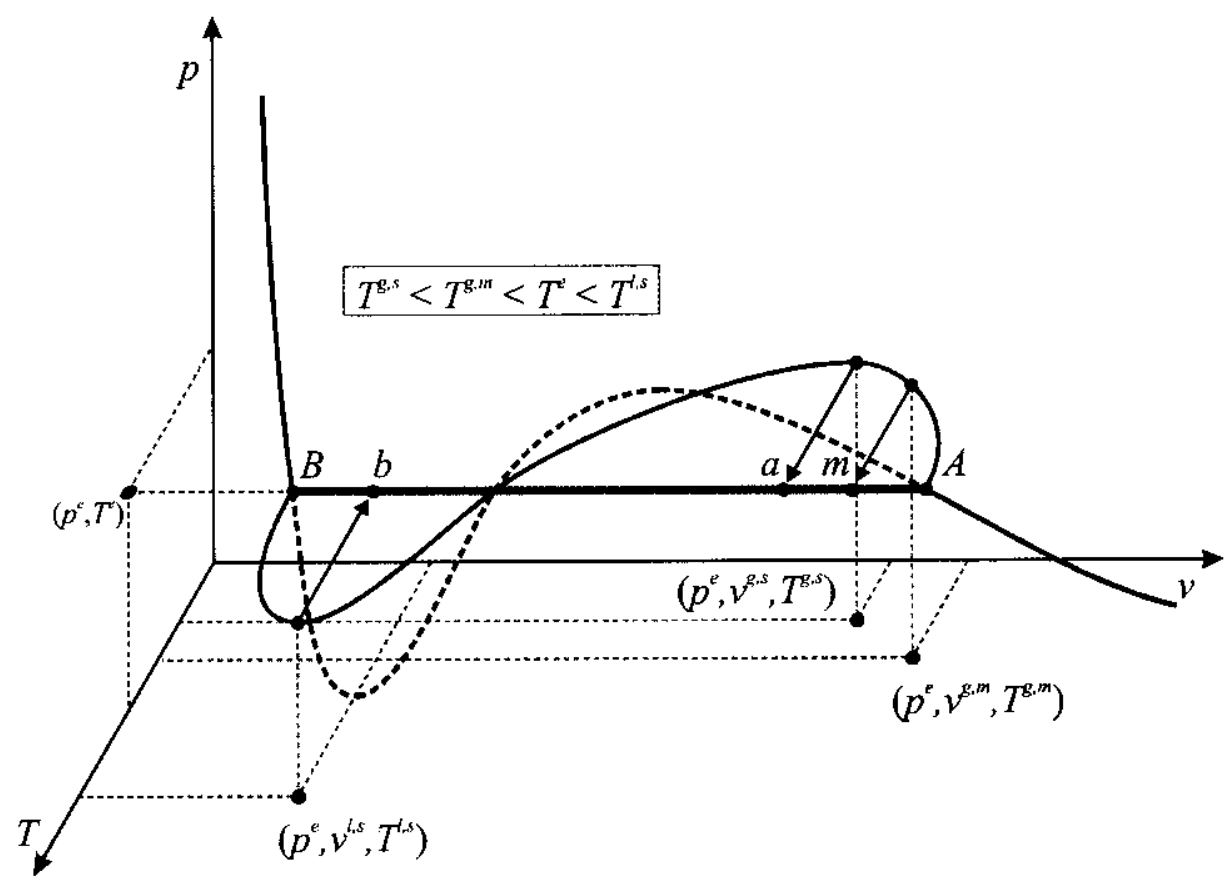

Fig. 5.13- Esquema ilustrando a variação de temperatura de um elemento de volume. Os pontos espinodais são projetados sobre a reta $p=p^{e}$.

subsistema atingindo a região de instabilidade (nas Figuras 4.12, 5.13 e 5.14 representado pelo segmento $\overline{a b}$ ) sofrerá decomposição espinodal. Neste processo, uma parte do subvolume evolverá para o estado gasoso $A$ e a outra para o estado líquido $B$ (veja Figura 4.12). A parte que evolveu para o gás no ponto $A$ será termalizada pelo resto do sistema e voltará ao estado $m$, metaestável. Por sua vez a parte que se liquefez em $B$, terá temperatura $T^{l, s}$ que será termalizada pelo sistema para a temperatura $T_{\exp }$.

\subsection{Cálculos}

A expressão para o núcleo crítico, equação (5.1), requer o cálculo das grandezas temperatura e entalpia no metaestável $\left(T^{g, m}\right.$ e $\left.h^{g, m}\right)$, no espinodal $\left(T^{g, s}, h^{g, s}\right.$ e $\left.h^{l, s}\right)$ e no binodal $\left(h^{l, e}\right)$, cuja determinação foi efetuada da seguinte maneira. 


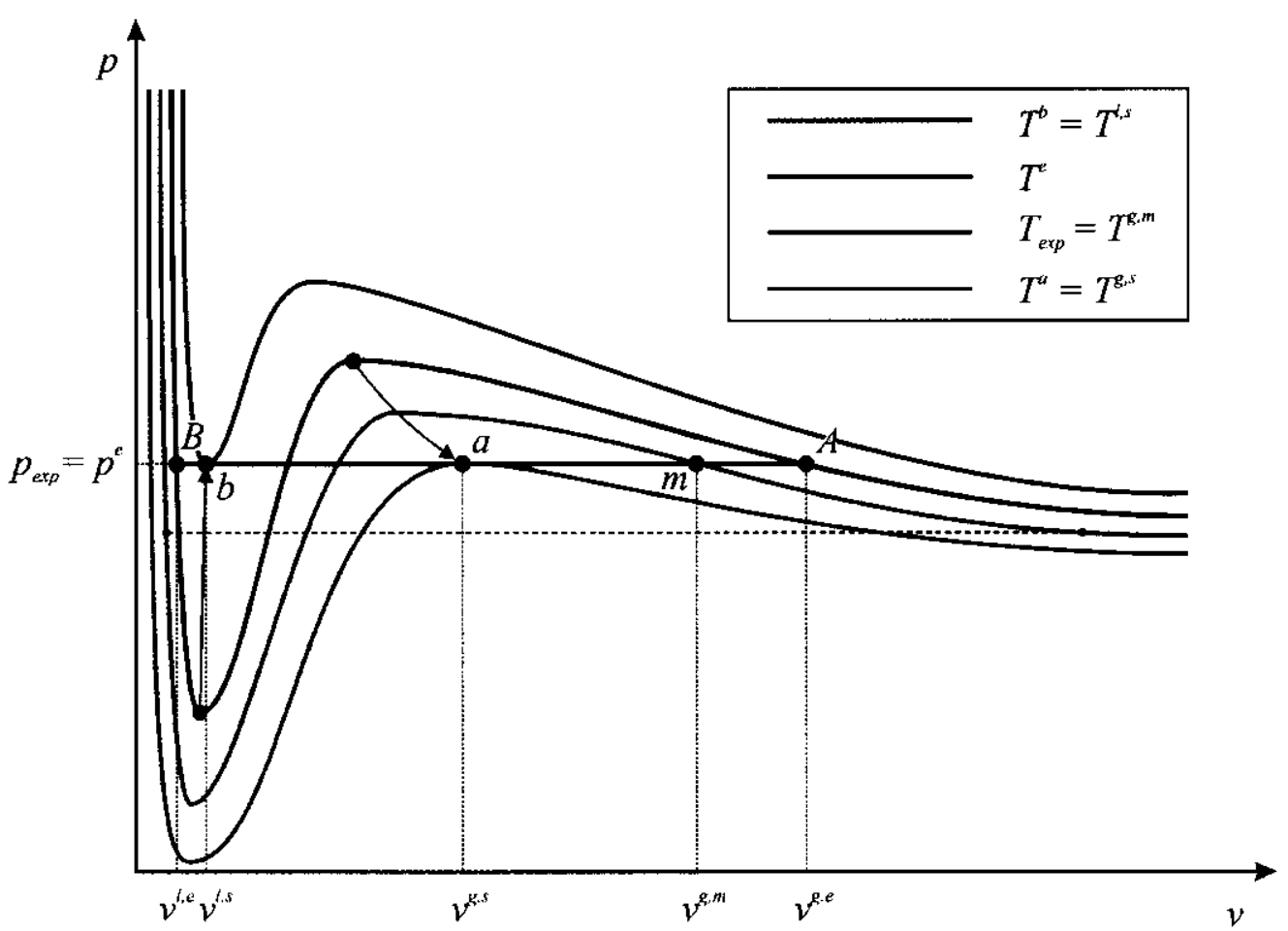

Fig. 5.14- Os pontos binodals, spinodals e metaestável estão sobre a reta $p=p^{e}$.

Sendo $p_{\exp }=p^{e}$, encontra-se $T^{e}$ pela equação empírica de G. S. Kell [23]

$$
p^{e}=\exp \left[77.34491-\frac{7235.42465}{T}-8.2 \ln (T)+0.0057113 T\right]
$$

É possível, porém, encotrar $T^{e}$, a partir da equação de van der Waals, mas de acurácia menor, conforme mostrado no Apêndice D.3. Com $T^{e}$ e $p^{e}$ na equação (5.2) resolvida para $v$ encontra-se $v^{l, e} \mathrm{e} v^{g, e}$, de modo que se tem os pontos binodais $A=\left(p^{e}, v^{g, e}, T^{e}\right)$ e $B=\left(p^{e}, v^{l, e}, T^{e}\right)$.

Com $p=p_{\exp }=p^{e}$ e $T=T_{\exp }=T^{g, m}$ na equação (5.2), encontra-se $v^{g, m}$. Tem-se assim, o ponto metaestável, $m=\left(p^{e}, v^{g, m}, T^{g, m}\right)$. 
Os pontos espinodais para a fase gasosa e para a fase líquida são encontrados conforme definição dada pela equação (4.11) calculada sobre a equação (5.2), ou seja,

$$
\left(\frac{\partial p}{\partial v}\right)_{T}=-\frac{R T}{(v-b)^{2}}+\frac{2 a}{v^{3}}=0 .
$$

Resolvendo para $T$ encontra-se

$$
T^{s}=\frac{2 a}{R\left(v^{s}\right)^{3}}\left(v^{s}-b\right)^{2}
$$

onde $T^{s} \mathrm{e} v^{s}$ são respectivamente temperatura e volume do fluido no espinodal $\left(v^{l, s} \mathrm{e} v^{g, s}\right)$. Levando $T^{s}$ na equação (5.2) escrita para os espinodais e calculada para $p^{e}$

$$
p^{e}=\frac{a}{\left(v^{s}\right)^{3}}\left(v^{s}-2 b\right)
$$

e evidenciando $v^{s}$ obtém-se

$$
\left(v^{s}\right)^{3}-\frac{a}{p^{e}} v^{s}+\frac{2 a b}{p^{e}}=0
$$

As raizes da equação (5.9) levadas em (5.7) fornece $T^{l, s}$ e $T^{g, s}$ e, conseqüentemente, os pontos espinodais $a=\left(p^{e}, v^{g, s}, T^{g, s}\right)$ e $b=\left(p^{e}, v^{l, s}, T^{l, s}\right)$.

Resumindo, com as equações (5.1) a (5.9) tem-se os seguintes valores

\begin{tabular}{l} 
Tabela 5.1 - Valores $(p, v, T)$ \\
\cline { 2 - 3 } \multicolumn{2}{c|}{ Subsistema } \\
\begin{tabular}{|c|c|c|}
\hline ponto $\backslash$ fase & líquida & gasosa \\
\hline$A$ & - & $\left(p^{e}, v^{g, e}, T^{e}\right)$ \\
\hline$m$ & - & $\left(p^{e}, v^{g, m}, T^{g, m}\right)$ \\
\hline$a$ & - & $\left(p^{e}, v^{g, s}, T^{g, s}\right)$ \\
\hline$b$ & $\left(p^{e}, v^{l, s}, T^{l, s}\right)$ & - \\
\hline$B$ & $\left(p^{e}, v^{l, e}, T^{e}\right)$ & - \\
\hline
\end{tabular}
\end{tabular}

Para o cálculo da entalpia nesses pontos, é necessário fazer uso das chamadas funções residuais (vide Apêndice F). Tais funções permitem o cálculo do desvio nas propriedades termodinâmicas de uma substância real. Para a entalpia, tal função é da forma 


$$
h_{f}=h^{v a p}+\int_{T_{i}=273.15}^{T_{f}} c_{v}^{0}(T) d T+h^{r e s},
$$

onde $h^{v a p}$ é a entalpia de vaporização e $h^{\text {res }}$ é a função residual, dada na forma geral por

$$
h^{r e s}=-\int_{\infty}^{v_{f}}\left[v\left(\frac{\partial p}{\partial v}\right)_{T}+T\left(\frac{\partial p}{\partial T}\right)_{v}\right]_{T_{f}} d v
$$

ou, usando a equação de van der Waals e efetuando a integração, obtém-se

$$
h^{r e s}=\frac{R T_{f} b}{v_{f}-b}-\frac{2 a}{v_{f}}
$$

Naturalmente, a entalpia nos pontos $b$ e $B$ (fase líquida) foi calculada desconsiderando $h^{v a p}$, conforme é explicado no Apêndice D.3. Dessa forma, os valores que devem ser calculados são:

Tabela 5.2 - Valores de $h$ e $T$ para o cálculo de $n^{*}$

\begin{tabular}{|c|c|c|}
\cline { 2 - 3 } \multicolumn{1}{c|}{} & \multicolumn{2}{c|}{ Subsistema } \\
\hline ponto \fase & líquida & gasosa \\
\hline$m$ & - & $\left(h^{g, m}, T^{g, m}\right)$ \\
\hline$a$ & - & $\left(h^{g, s}, T^{g, s}\right)$ \\
\hline$b$ & $\left(h^{l, s}\right)$ & - \\
\hline$B$ & $\left(h^{l, e}\right)$ & - \\
\hline
\end{tabular}

\subsection{Resultados}

Com os dados experimentais fornecidos por Viisanen et al. [6] e por Wölk-Strey [23], calculou-se o núcleo crítico experimental, $n_{\mathrm{exp}}^{*}$, via método dos mínimos quadrados (vide Apêndice G), para cada série de medidas feitas a determinada temperatura $T$, conforme mostrado na terceira coluna das Tabelas 5.3 e 5.4. A partir dos cálculos propostos na sessão anterior, encontrou-se o núcleo crítico teórico, $n_{t e o}^{*}$ (vide Apêndice $\mathrm{H})$, mostrado na quarta coluna das respectivas tabelas. E na quinta coluna encontra-se o desvio. 
Os gráficos (Figuras 5.15 e 5.16) evidenciam a dependência do tamanho do núcleo crítico com a temperatura, semelhante à variação do tamanho do núcleo crítico com a temperatura, segundo a TEN. Apesar de nos dois casos [6] [23] a experiência ser a mesma, nota-se que a dependência do núcleo crítico com a temperatura difere nos dois experimentos.

Tabela 5.3 - Comparação entre núcleo crítico experimental e teórico - Viisanen et al.

\begin{tabular}{|c|c|c|c|c|}
\hline Série $\backslash$ Dados & $T_{\exp } /(\mathrm{K})$ & $n_{\exp }^{*}$ & $n_{\text {teo }}^{*}\left(\times 10^{3}\right)$ & $\mid 1-n_{\text {teo }}^{*} / n_{\text {exp }}^{*}$ \\
\hline 1 & 217.1 & 27.79 & 22.93 & 0.17486 \\
\hline 2 & 222.6 & 28.25 & 24.27 & 0.14089 \\
\hline 3 & 228.2 & 28.07 & 25.60 & 0.08801 \\
\hline 4 & 233.5 & 30.75 & 26.89 & 0.12554 \\
\hline 5 & 238.8 & 33.32 & 28.34 & 0.14944 \\
\hline 6 & 244.1 & 37.75 & 29.83 & 0.20984 \\
\hline 7 & 248.5 & 36.52 & 31.03 & 0.15034 \\
\hline 8 & 253.7 & 38.29 & 32.66 & 0.14704 \\
\hline 9 & 259.0 & 41.48 & 34.29 & 0.17338 \\
\hline
\end{tabular}

Tabela 5.4 - Comparação entre núcleo crítico experimental e teórico - Wölk-Strey

\begin{tabular}{|c|c|c|c|c|}
\hline Série $\backslash$ Dados & $T_{\exp } /(\mathrm{K})$ & $n_{\text {exp }}^{*}$ & $n_{\text {teo }}^{*}\left(\times 10^{3}\right)$ & $1-n_{\text {teo }}^{*} / n_{\text {exp }}^{*}$ \\
\hline 1 & 220 & 20.73 & 32.85 & 0.19229 \\
\hline 2 & 230 & 25.75 & 33.75 & 0.00705 \\
\hline 3 & 240 & 30.03 & 34.54 & 0.05263 \\
\hline 4 & 250 & 32.52 & 35.44 & 0.03009 \\
\hline 5 & 260 & 33.28 & 36.24 & 0.03554 \\
\hline
\end{tabular}

Os resultados de Reiss-Kegel-Katz ${ }^{31}$ tem um desvio de quatro ordens de grandeza na taxa de nucleação (conforme mostrado Sessão 2.6).

No caso da TEN, deve-se ressaltar que a dependência encontrada do tamanho do núcleo crítico com a temperatura é semelhante ante as duas fontes de dados. Isto é notável, visto o nível de simplificação da teoria da flutuação e o tratamento da água como gás ideal. Ainda que os resultados teóricos encontrados sejam cerca de três ordens

31 Reiss, H., Kegel, W. K. and Katz, J. L. Resolution of the Problems of Replacement Free Energy, I/S, and Internal Consistency in Nucleation Theory by Consideration of the Length Scale for Mixing Entropy. Phys. Rev. Lett. 78 (1997) 4506. 


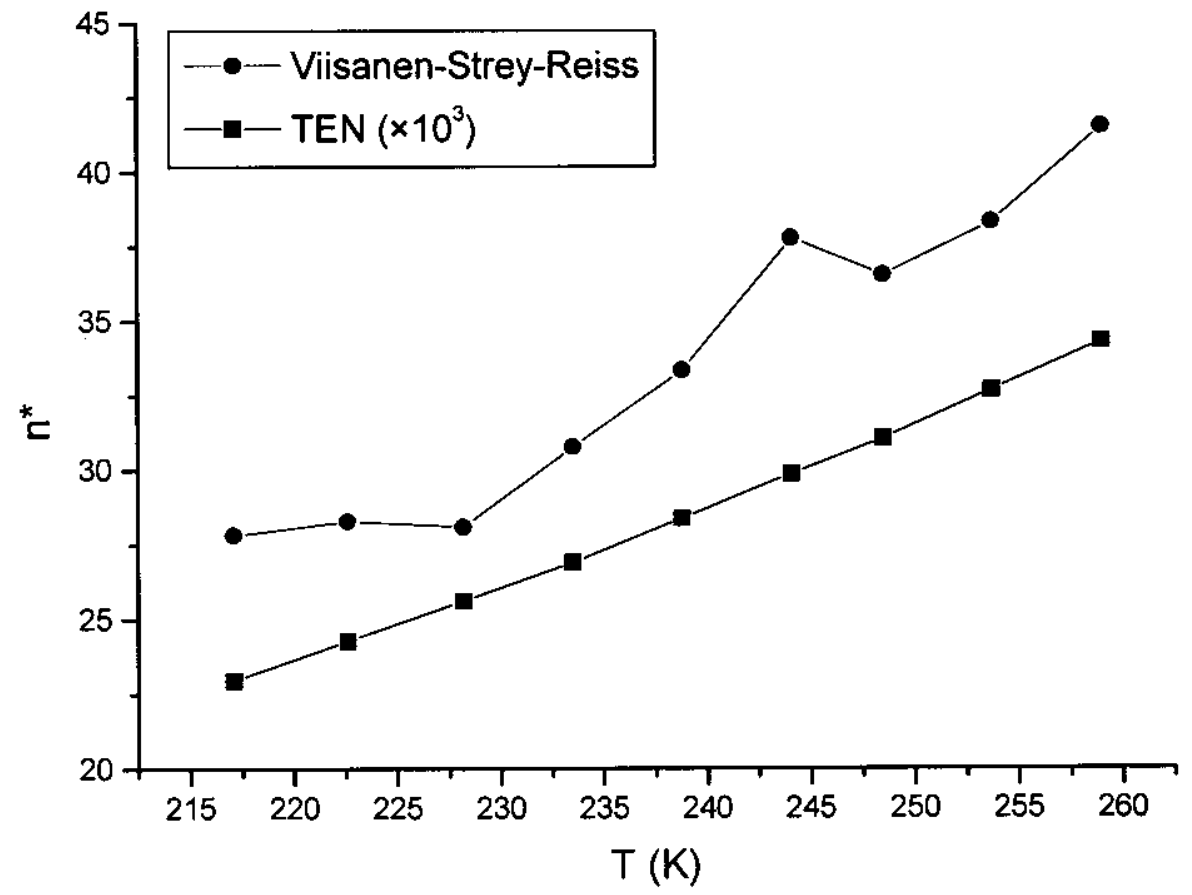

Fig. 5.15- O núcleo crítico calculado pela TEN apresenta dependência com a temperatura $T$, semelhante à encontrada por Viisanen et al.

de grandeza menores que os experimentais, tem-se que tal dependência é indicativo de que a abordagem feita com a TEN é promissora. 


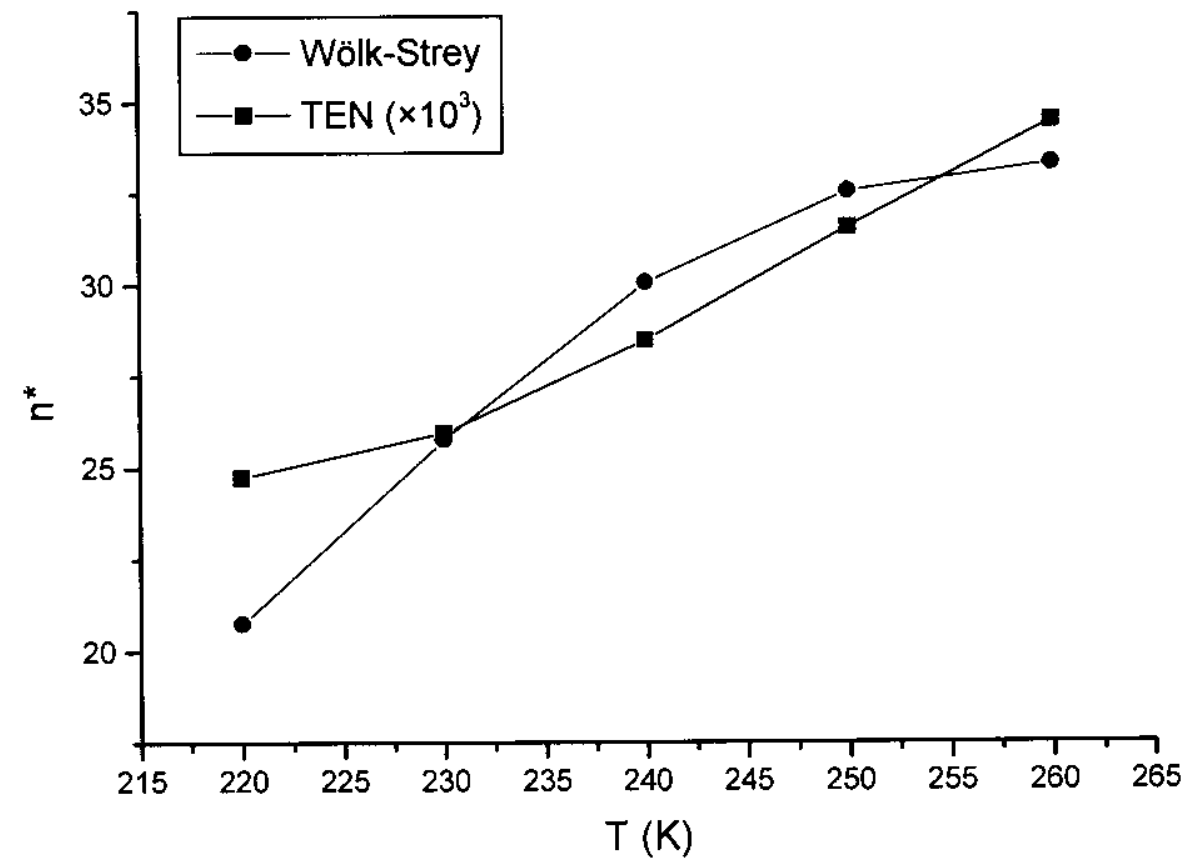

Fig. 5.16- O núcleo crítico calculado pela TEN apresenta dependência com a temperatura $T$, semelhante à encontrada por Wölk-Strey. 


\section{Capítulo 6 \\ Conclusões e Perspectivas}

Das motivações para a realização deste trabalho, duas destacam-se sobremaneira. Uma deve-se à possibilidade de se colocar mais um tijolo no edificio da Física, uma vez que o presente estudo é parte da busca pela compreensão e previsão de um fenômeno físico de significativo interesse científico e tecnológico e outra à oportunidade de lidar com a modelagem matemática, ferramenta essencial para a interpretação e manipulação de fenômenos da natureza.

O fenômeno da nucleação é extremamente sensivel a pequenas alterações nas condições do sistema: temperatura, pressão, impurezas. Embora em princípio este fato dificulte cálculos como a taxa de nucleação, é esperado que experimentos mais elaborados, como os de Wölk-Strey [6][23], consigam fomecer elementos para verificar teorias que se referem a eventos microscópicos. A compreensão do mecanismo da transição de fase, abre possibilidades para estabelecer controle sobre a taxa de nucleação e, a partir daí, mudar o curso do fenômeno e quiçá alterar ou criar materiais com novas propriedades.

O trabalho realizado sobre a transição de fase de primeira ordem, mais especificamente o fenômeno da nucleação em vapor de água, visto a partir da Teoria Entrópica da Nucleação (TEN), exigiu do autor a compreensão de conceitos fundamentais de Termodinâmica e sua aplicabilidade (quando se tornou tênue a linha que separa a Física da Engenharia). A TEN não poderia ser suficientemente bem entendida sem ter claro os fundamentos da Teoria Clássica da Nucleação. Seguindo concepções distintas, o fenômeno estudado é o mesmo, de modo que é importante ter noção de como outras teorias 
o abordam. Com sucessivos ajustes e correções introduzidos na TCN, conseguiram-se resultados razoavelmente satisfatórios, quando suas previsões teóricas são comparadas com dados experimentais ${ }^{32}$. Entretanto, experimentos recentes de maior acurácia mostram desvios sistemáticos daquilo predito pela TCN [6][23]. Um dos problemas apontados por vários autores é a incorreta dependência da taxa de nucleação com a temperatura, inconsistência esta observada em vários vapores ${ }^{33}$. Um outro é o uso de modelos fisicos que se aplicam a escalas espaciais que são largas quando comparadas com o tamanho dos monômeros, pois o núcleo crítico pode muitas vezes conter somente umas poucas dezenas de monômeros e o uso de termodinâmica contínua para descrever tais sistemas é de validade duvidosa $\mathrm{a}^{34}$.

Em contraste com a teoria semifenomenológica de Dillmann-Meier [7] [8], os autores Reiss-Kegel-Kat $\mathrm{z}^{35}$ desenvolveram uma teoria auto-consistente em que a dependência da taxa de nucleação com a temperatura mostra-se mais adequada. Entretanto, a comparação com resultados experimentais evidenciou uma diferença de cerca de quatro ordens de grandeza.

A inconsistência da TCN abre caminho para novas abordagens. Este é o caso da Teoria Adiabática da Nucleação, teoria esta que ainda guarda algo da TCN como a tensão superficial. Entretanto, a partir dela a TEN está sendo construída. O primeiro passo foi dado com o cálculo do tamanho do núcleo crítico. A formulação simplificada

32 Oxtoby, Acc. Chem. Res. 31 (1988) 91.

33 Wagner, P.E.; Strey, R. J. Chem. Phys. 1984, 105, 456. / Kacker, A.; Heist, R. H. J. Chem. Phys. 1985, 82, 2734. / Strey, R; Wagner, P.E.; Schmeling, T. J. Chem. Phys. 1986, 84, 2325. / Hung, C.; Krasnopoler, M. J.; Katz, J. L. J. Chem. Phys. 1989, 90, 1856.

34 Mokross, B. J. Nucleation Theory and Small System Thermodynamics. Mater. Phys. Mech. 5 (2002) 1-8.

35 Reiss, H.; Kegel,W. K.; Katz, J. L. Phys. Rev. Lett. 1997, 78, 4506. 
considerou a Teoria das Flutuações na sua formulação mais simples (pequenas amplitudes) e a quantidade de monômeros no núcleo crítico não foi otimizada em relação à entropia [18]. pois o número de partículas necessário para formar um núcleo crítico, como dado pela equação (5.1) é correto somente se a substância flutuante ou o núcleo crítico for homogêneo. Mesmo assim, a despeito disto e de possíveis imprecisões experimentais, os resultados mostram-se promissores.

A construção de uma função $s=s(h, p)$ é fundamental na construção da TEN. Com o processo de nucleação ocorrendo isobárica e adiabaticamente, as derivadas primeira e segunda da entropia por partícula em relação à entalpia por partícula, calculadas à pressão constante, fornecem todas as propriedades termodinâmicas necessárias ao cálculo do núcleo crítico. Para este cálculo, é importante incorporar flutuações de qualquer magnitude, de modo a considerar o fenômeno da nucleação em sistemas em qualquer estágio de supersaturação. Os investimentos feitos na busca desta função mostram que provavelmente deve-se lançar mão de outras ferramentas como Teoria de Muitos Corpos. Para se obter a curva $s=s(h)$ na região instável (entre os espinodais da Figura 4.12) é necessário desenvolver um modelo que permita caracterizar o sistema termodinamicamente nesta região, de maneira análoga ao que foi feito neste trabalho ao se utilizar a equação de estado de van der Waals.

Apesar de ser discutivel a aplicação dos métodos da termodinâmica contínua para pequenos aglomerados (embriões) é possivel, em trabalhos futuros, mediante a introdução de pequenas modificações [Bowles et al. ${ }^{36}$ and Hill ${ }^{37}$ ] proceder nesta direção, procurando desta forma a praticidade dos resultados obtidos por métodos ter-

36 Bowles, R.K.; Reguera, D; Djikaev, Y. and Reiss, H. J. Chem. Phys. 115 (2001) 1853.

37 Hill, T. L. Thermodynamic of Small Systems. New York. Dover. 1994. 
modinâmicos. Diante disso tudo, fica evidente que há muito a ser feito. Os resultados promissores indicam que o trabalho deve continuar. 


\section{Apêndice A \\ Relações Termodinâmicas}

\section{A.1 Relações de Maxwell}

Seja

$$
Z=Z(X, Y, \ldots)
$$

uma função de estado dependente de duas ou mais variáveis. Diferenciando resulta

$$
d Z=\left(\frac{\partial Z}{\partial X}\right)_{Y} d X+\left(\frac{\partial Z}{\partial Y}\right)_{X} d Y+\cdots
$$

Fazendo $\left(\frac{\partial Z}{\partial X}\right)_{Y}=M \mathrm{e}\left(\frac{\partial Z}{\partial Y}\right)_{X}=N$, os coeficientes (derivadas parciais específicas) tem-se

$$
d Z=M d X+N d Y+\cdots
$$

Para que a relação (A.3) seja matematicamente válida, é necessário e suficiente que

$$
\left(\frac{\partial M}{\partial Y}\right)_{X, \ldots}=\left(\frac{\partial N}{\partial X}\right)_{Y, \ldots}
$$

sendo esta igualdade conhecida com relação de Maxwell.

\section{A.2 Funções Termodinâmicas}

Tabela A.1 Volume

\begin{tabular}{|l|l|}
\hline Função & Variação \\
\hline$V=V(T, p)$ & $d V=V(\alpha d T-\beta d p)$ \\
\hline
\end{tabular}

Tabela A.2 Entropia

\begin{tabular}{|l|l|}
\hline Função & Variação \\
\hline$S=S(T, p)$ & $d S=\frac{C_{p}}{T} d T-V \alpha d p$ \\
\hline$S=S(T, V)$ & $d S=\frac{C_{V}}{T} d T+\frac{\alpha}{\beta} d V$ \\
\hline$S=S(p, V)$ & $d S=\frac{1}{T \alpha}\left(-C_{V} \beta d p+\frac{C_{p}}{V} d V\right)$ \\
\hline
\end{tabular}


obs.: $C_{v}=C_{p}-\frac{V T \alpha^{2}}{\beta}$

Tabela A.3 Energia Intema

\begin{tabular}{|c|c|c|}
\hline Funçäo & Variação & Relação de Maxwell \\
\hline$U=U(s, V)$ & $d U=T d S-p d V$ & $\left(\frac{\partial T}{\partial V}\right)_{S}=-\left(\frac{\partial p}{\partial S}\right)_{V}$ \\
\hline$U=U(T, p)$ & $d U=\left(C_{p}-p V \alpha\right) d T+V(p \beta-T \alpha) d p$ & \\
\hline$U=U(T, V)$ & $d U=C_{V} d T-\left(p-T \frac{\alpha}{\beta}\right) d V$ & \\
\hline$U=U(p, V)$ & $d U=\frac{C_{V} \beta}{\alpha} d p+\left(\frac{C_{p}}{V \alpha}-p\right) d V$ & \\
\hline
\end{tabular}

\begin{tabular}{|c|c|c|}
\hline Função & Variação & Relação de Maxwell \\
\hline$H=H(S, p)$ & $d H=T d S+V d p$ & $\left(\frac{\partial T}{\partial p}\right)_{S}=\left(\frac{\partial V}{\partial S}\right)_{n}$ \\
\hline$H=H(T, p)$ & $d H=C_{p} d T+V(1-\alpha T) d p$ & \\
\hline$H=H(T, V)$ & $d H=\left(C_{V}+V \frac{\alpha}{\beta}\right) d T-\frac{1}{\beta}(1-T \alpha) d V$ & \\
\hline$H=H(p, V)$ & $d H=\left[C_{p}+V(1-T \alpha)\right] d p+\frac{C_{p}}{V \alpha} d V$ & \\
\hline
\end{tabular}

Tabela A.5 Energia Livre de Helmholtz Definição: $\quad F=S-T S$

\begin{tabular}{|c|c|c|}
\hline Função & Variação & Relação de Maxwell \\
\hline$F=F(T, V)$ & $d F=-S d T-p d V$ & $\left(\frac{\partial T}{\partial V}\right)_{S}=-\left(\frac{\partial p}{\partial S}\right)$ \\
\hline$F=\tilde{F}(T, p)$ & $d F=-(S+p V \alpha) d T+p V \beta d p$ & \\
\hline$F=F(p, V)$ & $d F=\beta\left(p V-\frac{S}{\alpha}\right) d p-\left(p+\frac{S}{V \alpha}\right) d V$ & \\
\hline
\end{tabular}

Tabela A.6 Energia Livre de Gibbs Definiçסes: $\left\{\begin{array}{l}G=U-T S+p V \\ G=H-T S \\ G=F+p V\end{array}\right.$

\begin{tabular}{|l|l|l|}
\hline Função & Variação & Relação de Maxwell \\
\hline$G=G(T, p)$ & $d G=S d T-V d p$ & $\left(\frac{\partial S}{\partial p}\right)_{T}=-\left(\frac{\partial V}{\partial T}\right)_{p}$ \\
\hline$G=G(T, V)$ & $d G=\left(S-\frac{V \alpha}{\beta}\right) d T+\frac{1}{\beta} d V$ & \\
\cline { 1 - 2 } & \multicolumn{1}{|l}{$\left(\frac{S \beta}{\alpha}-V\right) d p+\frac{S}{V \alpha} d V$} & \\
\hline
\end{tabular}




\section{A.3 Outras Definições e Derivações}

Coeficiente de expanção isobárica, $\alpha$

$$
\alpha=\frac{1}{V}\left(\frac{\partial V}{\partial T}\right)_{p} .
$$

Coeficiente de compressão isotérmica, $\beta$

$$
\beta=-\frac{1}{V}\left(\frac{\partial V}{\partial p}\right)_{T} .
$$

Da Tabela III tem-se que

$$
\left(\frac{\partial U}{\partial V}\right)_{T}=p-T \frac{\alpha}{\beta}=p-T\left(\frac{\partial p}{\partial T}\right)_{V},
$$

de modo que

$$
\frac{\alpha}{\beta}=\left(\frac{\partial p}{\partial T}\right)_{V}
$$




\section{Apêndice B \\ Entropia de um Fluido Incompressível e de um Gás Perfeito}

Com a substância na fase líquida, em geral é ncessário aplicar variações muito grandes na pressão para provocar alteração significativa no volume específico [1]. Em muitos problemas a variação da temperatura é pequena o suficiente para que seus efeitos sobre o volume específico também possam ser desconsiderados. No caso da água, mesmo com a temperatura variando de 0 a $100{ }^{\circ} \mathrm{C}$ à pressão de 1.01325 bar ( 1 atm), a variação do volume é de cerca de $4 \%$. Para um fluido incompressível tem-se

$$
v=\text { cte ou } \rho=\text { cte. }
$$

É fato experimental que a energia interna por partícula $u$ de um fluido incompressível é função somente da temperatura [1], ou seja,

$$
u=u(T)
$$

A partir da Tabela III no Apêndice A para $u=u(T, v)$ tem-se

$$
d u=c_{v}(T) d T
$$

pois $d v=0$, e para $u=u(T, p)$ tem-se

$$
d u=c_{p}(T) d T
$$

pois, mesmo $d p \neq 0$, tem-se $\beta=\alpha=0$. Assim, para um fluido incompressivel, pode-se escrever, sem perda de generalidade,

$$
\left(\frac{\partial u}{\partial T}\right)_{v}=\left(\frac{\partial u}{\partial T}\right)_{p}
$$


ou,

$$
c_{v}=c_{p}=c
$$

As equações (B.3) e (B.4) podem ser reescritas como

$$
d u=c(T) d T
$$

a qual integrada resulta

$$
u_{2}-u_{1}=\int_{1}^{2} c(T) d T
$$

A entalpia definida como

$$
h=u+p v
$$

(conforme Tabela III no Apêndice A) tem a variação a volume constante dada por,

$$
h_{2}-h_{1}=u_{2}-u_{1}+v_{1}\left(p_{2}-p_{1}\right)
$$

Admitindo, pelas razões expostas acima, que o calor específico é constante, a equação (B.8) em (B.10) tem a forma

$$
h_{2}-h_{1}=c\left(T_{2}-T_{1}\right)+v_{1}\left(p_{2}-p_{1}\right) \text {. }
$$

A variação da entropia em função da temperatura e volume é expressa por

$$
d s=\frac{c_{v}}{T} d T+\frac{\beta}{\beta} d v
$$

(conforme Tabela II no Apêndice A) ou, para um fluido incompressível,

$$
d s=\frac{c}{T} d T
$$

a qual é facilmente integrável, ou seja,

$$
s_{2}-s_{1}=c \ln \left(\frac{T_{2}}{T_{1}}\right)
$$

É notável que a entropia de um fluido incompressivel ou sólido é função somente da temperatura. 
Resolvendo a equação (B.11) para $T_{2}$ e substituindo em (B.14) encontra-se a entropia de um fluido incompressível (ou de um sólido) como função da entalpia e pressão

$$
s_{2}-s_{1}=c \ln \left(\frac{\left(h_{2}-h_{1}\right)-v_{1}\left(p_{2}-p_{1}\right)}{c T_{1}}+1\right) .
$$

Para simplificar esta expressão, adota-se como estado de referência a vizinhança do ponto triplo $\left[P_{3}=\left(p^{r e f}, v^{(l, g), \text { ref }}, T^{r e f}\right)\right]$, de modo que $h^{1}=s^{1}=0$ [1]. Deste modo quando $p_{1}=p^{\text {ref }}=$ cte a função passa pelo zero, $h_{2}=s_{2}=0$. Assim, abandonando o sub-índice 2 e substituindo o 1 por $r e f$, pode-se reescrever esta expressão como

$$
s=c \ln \left(\frac{h-v^{r e f}\left(p-p^{r e f}\right)}{c T^{r e f}}+1\right) \text {. }
$$

Evidentemente que esta expressão é válida somente no domínio da fase líquida. Esta expressão foi obtida considerando-se a igualdade em (B.6), a qual deixa de valer na região no espinodal, quando $c_{p}$ diverge e $c_{v}$ não.

A partir da Tabela II do Apêndice A, tem-se que para um gás ideal, a entropia com função da temperatura e pressão é dada por

$$
d s=\frac{c_{p}^{\circ}}{T} d T-\frac{R}{p} d p
$$

Admitindo $c_{p}=$ cte e integrando resulta em

$$
s_{2}-s_{1}=c_{p}^{\circ}\left[\ln \left(\frac{T_{2}}{T_{1}}\right)-\frac{R}{c_{p}^{\circ}} \ln \left(\frac{p_{2}}{p_{1}}\right)\right]
$$

ou

$$
s_{2}-s_{1}=c_{p}^{0} \ln \left[\left(\frac{T_{2}}{T_{1}}\right)\left(\frac{p_{1}}{p_{2}}\right)^{\frac{R}{c_{p}^{0}}}\right] .
$$

A equação (B.11) para o gás ideal tem a forma

$$
h_{2}-h_{1}=c_{p}^{\circ}\left(T_{2}-T_{1}\right)+v_{1}\left(p_{2}-p_{1}\right) \text {. }
$$


Resolvendo esta expressão para $T_{2}$ e levando-a em (B.19) tem-se

$$
s_{2}-s_{1}=c_{p}^{\circ} \ln \left\{\left[\frac{\left(h_{2}-h_{1}\right)-v_{1}\left(p_{2}-p_{1}\right)}{c_{p}^{\circ} T_{1}}\right]\left(\frac{p_{1}}{p_{2}}\right)^{\frac{R}{c_{p}^{\circ}}}\right\} .
$$

Admitindo o mesmo estado de referência que em (B.16), pode-se escrever

$$
s=s^{v a p}+c_{p}^{\circ} \ln \left\{\left[\frac{\left(h-h^{v a p}\right)-v^{r e f}\left(p-p^{r e f}\right)}{c_{p}^{\circ} T^{r e f}}\right]\left(\frac{p^{r e f}}{p}\right)^{\frac{R}{c_{p}^{\circ}}}\right\},
$$

onde $s^{v a p}$ e $h^{v a p}$ são a entropia e a entalpia de vaporização, respectivamente. Deste modo, quando $p=p^{r e f}=c t e$, tem-se $h=h^{v a p}$ e $s=s^{v a p}$. 


\section{Apêndice C Teoria da Flutuação}

A flutuação de energia é dada por [14][21]

$$
\left\langle E_{j}\right\rangle=\frac{\sum_{j} E_{j} \exp \left(-\theta E_{j}\right)}{\sum_{j} \exp \left(-\theta E_{j}\right)}=-\frac{\partial}{\partial \theta} \ln Z,
$$

onde $Z$ é a função de partição, a qual no limite termodinâmico é dada por

$$
Z=\sum_{j} \exp \left(-\theta E_{j}\right)
$$

$\theta=\frac{1}{k_{B} T}$ e $j$ é o $j$-ésimo estado disponível do sistema.

O desvio quadrático é dado por [21]

$$
\begin{aligned}
\left\langle\left(\Delta E_{j}\right)^{2}\right\rangle & =\left\langle\left(E_{j}-\left\langle E_{j}\right\rangle\right)^{2}\right\rangle=\left\langle E_{j}^{2}\right\rangle-\left\langle E_{j}\right\rangle^{2} \\
& =\frac{\partial}{\partial \theta}\left[\frac{1}{Z} \frac{\partial Z}{\partial \theta}\right]=-\frac{\partial}{\partial \theta}\left\langle E_{j}\right\rangle
\end{aligned}
$$

e o desvio ou flutuação relativa é definida por

$$
\frac{\left\langle\left(E_{j}-\left\langle E_{j}\right\rangle\right)^{2}\right\rangle^{1 / 2}}{\left\langle E_{j}\right\rangle} \propto \frac{1}{\sqrt{N}} .
$$

Identificando o valor esperado da energia com a energia interna média, $\left\langle E_{j}\right\rangle \equiv$ $\langle U\rangle$,

$$
\left\langle(\Delta U)^{2}\right\rangle=-\frac{\partial}{\partial \theta}\langle U\rangle=k_{B} T^{2} \frac{\partial U}{\partial T}=N k_{B} T^{2} C_{v}
$$

onde a energia interna é escrita com base no teorema da equipartição de energia [2], ou seja,

$$
U=\frac{3}{2} N k_{B} T
$$

Cabe notar que $N$ representa a quantidade de monômeros do sistema, no caso um gás monoatômico ideal. 
Assim, tomando a variação da equação (C.6) e levando em (C.5) resulta

$$
\left\langle(\Delta T)^{2}\right\rangle=\frac{T^{2} C_{v}}{\frac{9}{4} N k_{B}},
$$

ou,

$$
\left\langle(\Delta T)^{2}\right\rangle=\frac{N k_{B} T^{2}}{C_{v}},
$$

onde $C_{v}$ é capacidade calorífica definida como

$$
C_{v}=\left(\frac{\partial U}{\partial T}\right)_{v}=\frac{3}{2} N k_{B} .
$$

Para o vapor de água, tratado como gás ideal, a flutuação da temperatura e o desvio quadrático, respectivamente, com ajuda da equação (C.9) em (C.8), são expressos por

$$
\left\langle(\Delta T)^{2}\right\rangle=\frac{2}{3} \frac{T^{2}}{N}
$$

e por

$$
\left\langle(\Delta T)^{2}\right\rangle^{1 / 2}=\sqrt{\frac{2 T^{2}}{3}} .
$$

No casa da entalpia, a flutuação relativa é dada por

$$
\frac{\left\langle(\Delta H)^{2}\right\rangle^{1 / 2}}{\langle H\rangle} \propto \frac{1}{\sqrt{N}}
$$

ou

$$
\left\langle(\Delta H)^{2}\right\rangle^{1 / 2} \propto \sqrt{N}\langle h\rangle .
$$




\section{Apêndice D \\ Equação de Estado van der Waals}

\section{D.1 Introdução}

Os estudos de van der Waals ${ }^{38}$ levaram-no ao estabelecimento do principio de continuidade das fases gasosa e liquida ${ }^{39}$. Mostrou que, em substâncias puras, a distinção entre líquido e gás é artificial. Porém, é impossivel indicar uma única equação de estado, $f(p, v, T)=0$, que cubra todo o intervalo das duas fases [20]. É conveniente, portanto, fazer aproximações em subintervalos como o da região de coexistência de fases. Uma equação de estado que fornece dados desta região com acurácia suficientemente boa é a equação de estado de van der Waals, dada pela expressão (1.11).

\section{D.2 Sobre a Equação de Estado}

A forma da equação (1.11),

$$
p=\frac{R T}{v-b}-\frac{a}{v^{2}}
$$

foi derivada a partir de considerações microscópicas. É uma extensão da lei dos gases perfeitos

$$
p v=R T,
$$

em que foram feitas duas correções.

A primeira, descrita pela constante $b$, refere-se ao menor volume que um gás pode ocupar, devido à extensão física das partículas do sistema. Portanto, $v-b$ repre-

38 Johannes Diderik van der Waals (1827-1923)

39 Vide [20], p. 234s. ou J. S. Rowlinson em J. D. van der Waals: On The Continuity of the Gaseous and Liquid States. Amsterdan. Elsevier. 1988. 
senta o volume do sistema disponível para o gás ocupar. O covolume b é determinado a partir de medidas macroscópicas, feitas para cada substância.

A segunda correção, $-\frac{a}{v^{2}}$, está relacionada às forças de atração ou de coesão, conhecidas como forças de van der Waals. O conceito de pressão (sobre o sistema) está relacionado com colisões de $n$ partículas idênticas com uma parede, onde o momento é conservado (colisões elásticas). Comparando com o gás ideal - onde não são consideradas interações intermoleculares --, é evidente que a presença de forças de van der Waals afetará aquela grandeza, de modo que pode ser escrita como $p+p^{\prime}$, onde $p^{\prime}$ é uma correção. Admitindo que $p^{\prime}$ é aproximadamente proporcional às $n$ partículas do sistema (através da força de atração), além das $n$ partículas que atingem a parede, pode-se escrever que

$$
p^{\prime} \sim n^{2}
$$

Uma vez que o volume específico é inversamente proporcional ao número de moléculas, tem-se que

$$
p^{\prime}=\frac{a}{v^{2}},
$$

onde $a$ é uma constante de proporcionalidade a ser determinada também a partir de medidas macroscópicas.

Introduzindo estas correções na lei dos gases perfeitos, obtém-se

$$
\left(p+\frac{a}{v^{2}}\right)(v-b)=R T
$$

que é a equação (D.1). 


\section{D.3 A Lei das Áreas de Maxwell}

Na Figura D.17 os pontos de interseç̧ão $a$ e $b$ de uma isoterma $T$ com as linhas binodais do líquido e do vapor, respectivamente, podem ser encontrados mediante a condição conhecida com a Lei das Áreas de Maxwell [20], a qual afirma que as áreas $A_{1}$ e $A_{2}$ devem ser iguais. Esta lei pode ser deduzida a partir do fato que o processo de evaporação representado pela horizondal $\overrightarrow{a e}$ dá-se isotérmica e isobaricamente.

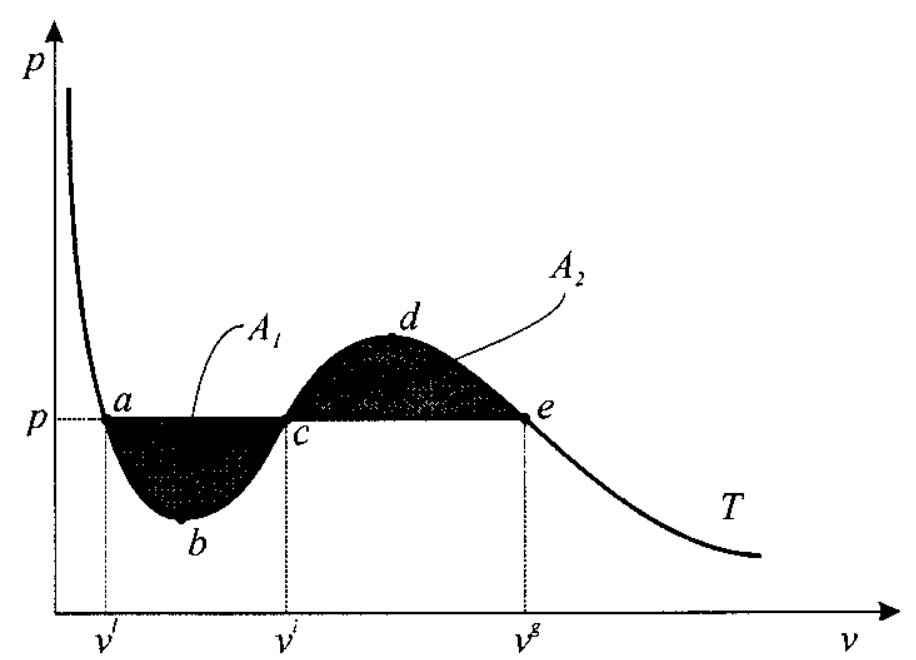

Fig. D.17- As propriedades termodinâmicas de um fluido VDW em equilíbrio podem ser encontradas calculando as áreas $A_{1}$ e $A_{2}$ de modo que $A_{1}=A_{2}$.

A partir da variação da energia livre de Gibbs específica (Tabela A.6)

$$
d g=-s d T+v d p
$$

segue que $d T=0$ e $d p=0$, ao longo da reta $a-c-e$, de modo que $g=c t e$ neste trecho. Tem-se portanto,

$$
g_{a}=g_{e}
$$

Conseqüentemente,

$$
g_{e}-g_{a}=\int_{a}^{e} v d p=0 \quad(T=c t e)
$$


o que prova as duas áreas da Figura D.17 devem ser iguais e de sinais opostos quando medida à pressão de equilíbrio termodinâmico $p^{e}$.

\section{D.3.1 Cálculo Analítico de $(p, v, T)$ no Equilíbrio Termodinâmico}

Usando a lei das áreas de Maxwell, é possível encontrar as propriedades termodinâmicas $(p, v, T)$ no binodal, a partir da pressão $p^{e}$ somente. Na Figura D.17, de maneira geral as áreas $A_{1}$ e $A_{2}$ são dadas por

$$
\begin{aligned}
A_{1} & =p\left(v^{i}-v^{l}\right)-\int_{v^{i}}^{v^{i}} p(v) d v \\
& =p\left(v^{i}-v^{l}\right)-R T \ln \left(\frac{v^{i}-b}{v^{l}-b}\right)-a\left(\frac{1}{v^{i}}-\frac{1}{v^{l}}\right)
\end{aligned}
$$

$\mathrm{e}$

$$
\begin{aligned}
A_{2} & =\int_{v^{i}}^{v^{g}} p(v) d v-p\left(v^{g}-v^{i}\right) \\
& =R T \ln \left(\frac{v^{g}-b}{v^{i}-b}\right)+a\left(\frac{1}{v^{g}}-\frac{1}{v^{i}}\right)-p\left(v^{g}-v^{i}\right)
\end{aligned}
$$

onde foi utilizada a equação de van der Waals.

Conforme a lei das áreas de Maxwell [20], no equilíbrio caracterizado por $p^{e}$ e $T^{e}$, tem-se

$$
A_{2}-A_{1}=0
$$

ou seja,

$$
R T^{e} \ln \left(\frac{v^{g, e}-b}{v^{l, e}-b}\right)+a\left(\frac{1}{v^{g, e}}-\frac{1}{v^{l, e}}\right)-p^{e}\left(v^{g, e}-v^{l, e}\right)=0
$$

É possível reescrever a equação acima eliminando a temperatura de equilíbrio, uma vez que ela ainda é desconhecida. Com a equação (D.1) calculada no binodal e resolvida para $T^{T e}$ tem-se

$$
T^{e}=\frac{1}{R}\left(p^{e}+\frac{a}{v^{g, e}}\right)\left(v^{g, e}-b\right),
$$


onde $v^{g, e}$ é o volume do gás no equilíbrio termodinâmico. Levando a equação (D.13) em (D.12) e resolvendo-a para $p^{e}$ resulta

$$
p^{e}=\frac{\frac{a}{v^{g, e}}\left(1-\frac{b}{v^{g, e}}\right) \ln \left(\frac{v^{g, e}-b}{v^{l, e}-b}\right)+\frac{a}{v^{g, e}}\left(1-\frac{v^{g, e}}{v^{l, e}}\right)}{\left(v^{g, e}-v^{l, e}\right)-\left(v^{g, e}-b\right) \ln \left(\frac{v^{g, e}-b}{v^{l, e}-b}\right)}
$$

Para eliminar $v^{l, e}$ ou $v^{g, e}$ da equação (D.14) considere que a equação de van der Waals é cúbica em $v$, ou seja,

$$
v^{3}+A v^{2}+B v+C=0
$$

onde

$$
A=-\left(b+\frac{R T}{p}\right), \quad B=\frac{a}{p} \text { e } C=-\frac{a b}{p} .
$$

Para uma determinada temperatura $T$ e pressão $p$, é esperado uma ou três raizes reais. Destacando estas raízes, tem-se

$$
\left(v-v^{l}\right)\left(v-v^{i}\right)\left(v-v^{g}\right)=0 .
$$

Fazendo

$$
\frac{v^{3}+A v^{2}+B v+C}{v-v^{g}}=v^{2}+\left(A+v^{g}\right) v+\left[\left(v^{g}\right)^{2}+A v^{g}+B\right]=0
$$

de onde tira-se que

$$
\begin{aligned}
v^{i}, v^{l} & =-\frac{1}{2}\left(A+v^{g}\right) \pm \frac{1}{2} \sqrt{\left(A+v^{g}\right)^{2}-4\left[\left(v^{g}\right)^{2}+A v^{g}+B\right]} \\
& =\frac{1}{2}\left(b+\frac{R T}{p}-v^{g}\right) \pm \frac{1}{2} \sqrt{\left[b+\frac{R T}{p}+v^{g}\right]^{2}-4\left[\left(v^{g}\right)^{2}+\frac{a}{p}\right]} . \text { (D.19) }
\end{aligned}
$$

Considerando que $v^{l}<v^{i}$, então no equilíbrio termodinâmico tem-se

$$
\begin{aligned}
v^{l, e}= & \frac{1}{2}\left[b+\frac{1}{p^{e}}\left(p^{e}+\frac{a}{v^{g, e}}\right)\left(v^{g, e}-b\right)-v^{g, e}\right] \\
& -\frac{1}{2} \sqrt{\left[b+\frac{1}{p^{e}}\left(p^{e}+\frac{a}{v^{g, e}}\right)\left(v^{g, e}-b\right)+v^{g, e}\right]^{2}-4\left[\left(v^{g, e}\right)^{2}+\frac{a}{p^{e}}\right]}(\mathrm{D} .20)
\end{aligned}
$$


e, com alguma manipulação algébrica,

$$
v^{l, e}=\frac{1}{2} \frac{a}{p^{e} v^{g, e}}\left(1-\frac{b}{v^{g, e}}\right)-\sqrt{\left[v^{g, e}+\frac{a}{2 p^{e} v^{g, e}}\left(1-\frac{b}{v^{g, e}}\right)\right]^{2}-\left(v^{g, e}\right)^{2}-\frac{a}{p^{e}}}
$$

Assim, levando a equação (D.21) em (D.14), obtém-se uma função do tipo

$$
f\left(p^{e}, v^{g, e}\right)=0
$$

Conhecendo-se $p^{e}$, um software como o Maple pode fornecer valores de $v^{g, e}$ até verificar a equação (D.22), como ilustrado na Figura D.18. Tendo $p^{e}$ e $v^{g, e}$, encontra-se $v^{l, e} \mathrm{e}$, principalmente, $T^{e}$.

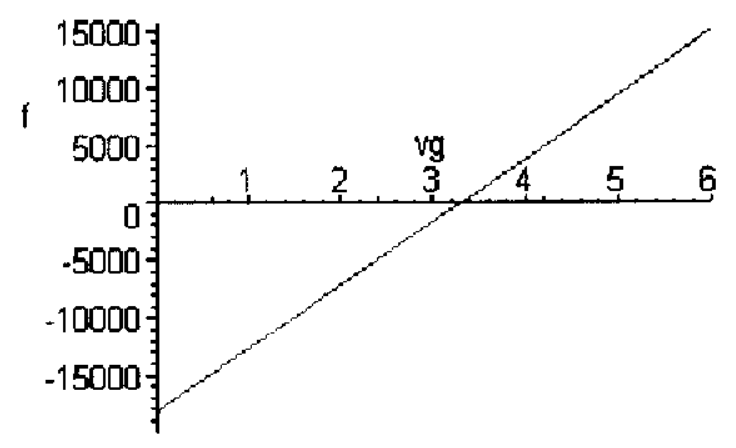

Fig. D.18- Para encontrar $T^{e}$ cumpre fixar $p^{e}$ e variar $v^{g, e}$ até encontrar $A_{1}=A_{2}$ ou $f\left(p^{e}, v^{g, e}\right)=0$.

\section{D.4 Comparação com experimento}

A importância da equação de van der Waals reside no fato de que, a partir de pressupostos microscópicos muito simples, é possível descrever de modo qualitativamente correto o estado gasoso bem como o líquido de uma substância pura [20]. A acurácia suficientemente boa não é superior em razão da impossibilidade de uma substância pu- 
ra ser representada com acurácia somente com auxílio de duas variáveis ajustáveis ( $a$ e $b)$.

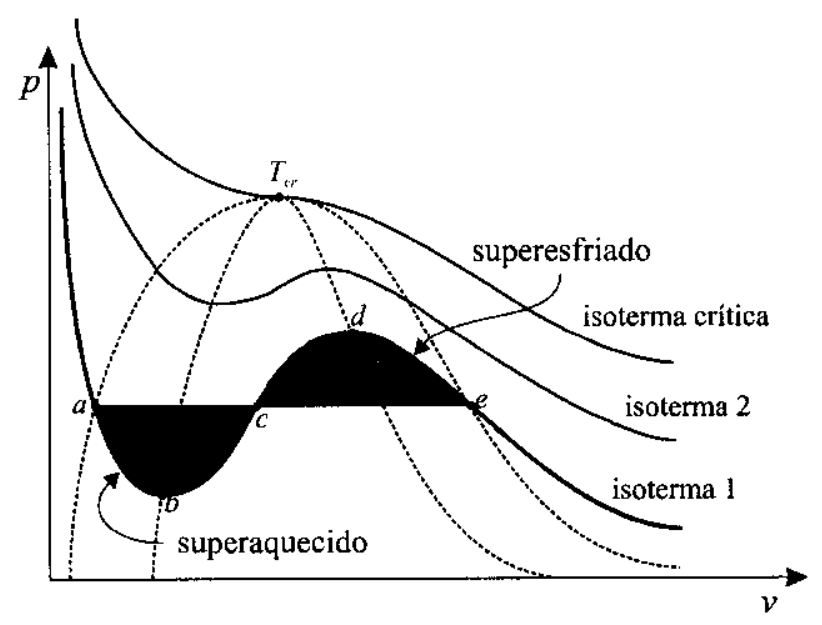

Fig. D.19- Os segmentos $\overline{a b}$ e $\overline{d e}$ têm significado físico.

Quando um líquido é expandido à temperatura constante e atinge o estado no ponto $a$ na Figura D.19, localizado sobre a linha de equilíbrio do líquido ou binodal (linha pontilhada), iniciará a evaporação. Neste ponto, o líquido está saturado. A evaporação estará completa quando o estado da substância atingir o ponto $e$, ponto da linha de equilibrio do gás (binodal).

Levando o sistema do ponto $a$ ao ponto $e$ à pressão constante (linha $a-c-e$ ) tem-se que o mesmo estará em em estado de equilíbrio termodinâmico a cada ponto $(p=T=c t e)$

Porém, se uma substância pura na fase líquida é expandida cuidadosamente desde o ponto $a$ até um ponto intermediário sobre a curva $\overline{a b}$, evitando-se grandes flutuações de pressão e de temperatura, é possível supersaturá-la e preservá-la nesta fase. Neste caso a pressão medida estará abaixo da pressão de saturação e a temperatura 
acima da de ebulição, ou seja,

$$
p^{l}<p^{e} \text { e } T^{l}>T^{e} \quad \text { (líquido em estado metaestável) }
$$

onde $p^{e}$ e $T^{e}$ são,O líquido encontra-se superaquecido.

Similarmente, estando a substância na fase líquida, é possível comprimi-la do ponto $e$ ao ponto $d$, ou seja, para além saturação, e ainda assim preservar sua fase. Neste caso, a pressão medida será maior que a de saturação e a temperatura menor que a de condensação, ou seja,

$$
p^{l}>p^{e} \text { e } T^{l}<T^{e} \quad \text { (gás em estado metaestável). }
$$

e o gás encontra-se superesfriado.

Entre os pontos $b$ e $d$ o estado termodinâmico da substância é instável e, portanto, os pontos neste segmento não representam realidade física, conforme mostrado no Capítulo 4 .

\section{D.5 Lei dos Estados Correspondentes}

O ponto crítico, $\left(p_{c}, v_{c}, T_{c}\right)$, é um caso limite (conforme Figura 1.1 na Sessão 1.1), caracterizado por

$$
\left[\left(\frac{\partial p}{\partial v}\right)_{T}\right]_{p_{c}, v_{c}, T_{c}}=\left[\left(\frac{\partial^{2} p}{\partial v^{2}}\right)_{T}\right]_{p_{c}, v_{c}, T_{c}}=0 .
$$

Dada a particularidade deste, é possível expressar as grandezas críticas $p_{c}, v_{c}, T_{c}$ em termos das constantes do fluido, $a$ e $b$. Considerando o estado de um sistema no ponto crítico, a partir da equação (D.1), tem-se que

$$
\begin{gathered}
p_{c}=\frac{R T_{c}}{v_{c}-b}-\frac{a}{v_{c}^{2}} . \\
{\left[\left(\frac{\partial p}{\partial v}\right)_{T}\right]_{p_{c}, v_{c}, T_{c}}=-\frac{R T_{c}}{\left(v_{c}-b\right)^{2}}+\frac{2 a}{v_{c}^{3}}=0}
\end{gathered}
$$




$$
\left[\left(\frac{\partial^{2} p}{\partial v^{2}}\right)_{T}\right]_{p_{c}, v_{c}, T_{c}}=\frac{3 R T_{c}}{\left(v_{c}-b\right)^{3}}-\frac{6 a}{v_{c}^{4}}=0
$$

Igualando as equações (D.27) e (D.28) tem-se, $v_{c}$ e $T_{c}$, os quais levados em (D.26) resulta em

$$
p_{c}=\frac{a}{27 b^{2}}, \quad v_{c}=3 b, \quad T_{c}=\frac{8 a}{27 R b} .
$$

Resolvendo estas três equações para as constantes do fluido tem-se

$$
a=3 p_{c} v_{c}^{2}, \quad b=\frac{1}{3} v_{c}, \quad R=\frac{8}{3} \frac{p_{c} v_{c}}{T_{c}} .
$$

Dada a dificuldade experimental em medir o volume crítico, é melhor manter a constante $R$ e expressar as constantes do fluido, $a$ e $b$, em termos de pressão e temperatura críticos, obtendo-se

$$
a=\frac{27}{64} \frac{R^{2} T_{c}^{2}}{p_{c}^{2}}, \quad b=\frac{1}{8} \frac{R T_{c}}{p_{c}} .
$$

Definindo pressão reduzida, $p_{r}=p / p_{c}$, volume específico reduzido, $v_{r}=v / v_{c}$ e temperatura reduzida, $T_{r}=T / T_{c}$, e substituindo na equação (D.5), juntamente com (D.30), resulta em

$$
\left(p_{r}+\frac{3}{v_{r}^{2}}\right)\left(3 v_{r}-1\right)=8 T_{r}
$$

a qual é denominada equação reduzida de VDW ou principio dos estados correspondentes. É uma equação universal no sentido de que não depende explicitamente das constantes do fluido. 


\section{Apêndice E \\ Sobre a Constante $\phi$}

É possível estimar a ordem de grandeza da constante $\phi$ proposta em (4.27). Levando nesta o valor do núcleo crítico obtido experimentalmente, $n_{\exp }^{*}$ (vide Apêndice G.2.2), tem-se,

$$
\phi=\sqrt{\frac{3}{2} n_{\text {exp }}^{*}} \frac{\left|\frac{T^{a}}{T^{m}}-1\right|\left|1-\frac{h^{b}}{h^{B}}\right|}{\left|\frac{h^{a}}{h^{m}}-1\right|} .
$$

Para os valores de $n_{\exp }^{*}$ encontrados no trabalho de Wölk-Strey tem-se que

$$
10^{2} \lesssim \phi^{2} \lesssim 10^{3}
$$




\section{Apêndice F Teoria das Funções Residuais}

O cálculo de variações nas propriedades termodinâmicas - entropia, $S$, energia interna, $U$, entalpia, $H$, energia livre de Helmholtz, $F$, energia livre de Gibbs, $G-$ de uma substância pura (ou de misturas com composição fixa), envolve o cálculo da chamada Função Residual ${ }^{40}$ [16]. Esta é a diferença entre a propriedade de interesse no estado real específico $X=(p, V, T)$ e a no estado de gás ideal, $X^{g a ́ s-i d e a l}$ à mesma temperatura $T$, com pressão $p \rightarrow 0$ (ou volume $V \rightarrow \infty$ ). Ou seja,

$$
X(T, p)-X^{g a s-i d e a l}(T, p \rightarrow 0)=X(T, p)-X^{\circ}\left(T, p^{\circ}\right)
$$

ou

$$
X(T, V)-X^{g a s-i d e a l}(T, V \rightarrow \infty)=X(T, V)-X^{\mathrm{o}}\left(T, V^{\mathrm{o}}\right)
$$

Como estas propriedades termodinâmicas independem do caminho, isto é, dependem somente dos estados inicial e final, pode-se escolher um caminho mais fácil para o seu cálculo. Nesse intuito, para calcular a variação de uma determinada propriedade termodinâmica, $X$, entre dois estados bem definidos, $\left(p_{1}, V_{1}, T_{1}\right)$ e $\left(p_{2}, V_{2}, T_{2}\right)$, considera-se três passos (conforme esquematizado na Figura F.20):

- Passo 1: expansão isotérmica à $T_{1}$, de $p=p_{1}$ até 0 (ou $V=V_{1}$ até $\infty$ )

- Passo 2: aquecimento isobárico de $T_{1}$ até $T_{2}$ em uma aproximação de estado de gás ideal $[p=0($ ou $V=\infty)]$

- Passo 3: compressão isotérmica à $T_{2}$ de $p=0$ até $p_{2}$ (ou de $V=\infty$ até $V_{2}$ ).

40 Do inglês departure functions. A designação Funções Residuais foi adotada em conformidade com o Curso de Termodinâmica da Poli (USP). 

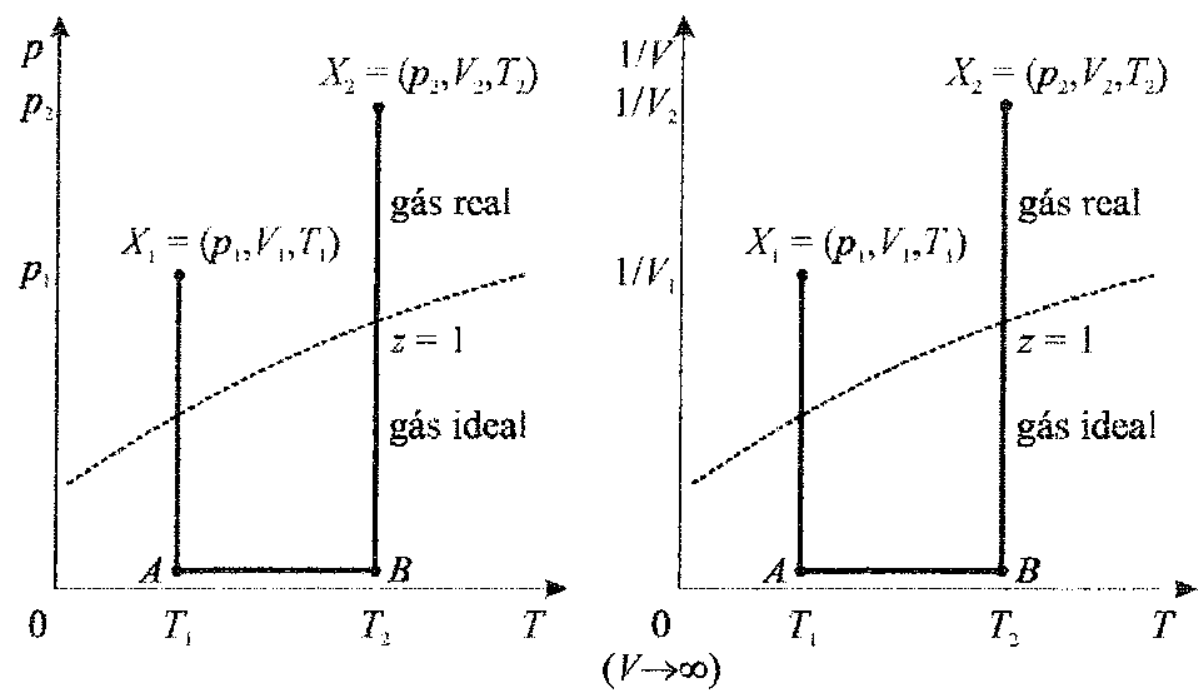

Fig. F.20- Os três passos propostos estão representados de forma equivalente nestes dois gráficos.

Matematicamente,

$$
\Delta X=\underbrace{\left(X_{2}-X_{B}\right)}_{\text {passo }-3}+\underbrace{\left(X_{B}-X_{A}\right)}_{\text {passo }-2}+\underbrace{\left(X_{A}-X_{1}\right)}_{\text {passo }-1}
$$

ou

$$
\begin{aligned}
\Delta X= & \underbrace{\left[X\left(p_{2}, V_{2}, T_{2}\right)-X\left(p \rightarrow 0, V \rightarrow \infty, T_{2}\right)\right]}_{\text {passo-3 }} \\
& +\underbrace{\left[X\left(p \rightarrow 0, V \rightarrow \infty, T_{2}\right)-X\left(p \rightarrow 0, V \rightarrow \infty, T_{1}\right)\right]}_{\text {passo-2 }} \\
& +\underbrace{\left[X\left(p \rightarrow 0, V \rightarrow \infty, T_{1}\right)-X\left(p_{1}, V_{1}, T_{1}\right)\right]}_{\text {passo-1 }} .
\end{aligned}
$$

Note que nos passos 1 e 3 a variável é a pressão (ou volume) e no 2 é a temperatura. A equação (F.3) pode ser reescrita em termos de integrais tendo como variáveis $T$ e $p$ ou $T$ e $V$. A preferência no uso de uma delas, depende da função de estado em questão. Optando pelas varíaveis $T$ e $p$, deve-se utilizar equações de estado volume-explícito, por exemplo, compressibilidade $z=f\left(p_{r}, T_{r}\right)$. Sendo a opção $T$ e $V$, deve-se trabalhar com funções de estado pressão-explícita, $p=f(T, V)$, como é o caso da VDW e da Peng-Robinson (PR). 
No caso deste trabalho, adotou-se a formulação pressão-explícita, de modo que a equação (F.3) é escrita como

$$
\Delta X=\int_{\infty}^{V_{2}}\left(\frac{\partial X}{\partial V}\right)_{T_{2}} d V+\underbrace{\int_{T_{1}}^{T_{2}}\left(\frac{\partial X^{\circ}}{\partial T}\right)_{V \rightarrow \infty} d T}_{\text {gás-ideal }}+\int_{V_{1}}^{\infty}\left(\frac{\partial X}{\partial V}\right)_{T_{1}} d V,
$$

onde a função residual, $\Delta X_{r e s}$, é dada pelo primeiro termo, isto é

$$
\Delta X_{\text {res }}(T, v)=\int_{\infty}^{V_{2}}\left(\frac{\partial X}{\partial V}\right)_{T_{2}} d V
$$

O último termo da equação (F.5), em geral é tabelado. Tendo como referência o ponto triplo, como mostrado no Apêndice B (ou em [1]), é nulo para líquidos e diz respeito à vaporização para gases.

\section{F.1 Cálculo da Entalpia}

Fazendo $X=H$ na equação (F.5) encontra-se

$$
\Delta H=\int_{\infty}^{V_{2}}\left(\frac{\partial H}{\partial V}\right)_{T_{2}} d V+\underbrace{\int_{T_{1}}^{T_{2}}\left(\frac{\partial H^{\circ}}{\partial T}\right)_{V \rightarrow \infty} d T}_{\text {gás-ideal }}+\int_{V_{1}}^{\infty}\left(\frac{\partial H}{\partial V}\right)_{T_{1}} d V
$$

onde $\left(\frac{\partial H^{\circ}}{\partial T}\right)_{V \rightarrow \infty}=c_{V}^{\circ}(T)$ e o último termo será a entalpia da vaporização, $H^{v a p}$, se for definido que o estado $\left(p_{1}, V_{1}, T_{1}\right)$ é referente ao ponto triplo, quando $H_{3}=0$ [20]. Assim, em termos específicos pode-se escrever

$$
h-h_{3}=\int_{\infty}^{v_{2}}\left(\frac{\partial h}{\partial v}\right)_{T_{2}} d v+\int_{T_{1}=273.16}^{T_{2}} c_{v}^{o}(T) d T+h^{v a p}
$$

ou

$$
h=h^{r e s}+\int_{T_{1}=273.16}^{T_{2}} c_{v}^{\circ}(T) d T+h^{\text {meep }}
$$

Para o cálculo de $h^{r e s}$, uma alternativa é escrever a entalpia específica como função da temperatura e do volume específico, $h=h(T, v)$, (vide Apêndice A),

$$
d h=c_{\eta} d T-\frac{1}{\beta}(1-T \alpha) d v
$$


de modo que,

$$
\left(\frac{\partial h}{\partial v}\right)_{T}=-\frac{1}{\beta}(1-T \alpha) .
$$

Usando a definição de $\alpha$ e de $\beta$, tem-se que

$$
\left(\frac{\partial h}{\partial v}\right)_{T}=v\left(\frac{\partial p}{\partial v}\right)_{T}-T\left(\frac{\partial p}{\partial v}\right)_{T}\left(\frac{\partial v}{\partial T}\right)_{p}
$$

ou, usando as propriedades do jacobiano

$$
\left(\frac{\partial h}{\partial v}\right)_{T}=v\left(\frac{\partial p}{\partial v}\right)_{T}+T\left(\frac{\partial p}{\partial T}\right)_{v}
$$

Assim a função residual para a entalpia específica em sua forma geral é

$$
h^{r e s}=\int_{\infty}^{v_{2}}\left[v\left(\frac{\partial p}{\partial v}\right)_{T_{2}}+T_{2}\left(\frac{\partial p}{\partial T}\right)_{v}\right] d v
$$

E, tendo a pressão através da equação de van der Waals,

$$
\left(\frac{\partial h}{\partial v}\right)_{T}=-\frac{R T b}{(v-b)^{2}}+\frac{2 a}{v^{2}}
$$

Substituindo e integrando,

$$
h=\left(\frac{R T_{2} b}{v_{2}-b}-\frac{2 a}{v_{2}}\right)+\int_{T_{1}=273.16}^{T_{2}} c_{v}^{o}(T) d T+h^{v a p} \text {. }
$$

Com a equação (F.16) pode-se encontrar a entalpia nos pontos $m, a, b$ e $B$, necessários para o cálculo do núcleo crítico. Cabe notar que para os pontos $b$ e $B$, portanto fase líquida, a entalpia de vaporização é zero, $h^{\text {vap }}=0$. 


\section{Apêndice G \\ Experimento com a Nucleação da Água}

O experimento consta de uma câmara de expansão, conforme esquematizado na Figura G.21, onde é estudado o processo nucleação homogênea pelo método do pulso de nucleação [6][23]. Uma determinada quantidade de vapor de água e de gás carregador previamente misturados é transferida para a câmara de expansão (chamber volume), que se encontra a temperatura $T_{0}$. Em seguida as pressões nos respectivos volumes são ajustadas de modo que a subseqüente expansão leve sempre à mesma temperatura experimental, $T_{\text {exp. }}$. Com isso, estabelece-se uma pressão inicial, $p_{0}$, dentro da câmara de expansão. Então, o sistema é expandido isotermicamente até a pressão $p_{\exp }$, quando inicia-se a transição de fase. Para medir a taxa de nucleação, é feita uma recompressão ao se abrir a válvula de recompressão, diminuindo assim a taxa de nucleação. A membrana de teflon funciona como um reservatório de volume, onde o objetivo destes volumes adicionais é suavizar o pulso de recompressão. Possíveis turbulências são controladas com a placa com furos. As micros gotas formadas são contadas por meio de espalhamento de luz.

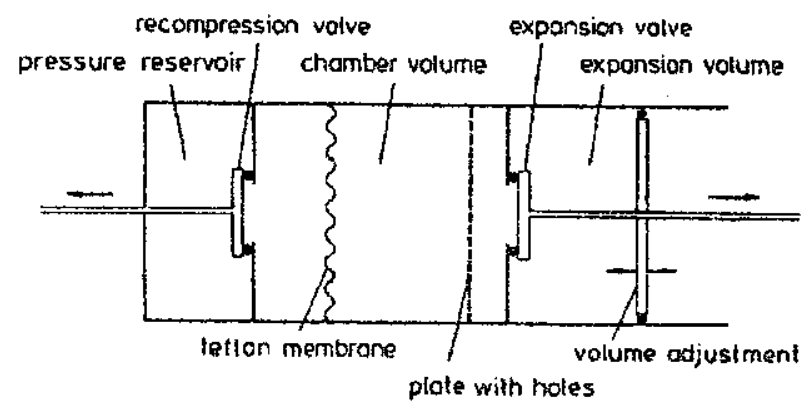

Fig. G.21- Esquema do equipamento usado no estudo da nucleação. 
A pressão parcial do vapor $p_{v}$ dentro da câmara, antes da expansão é determinada a partir da pressão total inicial $p_{0}$, por

$$
p_{v}=\omega p_{0}
$$

onde $\omega$ é a fração de vapor na mistura. A supersaturação $S$ é obtida através da pressão total inicial

$$
S=\frac{\omega p_{0}}{p^{e}(T)}
$$

onde $p^{e}(T)$ é a pressão de vapor no equilíbrio termodinâmico e $T$ é a temperatura de nucleação.

Com a expansão adiabática do vapor de água até $p_{\exp }$, inicia-se a nucleação. Este processo é muito rápido, de modo que uma recompressão do vapor (usualmente entre 2 e $6 \%$ da $\Delta p_{\max }$ ) é escolhida para reduzir a taxa de nucleação $J$ em pelo menos duas ordens de grandeza. O intervalo de tempo entre expansão e recompressão define um pulso de pressão, $\Delta t_{\exp } \cong 1 \mathrm{~ms}$, conforme Figura G.22. Com este procedimento a densidade de núcleos, $M_{\exp }$, tende a estabilizar-se (aproximação de estado estacionário, conforme Suposição 7 na Sessão 2.4). Os núcleos formados durante o pulso de nucleação $\left(n \geq n^{*}\right)$ podem ainda crescer até uma micro gota. A densidade de micro gotas $M_{\text {exp }}$ é observada por espalhamento de luz, de modo que a taxa de nucleação é dada por

$$
J=\frac{M_{\exp }}{\Delta t_{\exp }}
$$

admitindo o processo de nucleação estacionário, onde $\Delta t_{\exp }$ é o pulso de pressão. 


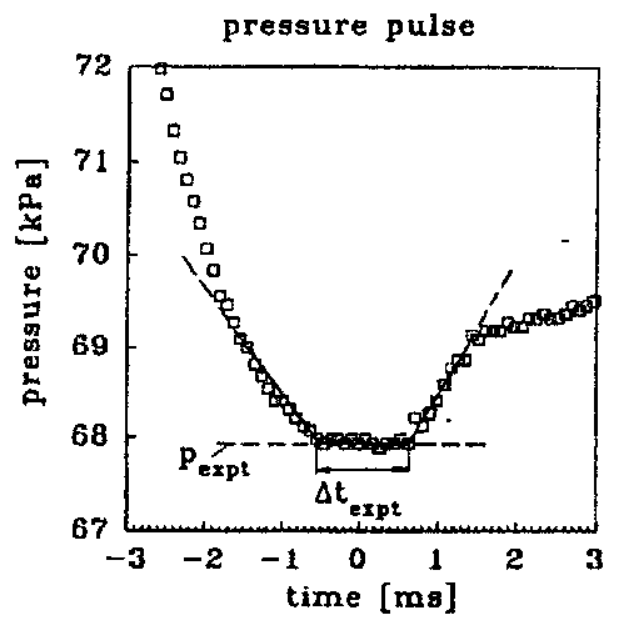

Fig. G.22- $\Delta t_{\exp }$ e $\Delta p_{\exp }$ são encontrados via cálculo do trapézio.

Wölk-Strey conseguiram um bom controle da expansão seguida da recompressão, o que permitiu a reprodução do experimento com boa acurácia. A Figura G.21 mostra que o controle é obtido com o reservatório de pressão

A diferença média $\Delta p=p_{0}-p_{\text {exp }}$ obtida sobre os pulsos dividida por $p_{0}$ permite calcular a temperatura de nucleação $T$ de acordo com a lei de Poisson [6][23]

$$
T=T_{0}\left(1-\frac{\Delta p}{p_{0}}\right)^{\frac{\gamma-1}{\gamma}}
$$

onde $T_{0}$ é a temperatura inicial da câmara de expansão e $\gamma$ é a razão entre os calores específicos calculada através da fórmula de Richarz [6]

$$
\gamma=1+\left[\frac{\omega_{v}}{\gamma_{v}-1}+\frac{1-\omega_{v}}{\gamma_{g}-1}\right]^{-1}
$$

onde $\gamma_{v}$ e $\gamma_{g}$ são as razões entre os calores específicos para o vapor e para o gás carregador, respectivamente

Cabe notar que em geral gás carregador é um gás nobre como o Argônio. WölkStrey [6][23] mostraram que estes gases não interferem na nucleação da água. A Figura 
G.23 mostra como diferentes gases afetam apenas a rapidez com que o sistema atinge a metaestabilidade.

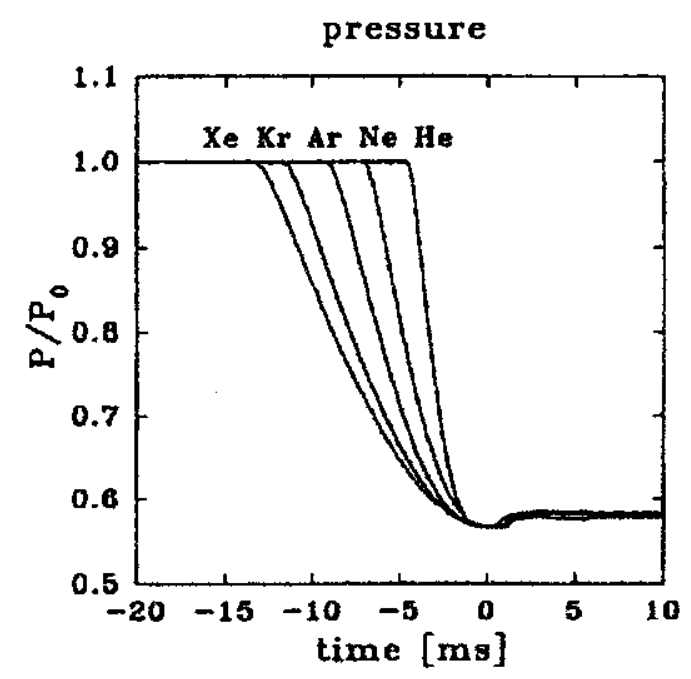

Fig. G.23- Os trabalhos de Strey et all. [6][23] mostram que o gás carregador não interfere na nucleação do vapor de água.

Wölk-Strey [23] realizaram uma série de experiências, separadas pela temperatura inicial da câmara e pela quantidade de vapor de água na mistura gasosa. Em cada uma delas observa-se os seguintes dados

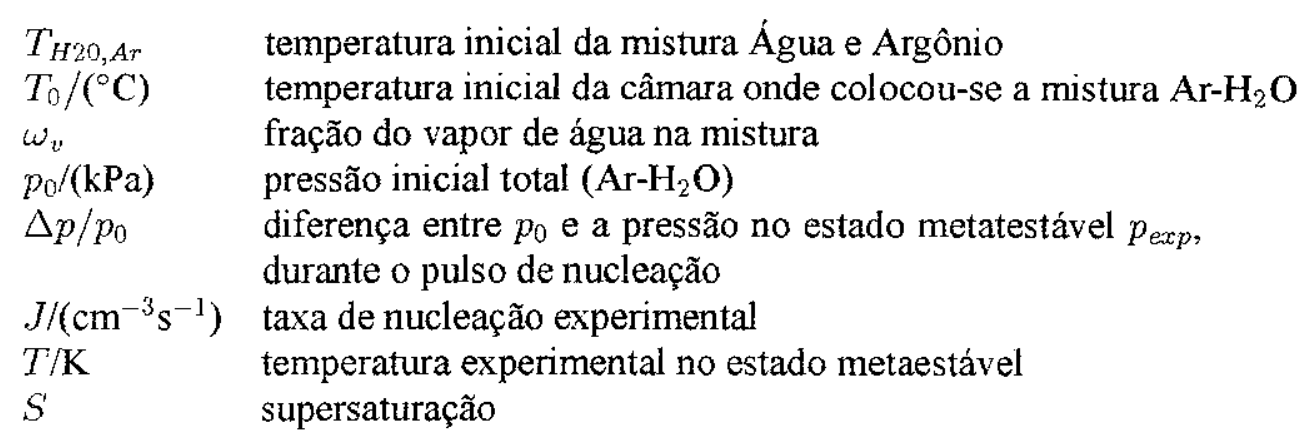

A seguir são apresentados os dados de uma dessas séries, a fim de ilustrar o tratamento feito com os dados pelo autor deste trabalho. No caso escolheu-se a série 
para $T_{H_{2} 0, A r}=240 \mathrm{~K}$ em razão da $T C N$ apresentar resultados razoáveis nesta faixa de temperatura (vide Capítulo 2).

\section{G.1 Dados Coletados para $T_{H_{2} 0, A r}=240 \mathbf{K}$}

Mistura $\mathrm{H}_{2} \mathrm{O}$ e Argônio a $T_{\mathrm{H}_{2} \mathrm{O}, \mathrm{Ar}}=240 \mathrm{~K}$ e $T_{0}=20^{\circ} \mathrm{C}$

Tabela G.1 - Ensaio 1 - fração de vapor de água $\omega_{v}=0.006797$

\begin{tabular}{|c|c|c|c|c|c|}
\hline$p_{0} /(\mathrm{kPa})$ & {$\left[\Delta p / p_{0}\right] \exp$} & {$\left[\Delta p / p_{0}\right]$} & $J /\left(\mathrm{cm}^{-3} \mathrm{~s}^{-1}\right)$ & $T /(\overline{\mathrm{K}})$ & $S$ \\
\hline 99.45 & 0.3947 & 0.3974 & $2.38 \times 107$ & 239.58 & 11.34 \\
\hline 99.45 & 0.3941 & 0.3968 & $2.15 \times 107$ & 239.68 & 11.24 \\
\hline 99.45 & 0.3950 & 0.3977 & $2.12 \times 107$ & 239.54 & 11.38 \\
\hline 99.45 & 0.3953 & 0.3980 & $3.02 \times 107$ & 239.49 & 11.43 \\
\hline 99.45 & 0.3950 & 0.3977 & $2.62 \times 107$ & 239.54 & 11.38 \\
\hline 94.48 & 0.3944 & 0.3971 & $4.51 \times 106$ & 239.63 & 10.73 \\
\hline 94.48 & 0.3944 & 0.3971 & $3.74 \times 106$ & 239.63 & 10.71 \\
\hline 94.48 & 0.3946 & 0.3973 & $4.35 \times 106$ & 239.60 & 10.75 \\
\hline 94.48 & 0.3948 & 0.3975 & $6.18 \times 106$ & 239.57 & 10.78 \\
\hline 89.75 & 0.3947 & 0.3974 & $1.31 \times 106$ & 239.58 & 10.22 \\
\hline
\end{tabular}

Tabela G. 2 - Ensaio 2 - fração de vapor de água $\omega_{v}=0.006808$

\begin{tabular}{|c|c|c|c|c|c|}
\hline$p_{0} /(\mathrm{kPa})$ & {$\left[\Delta p / p_{0}\right]_{\exp }$} & {$\left[\Delta p / p_{0}\right]$} & $J /\left(\mathrm{cm}^{-3} \mathrm{~s}^{-1}\right)$ & $T /(\mathrm{K})$ & $S$ \\
\hline 99.45 & 0.3950 & 0.3977 & $2.97 \times 107$ & 239.54 & 11.40 \\
\hline 99.45 & 0.3948 & 0.3975 & $2.36 \times 107$ & 239.57 & 11.37 \\
\hline 99.45 & 0.3950 & 0.3977 & $2.50 \times 107$ & 239.54 & 11.40 \\
\hline 104.68 & 0.3945 & 0.3972 & $9.64 \times 107$ & 239.62 & 11.92 \\
\hline 104.68 & 0.3946 & 0.3973 & $1.06 \times 108$ & 239.60 & 11.93 \\
\hline 104.68 & 0.3942 & 0.3969 & $1.09 \times 108$ & 239.67 & 11.86 \\
\hline 110.19 & 0.3946 & 0.3973 & $4.67 \times 108$ & 239.60 & 12.55 \\
\hline 110.19 & 0.3946 & 0.3973 & $4.33 \times 108$ & 239.60 & 12.56 \\
\hline
\end{tabular}

Tabela $G .3$ - Ensaio 3 - fração de vapor de água $\omega_{v}=0.006650$ 


\begin{tabular}{|c|c|c|c|c|c|}
\hline$p_{0} /(\mathrm{kPa})$ & {$\left[\Delta p / p_{0}\right] \exp$} & {$\left[\Delta p / p_{0}\right]$} & $J /\left(\mathrm{cm}^{-3} \mathrm{~s}^{-1}\right)$ & $T /(\mathrm{K})$ & $S$ \\
\hline 110.19 & 0.3946 & 0.3973 & $2.94 \times 108$ & 239.60 & 12.28 \\
\hline 110.19 & 0.3944 & 0.3971 & $2.42 \times 108$ & 239.63 & 12.24 \\
\hline 110.19 & 0.3951 & 0.3978 & $2.81 \times 108$ & 239.52 & 12.36 \\
\hline 110.19 & 0.3946 & 0.3973 & $2.39 \times 108$ & 239.60 & 12.26 \\
\hline 113.02 & 0.3952 & 0.3979 & $5.86 \times 108$ & 239.50 & 12.69 \\
\hline 113.02 & 0.3943 & 0.3970 & $4.49 \times 108$ & 239.65 & 12.52 \\
\hline 113.02 & 0.3945 & 0.3972 & $5.35 \times 108$ & 239.61 & 12.56 \\
\hline 101.71 & 0.3949 & 0.3976 & $2.84 \times 107$ & 239.55 & 11.38 \\
\hline 101.71 & 0.3949 & 0.3976 & $2.24 \times 107$ & 239.55 & 11.38 \\
\hline 101.71 & 0.3949 & 0.3976 & $3.56 \times 107$ & 239.55 & 11.38 \\
\hline
\end{tabular}

Tabela $G .4$ - Ensaio 4 - fração de vapor de água $\omega_{v}=0.006862$

\begin{tabular}{|c|c|c|c|c|c|}
\hline$p_{0} /(\mathrm{kPa})$ & {$\left[\Delta p / p_{0}\right]_{\exp }$} & {$\left[\Delta p / p_{0}\right]$} & $J /\left(\mathrm{cm}^{-3} \mathrm{~s}^{-1}\right)$ & $T / \mathrm{K})$ & $S$ \\
\hline 113.02 & 0.3948 & 0.3975 & $1.23 \times 109$ & 239.57 & 13.01 \\
\hline 113.02 & 0.3952 & 0.3979 & $1.27 \times 109$ & 239.50 & 13.09 \\
\hline 113.02 & 0.3947 & 0.3974 & $1.38 \times 109$ & 239.59 & 13.01 \\
\hline 107.37 & 0.3946 & 0.3973 & $3.53 \times 108$ & 239.60 & 12.34 \\
\hline 107.37 & 0.3942 & 0.3969 & $3.18 \times 108$ & 239.67 & 12.26 \\
\hline 107.37 & 0.3945 & 0.3972 & $3.20 \times 108$ & 239.62 & 12.32 \\
\hline 102.00 & 0.3951 & 0.3978 & $8.31 \times 107$ & 239.52 & 11.80 \\
\hline 102.00 & 0.3946 & 0.3973 & $7.63 \times 107$ & 239.60 & 11.71 \\
\hline 102.00 & 0.3943 & 0.3970 & $8.12 \times 107$ & 239.65 & 11.67 \\
\hline 91.80 & 0.3942 & 0.3969 & $3.74 \times 106$ & 239.67 & 10.48 \\
\hline
\end{tabular}

Tabela G.5 - Ensaio 5 - fração de vapor de água $\omega_{v}=0.006917$

\begin{tabular}{|c|c|c|c|c|c|}
\hline$p_{0} /(\mathrm{kPa})$ & {$\left[\Delta p / p_{0}\right]_{\exp }$} & {$\left[\Delta p / p_{0}\right]$} & $J /\left(\mathrm{cm}^{-3} \mathrm{~s}^{-1}\right)$ & $T /(\mathrm{K})$ & $S$ \\
\hline 107.37 & 0.3949 & 0.3976 & $3.43 \times 108$ & 239.56 & 12.49 \\
\hline 107.37 & 0.3951 & 0.3978 & $4.28 \times 108$ & 239.52 & 12.52 \\
\hline 107.37 & 0.3946 & 0.3973 & $3.71 \times 108$ & 239.60 & 12.42 \\
\hline 103.08 & 0.3947 & 0.3974 & $1.33 \times 108$ & 239.59 & 11.94 \\
\hline 103.08 & 0.3946 & 0.3973 & $1.17 \times 108$ & 239.60 & 11.93 \\
\hline 103.08 & 0.3945 & 0.3972 & $1.21 \times 108$ & 239.62 & 11.92 \\
\hline 97.92 & 0.3943 & 0.3970 & $2.59 \times 107$ & 239.65 & 11.28 \\
\hline 97.92 & 0.3943 & 0.3970 & $2.46 \times 107$ & 239.65 & 11.29 \\
\hline 97.92 & 0.3949 & 0.3976 & $3.66 \times 107$ & 239.56 & 11.39 \\
\hline 93.03 & 0.3947 & 0.3974 & $6.24 \times 106$ & 239.59 & 10.78 \\
\hline 93.03 & 0.3953 & 0.3980 & $9.10 \times 106$ & 239.49 & 10.89 \\
\hline 93.03 & 0.3951 & 0.3978 & $5.38 \times 106$ & 239.52 & 10.85 \\
\hline 88.37 & 0.3951 & 0.3978 & $9.63 \times 105$ & 239.52 & 10.31 \\
\hline
\end{tabular}

Tabela G.6 - Ensaio 6 - fração de vapor de água $\omega_{v}=0.006827$ 


\begin{tabular}{|c|c|c|c|c|c|}
\hline$p_{0} /(\mathrm{kPa})$ & {$\left[\Delta p / p_{0}\right]_{\exp }$} & {$\left[\Delta p / p_{0}\right]$} & $J /\left(\mathrm{cm}^{-3} \mathrm{~s}^{-1}\right)$ & $T /(\mathrm{K})$ & $S$ \\
\hline 103.08 & 0.3948 & 0.3975 & $6.15 \times 107$ & 239.57 & 11.82 \\
\hline 103.08 & 0.3947 & 0.3974 & $7.03 \times 107$ & 239.59 & 11.80 \\
\hline 103.08 & 0.3954 & 0.3981 & $7.24 \times 107$ & 239.47 & 11.91 \\
\hline 96.90 & 0.3949 & 0.3976 & $1.38 \times 107$ & 239.55 & 11.12 \\
\hline 96.90 & 0.3950 & 0.3977 & $1.12 \times 107$ & 239.54 & 11.13 \\
\hline 96.90 & 0.3946 & 0.3973 & $1.48 \times 107$ & 239.60 & 11.08 \\
\hline 92.05 & 0.3949 & 0.3976 & $2.78 \times 106$ & 239.55 & 10.57 \\
\hline 92.05 & 0.3948 & 0.3975 & $2.06 \times 106$ & 239.57 & 10.55 \\
\hline 92.05 & 0.3951 & 0.3978 & $2.05 \times 106$ & 239.52 & 10.59 \\
\hline 87.45 & 0.3943 & 0.3970 & $3.75 \times 105$ & 239.65 & 9.95 \\
\hline 87.45 & 0.3946 & 0.3973 & $3.31 \times 105$ & 239.60 & 10.00 \\
\hline
\end{tabular}

\section{G.2 Análise dos Dados}

\section{G.2.1 Método Mínimos Quadrados}

Com a taxa de nucleação $J$ e a supersaturação $S$ calculou-se através do método dos mínimos quadrados, via sofware Maple V, o núcleo crítico $n^{*}$ para cada série de experiências. O procedimento resulta uma reta

$$
\ln J=a+\left(n^{*}\right) \ln S,
$$

referente a cada série, em que o coeficiente angular é o núcleo crítico, conforme sugerido pela equação (2.90)

$$
\frac{\partial \ln J}{\partial \ln S} \cong n^{*}
$$

Selecionou-se o ponto que apresentou o menor erro experimental.

Em seguida, calculou-se novamente o tamanho do núcleo crítico para cada conjunto de experiências realizadas à mesma temperatura. Novamente escolheu-se o ponto que apresentou o menor erro experimental. Foi com os dados deste ponto experimental que se trabalhou na TEN. 


\section{A seguir é apresentado a programação feita no Maple para o conjunto de dado}

obtidos à $T_{H_{2} 0, A r}=240 \mathrm{~K}$

\section{Conjunto de dados}

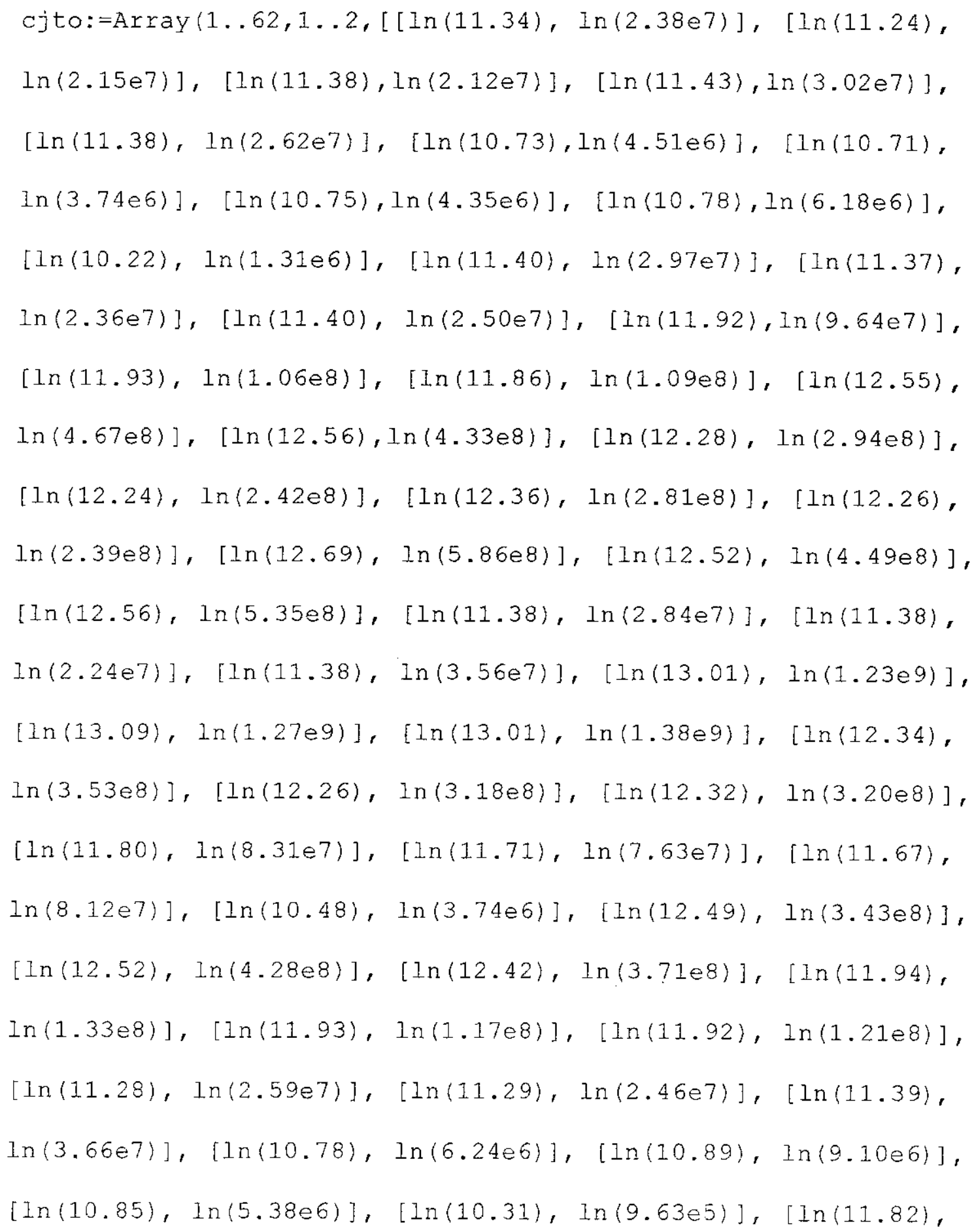


$\ln (6.15 e 7)],[\ln (11.80), \ln (7.03 e 7)],[\ln (11.91), \ln (7.24 \mathrm{e})]$, $[\ln (11.12), \ln (1.38 \mathrm{e})],[\ln (11.13), \ln (1.12 e 7)],[\ln (11.08)$, $\ln (1.48 e 7)],[\ln (10.57), \ln (2.78 e 6)],[\ln (10.55), \ln (2.06 e 6)]$, $[\ln (10.59), \ln (2.05 e 6)],[\ln (9.95), \ln (3.75 e 5)],[\ln (10.00)$, $\ln (3.31 e 5)]]):$

Equação da reta, a constante e o núcleo crítico

InJ:=Leastsquares (cjto, lns):

$\mathrm{a}:=\operatorname{subs}(\ln S=0, \ln J):$

$n:=\operatorname{diff}(\ln J, \ln S) ;$

Algoritmo para encontrar o ponto com menor erro experimental

for $i$ from 1 by 1 while $i<63$ do

Teste $3:=i ; \operatorname{abs}(1-(p t 3[i, 2]-a 3) /(p t 3[i, 1] \star n 3)):$

end do:

\section{G.2.2 Resultados Gerais: Viisanen et al.}

Segue os resultados dos cálculos propostos acima para todas as séries de experiências feitas por Viisanen et al. [6].

Tabela G.7 - Série 1 - Mistura $\mathrm{H}_{2} \mathrm{O}$ e Argônio ou Xenônio a $T_{H 20, X e}=259 \mathrm{~K}$ e $T_{0}=33^{\circ} \mathrm{C}$

\begin{tabular}{|c|c|c|c|c|c|c|c|}
\hline Ensaio & $\omega_{v}$ & $p_{0} /(\mathrm{kPa})$ & {$\left[\Delta p / p_{0}\right]$} & $J /\left(\mathrm{cm}^{-3} \mathrm{~s}^{-1}\right)$ & $T /(\mathrm{K})$ & $S$ & $n_{\exp }^{*}$ \\
\hline$B$ & 0.02127 & 120.23 & 0.3451 & $6.80 \times 10^{7}$ & 258.99 & 8.19 & 41.48 \\
\hline
\end{tabular}

Tabela G. 8 - Série 2 - Mistura $\mathrm{H}_{2} \mathrm{O}$ e Argônio ou Xenônio a $T_{H_{2} 0, A r}=253.7 \mathrm{~K} \mathrm{e}$ $T_{0}=33^{\circ} \mathrm{C}$

\begin{tabular}{|c|c|c|c|c|c|c|c|}
\hline Ensaio & $\omega_{v}$ & $p_{0} /(\mathrm{kPa})$ & {$\left[\Delta p / p_{0}\right]$} & $J /\left(\mathrm{cm}^{-3} \mathrm{~s}^{-1}\right)$ & $T /(\mathrm{K})$ & $S$ & $n_{\exp }^{*}$ \\
\hline$C$ & 0.01610 & 122.67 & 0.3779 & $1.40 \times 10^{8}$ & 253.65 & 9.40 & 38.29 \\
\hline
\end{tabular}


Tabela G.9 - Série 3 - Mistura $\mathrm{H}_{2} \mathrm{O}$ e Argônio ou Xenônio a $T_{H_{2} 0, A r}=248.5 \mathrm{~K} \mathrm{e}$ $T_{0}=33^{\circ} \mathrm{C}$

\begin{tabular}{|c|c|c|c|c|c|c|c|}
\hline Ensaio & $\omega_{v}$ & $p_{0} /(\mathrm{kPa})$ & {$\left[\Delta p / p_{0}\right]$} & $J /\left(\mathrm{cm}^{-3} \mathrm{~s}^{-1}\right)$ & $T /(\mathrm{K})$ & $S$ & $n_{\text {exp }}^{*}$ \\
\hline$F$ & 0.01271 & 106.51 & 0.4086 & $4.90 \times 10^{6}$ & 248.5 & 9.63 & 36.52 \\
\hline
\end{tabular}

Tabela G.10 - Série 4 - Mistura $\mathrm{H}_{2} \mathrm{O}$ e Argônio ou Xenônio a $T_{\mathrm{H}_{2} \mathrm{O}, A r}=244.1 \mathrm{~K} \mathrm{e}$ $T_{0}=15,63^{\circ} \mathrm{C}$

\begin{tabular}{|c|c|c|c|c|c|c|c|}
\hline Ensaio & $\omega_{y}$ & $p_{0} /(\mathrm{kPa})$ & {$\left[\Delta p / p_{0}\right]$} & $J /\left(\mathrm{cm}^{-3} \mathrm{~s}^{-1}\right)$ & $T /(\mathrm{K})$ & $S^{\prime}$ & $n_{\exp }^{*}$ \\
\hline$H$ & 0.008022 & 120.23 & 0.3445 & $8.70 \times 10^{7}$ & 244.08 & 11.50 & 37.75 \\
\hline
\end{tabular}

Tabela G. 11 - Série 5 - Mistura $\mathrm{H}_{2} \mathrm{O}$ e Argônio ou Kriptônio a $T_{H_{2} 0, K r}=238.8 \mathrm{~K} \mathrm{e}$ $T_{0}=15.63^{\circ} \mathrm{C}$

\begin{tabular}{|c|c|c|c|c|c|c|c|}
\hline Ensaio & $\omega_{v}$ & $p_{0} /(\mathrm{kPa})$ & {$\left[\Delta p / p_{0}\right]$} & $J /\left(\mathrm{cm}^{-3} \mathrm{~s}^{-1}\right)$ & $T /(\mathrm{K})$ & $S$ & $n_{\exp }^{*}$ \\
\hline$L$ & 0.005744 & 117.83 & 0.3791 & $2.10 \times 10^{7}$ & 238.81 & 12.57 & 33.32 \\
\hline
\end{tabular}

Tabela G. 12 - Série 6 - Mistura $\mathrm{H}_{2} \mathrm{O}$ e Argônio ou Kriptônio a $T_{H_{2} 0, A \tau}=233.5 \mathrm{~K}$ e $T_{0}=15.63^{\circ} \mathrm{C}$

\begin{tabular}{|c|c|c|c|c|c|c|c|}
\hline Ensaio & $\omega_{v}$ & $p_{0} /(\mathrm{kPa})$ & {$\left[\Delta p / p_{0}\right]$} & $J /\left(\mathrm{cm}^{-3} \mathrm{~s}^{-1}\right)$ & $T /(\mathrm{K})$ & $S$ & $n_{\exp }^{*}$ \\
\hline$N$ & 0.004206 & 106.50 & 0.4127 & $1.80 \times 10^{6}$ & 233.52 & 13.41 & 30.75 \\
\hline
\end{tabular}

Tabela G. 13 - Série 7 - Mistura $\mathrm{H}_{2} \mathrm{O}$ e Hélio ou Neônio ou Argônio ou Kriptônio ou Xenônio a $T_{H_{2} \mathrm{O}, \mathrm{Ar}}=228 \mathrm{Ke} T_{0}=15.63^{\circ} \mathrm{C}$

\begin{tabular}{|c|c|c|c|c|c|c|c|}
\hline Ensaio & $\omega_{v}$ & $p_{0} /(\mathrm{kPa})$ & {$\left[\Delta p / p_{0}\right]$} & $J /\left(\mathrm{cm}^{-3} \mathrm{~s}^{-1}\right)$ & $T /(\mathrm{K})$ & $S$ & $n_{\exp }^{*}$ \\
\hline$R$ & 0.02905 & 117.83 & 0.4455 & $1.90 \times 10^{7}$ & 228.19 & 17.01 & 28.07 \\
\hline
\end{tabular}

Tabela G. 14 - Série 8 - Mistura $\mathrm{H}_{2} \mathrm{O}$ e Argônio a $T_{H_{2} 0, A r}=222.6 \mathrm{~K}$ e $T_{0}=15.63^{\circ} \mathrm{C}$

\begin{tabular}{|c|c|c|c|c|c|c|c|}
\hline Ensaio & $\omega_{v}$ & $p_{0} /(\mathrm{kPa})$ & {$\left[\Delta p / p_{0}\right]$} & $J /\left(\mathrm{cm}^{-3} \mathrm{~s}^{-1}\right)$ & $T /(\mathrm{K})$ & $S$ & $n_{\exp }^{*}$ \\
\hline$V$ & 0.002016 & 122.68 & 0.4786 & $1.30 \times 10^{8}$ & 222.63 & 21.51 & 28.25 \\
\hline
\end{tabular}

Tabela G. 15 - Série 9 - Mistura $\mathrm{H}_{2} \mathrm{O}$ e Argônio a $T_{H_{2} \mathrm{O}, \mathrm{A} T}=217.1 \mathrm{~K}$ e $T_{0}=15.63^{\circ} \mathrm{C}$

\begin{tabular}{|c|c|c|c|c|c|c|c|}
\hline Ensaio & $\omega_{v}$ & $p_{0} /(\mathrm{kPa})$ & {$\left[\Delta p / p_{0}\right]$} & $J /\left(\mathrm{cm}^{-3} \mathrm{~s}^{-1}\right)$ & $T /(\mathrm{K})$ & $S$ & $n_{\text {exp }}^{*}$ \\
\hline$W$ & 0.001416 & 106.51 & 0.5101 & $1.90 \times 10^{7}$ & 217.12 & 23.64 & 27.79 \\
\hline
\end{tabular}




\section{G.2.3 Resultados Gerais: Wölk-Strey}

Segue os resultados dos cálculo propostos acima para todas as séries de experiências feitas por Strey al all. [23]

Tabela G.16 - Série A - Mistura $\mathrm{H}_{2} \mathrm{O}$ e Argônio a $T_{H 20, A r}=260 \mathrm{~K}$ e $T_{0}=30^{\circ} \mathrm{C}$

\begin{tabular}{|c|c|c|c|c|c|c|c|}
\hline Ensaio & $\omega_{v}$ & $p_{0} /(\mathrm{kPa})$ & {$\left[\Delta p / p_{0}\right]$} & $J /\left(\mathrm{cm}^{-3} \mathrm{~s}^{-1}\right)$ & $T /(\mathrm{K})$ & $S$ & $n^{*}$ \\
\hline 1 & 0.02641 & 92.88 & 0.3241 & $1.94 \times 10^{8}$ & 259.82 & 7.58 & 37.41 \\
\hline 2 & 0.02646 & 97.77 & 0.3235 & $5.67 \times 10^{8}$ & 259.92 & 7.94 & 32.81 \\
\hline 3 & 0.02623 & 97.77 & 0.3237 & $2.75 \times 10^{8}$ & 259.88 & 7.90 & 32.12 \\
\hline 4 & 0.02653 & 97.77 & 0.3245 & $8.99 \times 10^{8}$ & 259.76 & 8.05 & 36.99 \\
\hline 5 & 0.02587 & 92.88 & 0.3243 & $5.11 \times 10^{7}$ & 259.78 & 7.45 & 30.39 \\
\hline 6 & 0.02640 & 88.24 & 0.3235 & $7.95 \times 10^{6}$ & 259.92 & 7.15 & 32.73 \\
\hline 7 & 0.02624 & 88.24 & 0.3234 & $3.83 \times 10^{6}$ & 259.93 & 7.10 & 34.25 \\
\hline 8 & 0.02651 & 102.92 & 0.3242 & $1.81 \times 10^{9}$ & 259.81 & 8.44 & 31.04 \\
\hline
\end{tabular}

Melhores dados

\begin{tabular}{|c|c|c|c|c|c|c|c|}
\hline Ensaio & $\omega_{v}$ & $p_{0} /(\mathrm{kPa})$ & {$\left[\Delta p / p_{0}\right]$} & $J /\left(\mathrm{cm}^{-3} \mathrm{~s}^{-1}\right)$ & $T /(\mathrm{K})$ & $S$ & $n^{*}$ \\
\hline 3 & 0.02623 & 92.88 & 0.3240 & $5.30 \times 10^{7}$ & 259.83 & 7.52 & 33.28 \\
\hline
\end{tabular}

Tabela G. 17 - Série B - Mistura $\mathrm{H}_{2} \mathrm{O}$ e Argônio a $T_{H 20, A r}=250 \mathrm{~K}$ e $T_{0}=25^{\circ} \mathrm{C}$

\begin{tabular}{|c|c|c|c|c|c|c|c|}
\hline Ensaio & $\omega_{v}$ & $p_{0} /(\mathrm{kPa})$ & {$\left[\Delta p / p_{0}\right]$} & $J /\left(\mathrm{cm}^{-3} \mathrm{~s}^{-1}\right)$ & $T /(\mathrm{K})$ & $S$ & $n^{*}$ \\
\hline 1 & 0.01677 & 78.12 & 0.3604 & $2.00 \times 10^{7}$ & 249.79 & 9.00 & 32.45 \\
\hline 2 & 0.01652 & 82.23 & 0.3613 & $8.22 \times 10^{7}$ & 249.64 & 9.44 & 31.78 \\
\hline 3 & 0.01677 & 86.55 & 0.3612 & $7.55 \times 10^{8}$ & 249.67 & 10.06 & 33.61 \\
\hline
\end{tabular}

Melhores dados

\begin{tabular}{|c|c|c|c|c|c|c|c|}
\hline Ensaio & $\omega_{v}$ & $p_{0} /(\mathrm{kPa})$ & {$\left[\Delta p / p_{0}\right]$} & $J /\left(\mathrm{cm}^{-3} \mathrm{~s}^{-1}\right)$ & $T /(\mathrm{K})$ & $S$ & $n^{*}$ \\
\hline 1 & 0.01677 & 91.11 & 0.3601 & $2.42 \times 10^{9}$ & 249.84 & 10.45 & 32.52 \\
\hline
\end{tabular}

Tabela G. 18 - Série C - Mistura $\mathrm{H}_{2} \mathrm{O}$ e Argônio a $T_{H 20, A r}=240 \mathrm{~K}$ e $T_{0}=20^{\circ} \mathrm{C}$

\begin{tabular}{|c|c|c|c|c|c|c|c|}
\hline Ensaio & $\omega_{v}$ & $p_{0} /(\mathrm{kPa})$ & {$\left[\Delta p / p_{0}\right]$} & $J /\left(\mathrm{cm}^{-3} \mathrm{~s}^{-1}\right)$ & $T /(\mathrm{K})$ & $S$ & $n^{*}$ \\
\hline 1 & 0.006797 & 99.45 & 0.3977 & $2.62 \times 10^{7}$ & 239.54 & 11.38 & 28.61 \\
\hline 2 & 0.006808 & 110.19 & 0.3973 & $4.67 \times 10^{8}$ & 239.60 & 12.55 & 29.29 \\
\hline 3 & 0.006650 & 113.02 & 0.3970 & $4.49 \times 10^{8}$ & 239.65 & 12.52 & 28.80 \\
\hline 4 & 0.006862 & 102.00 & 0.3973 & $7.63 \times 10^{7}$ & 239.60 & 11.71 & 26.74 \\
\hline 5 & 0.006917 & 103.08 & 0.3973 & $1.17 \times 10^{8}$ & 239.60 & 11.93 & 30.00 \\
\hline 6 & 0.006827 & 96.90 & 0.3977 & $1.12 \times 10^{7}$ & 239.54 & 11.13 & 30.72 \\
\hline
\end{tabular}

Melhores dados 


\begin{tabular}{|c|c|c|c|c|c|c|c|}
\hline Ensaio & $\omega_{v}$ & $p_{0} /(\mathrm{kPa})$ & {$\left[\Delta p / p_{0}\right]$} & $J /\left(\mathrm{cm}^{-3} \mathrm{~s}^{-1}\right)$ & $T /(\mathrm{K})$ & $S$ & $n^{*}$ \\
\hline 1 & 0.006797 & 94.48 & 0.3971 & $3.74 \times 10^{6}$ & 239.63 & 10.71 & 30.03 \\
\hline
\end{tabular}

Tabela G. 19 - Série D - Mistura $\mathrm{H}_{2} \mathrm{O}$ e Argônio a $T_{H 20, A r}=230 \mathrm{~K}$ e $T_{0}=10^{\circ} \mathrm{C}$

\begin{tabular}{|c|c|c|c|c|c|c|c|}
\hline Ensaio & $\omega_{y}$ & $p_{0} /(\mathrm{kPa})$ & {$\left[\Delta p / p_{0}\right]$} & $J /\left(\mathrm{cm}^{-3} \mathrm{~S}^{-1}\right)$ & $T /(\mathrm{K})$ & $S$ & $n^{*}$ \\
\hline 1 & 0.003404 & 93.02 & 0.4087 & $1.18 \times 10^{7}$ & 229.58 & 14.51 & 26.67 \\
\hline 2 & 0.003433 & 93.02 & 0.4092 & $1.08 \times 10^{7}$ & 229.49 & 14.37 & 25.84 \\
\hline 3 & 0.003340 & 90.44 & 0.4087 & $4.70 \times 10^{6}$ & 229.57 & 13.85 & 24.52 \\
\hline 4 & 0.003331 & 105.78 & 0.4092 & $3.01 \times 10^{8}$ & 229.49 & 16.28 & 25.49 \\
\hline
\end{tabular}

Melhores dados

\begin{tabular}{|c|c|c|c|c|c|c|c|}
\hline Ensaio & $\omega_{v}$ & $p_{0} /(\mathrm{kPa})$ & {$\left[\Delta p / p_{0}\right]$} & $J /\left(\mathrm{cm}^{-3} \mathrm{~s}^{-1}\right)$ & $T /(\mathrm{K})$ & $S$ & $n^{*}$ \\
\hline 1 & 0.003404 & 103.07 & 0.4087 & $1.91 \times 10^{8}$ & 229.58 & 16.06 & 25.75 \\
\hline
\end{tabular}

Tabela G. 20 - Série E - Mistura $\mathrm{H}_{2} \mathrm{O}$ e Argônio a $T_{H 20, A r}=220 \mathrm{~K}$ e $T_{0}=10^{\circ} \mathrm{C}$

\begin{tabular}{|c|c|c|c|c|c|c|c|}
\hline Ensaio & $\omega_{v}$ & $p_{0} /(\mathrm{kPa})$ & {$\left[\Delta p / p_{0}\right]$} & $J /\left(\mathrm{cm}^{-3} \mathrm{~s}^{-1}\right)$ & $T /(\mathrm{K})$ & $S$ & $n^{*}$ \\
\hline 1 & 0.001520 & 93.30 & 0.4745 & $1.78 \times 10^{7}$ & 218.96 & 19.33 & 20.28 \\
\hline 2 & 0.001567 & 93.30 & 0.4747 & $3.43 \times 10^{7}$ & 218.92 & 20.00 & 17.32 \\
\hline 3 & 0.001635 & 103.38 & 0.4744 & $3.46 \times 10^{8}$ & 218.98 & 22.98 & 17.51 \\
\hline 4 & 0.001708 & 93.30 & 0.4748 & $1.69 \times 10^{8}$ & 218.91 & 21.84 & 22.34 \\
\hline 5 & 0.001645 & 80.84 & 0.4748 & $3.91 \times 10^{6}$ & 218.91 & 18.22 & 19.39 \\
\hline
\end{tabular}

Melhores dados

\begin{tabular}{|c|c|c|c|c|c|c|c|}
\hline Ensaio & $\omega_{v}$ & $p_{0} /(\mathrm{kPa})$ & {$\left[\Delta p / p_{0}\right]$} & $J /\left(\mathrm{cm}^{-3} \mathrm{~s}^{-1}\right)$ & $T /(\mathrm{K})$ & $S$ & $n^{*}$ \\
\hline 4 & 0.001708 & 79.99 & 0.4744 & $5.61 \times 10^{6}$ & 218.98 & 18.57 & 20.73 \\
\hline
\end{tabular}




\section{Apêndice H \\ Programação Maple V para Cálculo Núcleo Crítico}

Conforme mostrado no Capítulo 5 o cálculo do núcleo crítico envolveu a equação de estado de van der Waals e a Teoria de Funções Residuais. Entretanto, ao invés de usar aquela para encontrar as propriedades termodinâmicas no equilibrio, como sugerido no Apêndice D, optou-se por uma função empírica de P. E. Wagner ${ }^{41}$, usada por Wölk-Strey [23], em função de sua acurácia. O calor específico para a fase vapor foi tratado como função da temperatura, conforme Tester\&Modell [16]. E para a fase líquida como constante. Quanto às unidades de medida, adotou-se o Sistema Internacional: pressão, $[\mathrm{p}]=\mathrm{Pa}$; volume, $[\mathrm{v}]=\mathrm{m}^{3} / \mathrm{mol}$; temperatura, $[\mathrm{T}]=\mathrm{K}$; entalpia, $[\mathrm{h}]=$ $\mathrm{J} / \mathrm{mol}=\mathrm{m}^{3} \cdot \mathrm{Pa} / \mathrm{mol}$; constante universal dos gases $[\mathrm{R}]=\mathrm{J} / \mathrm{mol} \cdot \mathrm{K}=\mathrm{m}^{3} \cdot \mathrm{Pa} / \mathrm{mol} \cdot \mathrm{K}$

Van der Waals

$\mathrm{p}:=\mathrm{R}^{\star} \mathrm{T} /(\mathrm{v}-\mathrm{b})-\mathrm{a} / \mathrm{v}^{\wedge} 2:$

$\operatorname{dp}:=\operatorname{diff}(p, v):$

$\mathrm{a}:=27 * \mathrm{R}^{\wedge} 2 * \mathrm{TC}^{\wedge} 2 /(64 * \mathrm{pc}):$

$b:=R^{\star} T c /(8 * p c):$

$\mathrm{R}:=8.314:$

$p c:=220.60 e 5:$

$\mathrm{TC}:=647.31:$

Fórmula de Strey para cálculo da pressão de vapor $\mathrm{pv}:=\exp \left(77.34491-7235.42465 / \mathrm{T}-8.2 * \log (\mathrm{T})+0.0057113{ }^{*} \mathrm{~T}\right):$

41 Wagner, P. E. Aerosol Researsh HII, Wien 1981, 209. 


\section{Calor específico com função de $T$}

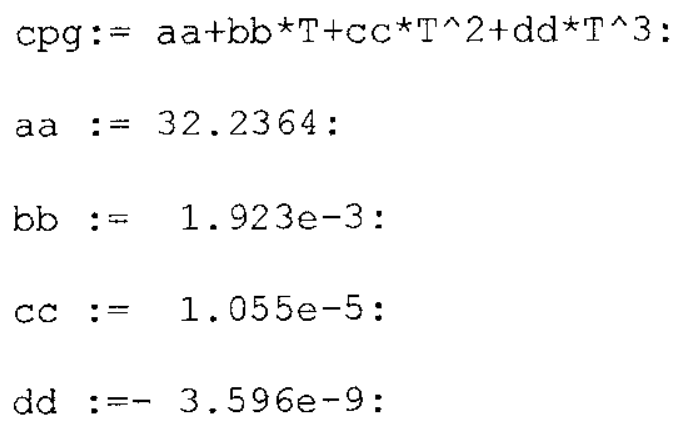

\section{Estado Referência (ponto triplo)}

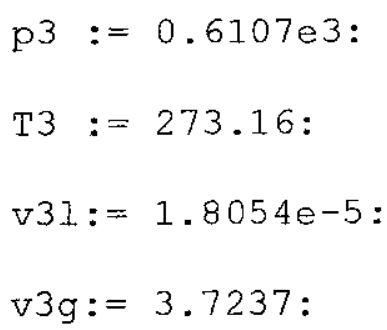

Cálculo da Entalpia

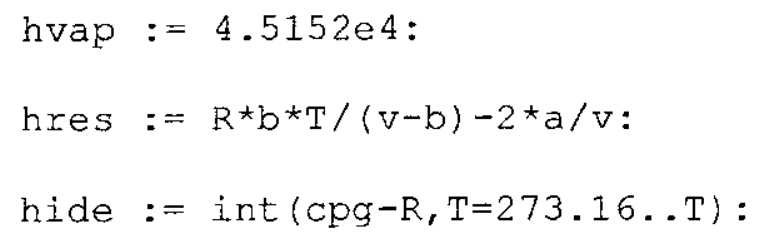

Para uma dada pressão, $p_{\exp }$, tem-se a temperatura de equilíbrio, $T^{e}$, e encontra-se volume da fase líquida e da fase gasosa Te := solve $(p v=p e x p, T):$ 


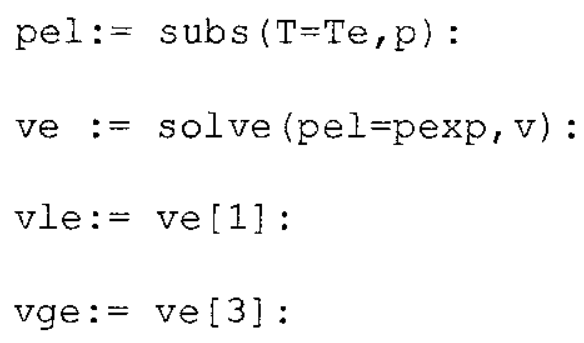

Temperatura e Volume no Estado Metaestável (gás)

Tgm: $=$ Texp:

$\mathrm{pm}:=\operatorname{subs}(\mathrm{T}=\mathrm{Tgm}, \mathrm{p}):$

$\mathrm{vm}:=$ solve $(\mathrm{pm}=\mathrm{pexp}, \mathrm{v}):$

$\operatorname{vgm}:=\operatorname{vm}[3]:$

Temperatura e Volume no Spinodal (líquido e gás)

Ts : $=$ solve $(d p=0, T):$

ps $:=\operatorname{simplify}(\operatorname{subs}(T=T s, p)):$

vs $:=$ solve $(\mathrm{ps}=\mathrm{pexp}, \mathrm{v}):$

VIs: $=\operatorname{Vs}[3]:$

Tls:= subs $(\mathrm{V}=\mathrm{VI} s, \mathrm{Ts}):$

$\operatorname{vgs}:=\operatorname{vs}[4]:$

Tgs $:=\operatorname{subs}(v=v g s, T s):$

Cálculo da Entalpia hgm (gás metaestável)

hg1: = subs $(\mathrm{T}=\mathrm{Tgm}, \mathrm{V}=\mathrm{vgm}, \mathrm{hres}):$

hg2: $=\operatorname{subs}(\mathrm{T}=$ Tgm, hide $):$

hgm:= evalf $($ hgl 1 hg 2$)+$ hvap:

Cálculo da Entalpia hl (gás no spinodal)

hg3: $=$ subs $(T=T g s, v=v g s$, hres $):$

hg $4:=$ subs $(\mathrm{T}=\mathrm{Tgs}, \mathrm{hide}):$ 
hgs:= evalf(hg3+hg4)+hvap:

Cálculo da Entalpia h2 (líquido no spinodal)

hll: $=\operatorname{subs}(\mathrm{T}=\mathrm{T} l \mathrm{~s}, \mathrm{v}=\mathrm{vls}, \mathrm{hres}):$

$h 12:=\operatorname{subs}(T=T 1 s, h i d e):$

hls:= evalf $(h I 1+h 12):$

Cálculo da Entalpia hB (líquido estável)

h13:= subs $(T=T e, v=v l e, h r e s):$

hI4:= subs $(T=T e, h i d e):$

hls: = evalf $(h 13+h 14):$

Cálculo do Tamanho do Núcleo Crítico (no caso para $T=240 \mathrm{~K}$ )

N240:= 2/3*(abs (hgs/hgm-1)/(abs $(1-h$ ls/hle)*abs (Tgs/Tgm-1)) )^2; 


\section{Referências}

[1] Kestin, Joseph. A Course in Thermodynamics. Massachusets. Vol. 1. Blaisdell. 1966.

[2] Zemansky, M. W. Heat and Thermodynamics. 5a. ed. Tokio. McGraw-Hill 1968.

[3] Landau, L., Ajiezer, A., Lifshitz, E. Curso de Fisica General. Moscù. Mir. 1979.

[4] Gutzow, I e Schmelzer, J. The Vitreous State. Germany. Springer. 1995.

[5] Kashchiev, D. Nucleation: basic theory with applications. Oxford. Butterworth-Heinemann. 2000.

[6] Y. Viisanen, R. Strey, e H. Reiss. Homogeneous nucletion rates for water. J. Chem. Phys. 99 (1993) 4680.

[7] Dillmann, A. e Meier, G.E.A. Homogeneous Nucleation of Supersaturated Vapor. Chem. Phys. Lett. 160 (1989) 71.

[8] Dillmann, A. e Meier, G.E.A. Homogeneous Nucleation of Supersaturated Vapor. J. Chem. Phys. 94 (1991) 3872.

[9] Meyer,E. Adiabatic nucleation in glasses, polymers and liquid metals. J. Non-Crys. Sol. 219 (1997) 30.

[10] Meyer, E. Adiabatic nucleation in superheated and supercooled liquids. Corrent Topics Crys. Grow. Res., 2 (1995) 123.

[11] Meyer, E. Adiabatic nucleation. J. Crys. Grow. 74 (1986) 425-438

[12] de Sá, E. M. Nucleação adiabática em líquidos superaquecidos e em vapores superesfriados. UFRJ. Tese. 2001.

[13] DeHoff, Robert T. Thermodynamics in Materials Science. Singapore McGraw-Hill. 1993

[14] Landau,L.D. and Lifshitz,E.M. Statistical Physics. 3rd edition. Part 1. Great Britain. Butterworth-Heinemannl 14997. p. $333 \mathrm{ff}$.

[15] Arfken, G.B. and Weber, H.J. Mathematical Methods for Physicists. 4th edition. London. Academic Press. 1995. p. 319. 
[16] Tester, J.W. and Modell, M. Thermodynamics and Its Applications. 3rd edition. New Jersey. Prentice Hall. 1996.

[17] Mokross, B.J. Nucleation Theory and Application. J.W.P. Schmelzer, G. Röpke, V.B. Priezzhev (eds.). Russia. Joint Institute for Nuclear Research (JINR). 1999.

[18] Mokross, B.J. Entropic Nucleation Theory. J. Non-Crys. Sol. 284 (2001) 91.

[19] de Sá, E. M.; Meyer, E; Soares V. Adiabatic nucleation in the liquid-vapor phase transition. J. Chem. Phys. 114 (2001) 8505.

[20] Kestin, Joseph. A Course in Thermodynamics. Vol. 2. Massachusets. Blaisdell. 1968.

[21] Salinas, S.R.A. Introdução à Física Estatística. $2^{a}$ edição. São Paulo. Edusp. 1999.

[22] Glansdorff, P. e Prigogine, I. Thermodynamic Theory of Structure, Stability and Fluctuations. London. Wiley. 1974.

[23] Wölk, J. and Strey, R. Homogeneous Nucleation of $\mathrm{H}_{2} \mathrm{O}$ and $\mathrm{D}_{2} \mathrm{O}$ in Comparison: The Isotope Effect. J. Phys. Chem. B, 105 (2001) 11683. 